MICHEL REJANI MIYAZAKI

\title{
DESENVOLVIMENTO DE SISTEMA DE POSICIONAMENTO DINÂMICO COM APROAMENTO AUTOMÁTICO
}

São Paulo 
MICHEL REJANI MIYAZAKI

\title{
DESENVOLVIMENTO DE SISTEMA DE POSICIONAMENTO DINÂMICO COM APROAMENTO AUTOMÁTICO
}

\author{
Dissertação apresentada à Escola \\ Politécnica da Universidade de São Paulo \\ para obtenção do título de Mestre em \\ Ciências
}

São Paulo 
MICHEL REJANI MIYAZAKI

\title{
DESENVOLVIMENTO DE SISTEMA DE POSICIONAMENTO DINÂMICO COM APROAMENTO AUTOMÁTICO
}

\author{
Dissertação apresentada à Escola \\ Politécnica da Universidade de São Paulo \\ para obtenção do título de Mestre em \\ Ciências
}

Área de Concentração:

Engenharia de Controle e Automação Mecânica

Orientador: Eduardo Aoun Tannuri

São Paulo 
Este exemplar foi revisado e corrigido em relação à versão original, sob responsabilidade única do autor e com a anuência de seu orientador.

São Paulo, de abril de 2013.

Assinatura do autor

Assinatura do orientador

FICHA CATALOGRÁFICA

Miyazaki, Michel Rejani

Desenvolvimento de sistema de posicionamento dinâmico com aproamento automático / M.R. Miyazaki. -- São Paulo, 2013. $108 \mathrm{p}$.

Dissertação (Mestrado) - Escola Politécnica da Universidade de São Paulo. Departamento de Engenharia Mecatrônica e de Sistemas Mecânicos.

1. Controle adaptativo 2. Simulação 3. Comportamento de embarcações no mar I. Universidade de São Paulo. Escola Politécnica. Departamento de Engenharia Mecatrônica e de Sistemas Mecânicos II. t. 
DEDICATÓRIA

Às mulheres que fizeram de mim quem eu sou,

Márcia e Nathália 


\section{AGRADECIMENTOS}

Ao meu orientador e amigo Prof. Dr. Eduardo Aoun Tannuri, que me guiou durante os últimos 3 anos. Além disso, sempre me mostrou grandes desafios em engenharia e incentivou fortemente o meu desenvolvimento analítico.

Aos professores e demais colegas do TPN, por todo o apoio e sugestões durante o curto período em que estamos trabalhando juntos.

À CNPq pela bolsa de estudos concedida.

A Petrobras, em especial ao CENPES, pelo suporte financeiro à presente pesquisa e à motivação inicial.

Aos amigos da equipe Thunderatz, com os quais compartilhei grandes momentos e me desenvolvi como engenheiro.

À minha mãe Marcia Rejani, que além de todas as revisões, sempre me ajudou em tudo que foi necessário.

À Nathália Gutierrez, mulher que fez de mim quem eu sou. 


\section{RESUMO}

Durante o desenvolvimento dessa dissertação foi criado um novo controlador de navios para aproamento automático de mínima energia (weathervane), de acordo com condições ambientais incidentes, mantendo o posicionamento de um ponto de controle arbitrário. O controlador proposto utiliza a metodologia ZPC (Zero Power Control), empregando o método da integral de realimentação, originalmente proposto para aplicação em sistemas de levitação magnética.

Além da análise de estabilidade, também foi utilizado o simulador numérico de sistemas oceânicos TPN (Tanque de Provas Numérico), atestando o funcionamento do controlador sob a influência de diversas condições. Foram simulados casos com agentes ambientais (onda, vento e correnteza) desalinhados, ondas irregulares, posicionamento da popa no navio, dentre outros.

O desempenho do controlador desenvolvido foi comparado, através de análise estática, com o desempenho de outras lógicas de controle weathervane, apresentando desempenho igual ou superior.

Finalmente, um navio em escala reduzida foi submetido a testes em um tanque físico. Os resultados experimentais foram bastante satisfatórios, validando os resultados numéricos obtidos.

Com isto, conclui-se que o controlador projetado atende os propósitos para o qual foi concebido com sucesso, sendo viável e possuindo diversas aplicações práticas imediatas.

Palavras Chave: Controle, simulação, sistemas oceânicos, sistema de posicionamento dinâmico. 


\section{ABSTRACT}

A new controller was developed during this thesis, intended to automatically calculate the optimum heading (weathervane) for any given environmental condition. The vessel positioning is kept while this controller adapts the heading. The proposed controller utilizes the Zero Power Control (ZPC) methodology, generally applied to magnetic levitation systems. The chosen ZPC strategy is the integral feedback.

A stability analysis was carried, in addition to simulations at the oceanic systems numerical simulator TPN (Numerical Offshore Tank), proving the controller availability under the influence of several environmental conditions. Cases with misaligned environmental agents (wind, waves and current), irregular waves, stern control, among others were simulated.

In order to prove its performance, the final controller was compared with existing weathervane controllers through a static analysis, showing that it was equal or superior.

Finally, a scale model ship was undergone to tests on a physical tank. The experimental results were pretty good, validating the obtained numerical results.

In conclusion, the designed controller attends its design requirements successfully, being viable and having several immediate practical applications.

Keywords: Control, simulation, oceanic systems, dynamic positioning systems. 


\section{LISTA DE ILUSTRAÇÕES}

Figura 1 - Exemplo de limites de aproamento para operação de alívio (fonte: Tannuri et. al (2009)) 2

Figura 2 - Alteração de aproamento para mitigar o consumo do Sistema DP em operação de alívio. (fonte: Tannuri et. al (2009))

Figura 3 - Força média aplicada por cada propulsor (fonte: Tannuri et, al. (2009)). 3

Figura 4 - Evolução de controladores navais (fonte: Fossen (2000)) ….........10

Figura 5 - Proposta desenvolvida por Pinkster e Nienhuis (1986) ..................13

Figura 6 - Controlador proposto pelo WOPC (baseado em Fossen e Strand (2001)).

Figura 7 - Condição ambiental para a simulação apresentada em Kaasen et al. (2005)

Figura 8 - Gráfico mostrando esforços ambientais agindo sobre navio aliviador em função de seu aproamento, com condições ambientais exibidas na Figura 7 (fonte: Kaasen et. al. (2005)).

Figura 9 - Sistema maglev híbrido, constituído por um ímã permanente e bobinas eletromagnéticas.

Figura 10 - Posição de equilíbrio do sistema para suspensão utilizando (A) Mola simples e (B) suspensão magnetica ZPC (fonte: Mizuno (2002)).

Figura 11 - Diagrama de blocos de um sistema com controle e realimentação unitária

Figura 12 - Diagrama de blocos de um sistema de controle ZPC (baseado em Morishita et. al. (1989)).

Figura 13 - Coeficiente de forças laterais devido ao vento, conforme será definido pela seção 3.2.1

Figura 14 - Atuação do ZPC sobre um navio 19

Figura 15 - Coeficiente momento devido ao vento, conforme será definido pela seção 3.2.1 20

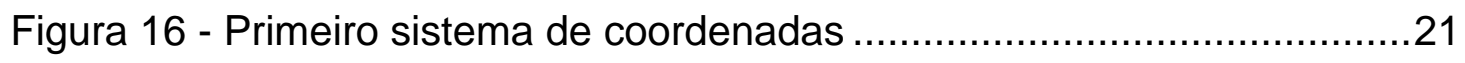

Figura 17 - Segundo sistema de coordenadas ..........................................22

Figura 18 - Terceiro sistema de coordenadas .........................................22

Figura 19 - Definição do ângulo de incidência ...............................................24 
Figura 20 - Coeficientes adimensionais de vento dos navios (a) aliviador em condição de lastro, (b) aliviador cheio e (c) barcaça DP 26

Figura 21 - Coeficientes adimensionais de correnteza dos navios (a) aliviador em condição de lastro, (b) aliviador cheio e (c) barcaça DP

Figura 22 - Espectro de onda para $\omega 0=\mathrm{rad} / \mathrm{s}$ e $H s=5,5 \mathrm{~m}$ 30

Figura 23 - Sistema de coordenadas local (o3, x3 e y3) previamente definido33

Figura 24 - Condições ambientais usadas nas análises 1 a 4 respectivamente

Figura 25- Aproamento ótimo do navio aliviador em condição de lastro sob a influência da combinação ambiental \#1

Figura 26 - Aproamento de equilíbrio da barcaça utilizando o controle de bombordo.

Figura 27 - Aproamento do navio aliviador em condição de lastro seguindo lógica de controle de momento nulo em relação à meia nau .44

Figura 28 - Aproamento do navio aliviador carregado seguindo lógica de controle de momento nulo em relação à meia nau

Figura 29 - Variação de Q em função do aproamento para a segunda análise

Figura 30 - Aproamento do navio aliviador carregado seguindo lógica de controle de bombordo 46

Figura 31 - Aproamento ótimo do navio aliviador carregado 47

Figura 32 - Variação de Q em função do aproamento para a terceira análise 47

Figura 33 - Variação de $Q$ em função do aproamento para a quarta análise .49

Figura 34 - Estrutura modificada do controlador para aplicação de técnicas de ZPC .51

Figura 35 - Representação gráfica do sinal das forças laterais do navio.........52

Figura 36 - Representação gráfica do sinal do momento de yaw em relação à meia nau. .53

Figura 37 - Análise de estabilidade em função do ganho de adaptação ........56

Figura 38 - Set-point do aproamento do navio em função do tempo para diferentes valores de $K_{\text {int }}$ analisados

Figura 39 - Posição e aproamento do navio para o controle da meia-nau......62

Figura 40 - Posição do ponto de controle.... 
Figura 41 - Aproamento do navio .62

Figura 42 - Força lateral de controle. .62

Figura 43 - Posição e aproamento do navio para o controle da proa .64

Figura 44 - Posição do ponto de controle .64

Figura 45 - Aproamento do navio .64

Figura 46 - Força lateral de controle. .64

Figura 47 - Posição e aproamento do navio para o controle de sua lateral ....66

Figura 48 - Posição do ponto de controle ...... .66

Figura 49 - Aproamento do navio 66

Figura 50 - Força lateral de controle. .66

Figura 51 - Posição e aproamento do navio para o controle de sua popa......68

Figura 52 - Posição do ponto de controle.... .68

Figura 53 - Aproamento do navio .68

Figura 54 - Força lateral de controle. .68

Figura 55 - Posição e aproamento do navio para o controle em caso multi ondas .70

Figura 56 - Posição do ponto de controle ................................................ 70

Figura 57 - Aproamento do navio ....................................................... 70

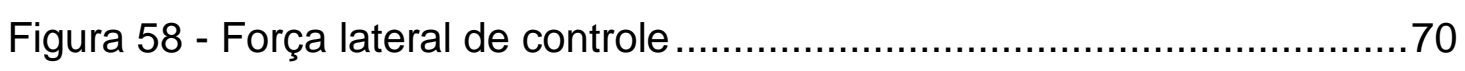

Figura 59 - Posição e aproamento do navio para o controle em caso de

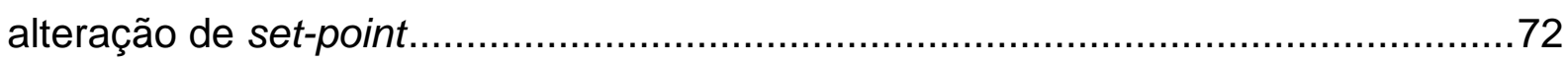

Figura 60 - Posição do ponto de controle ...............................................72

Figura 61 - Aproamento do navio ........................................................ 72

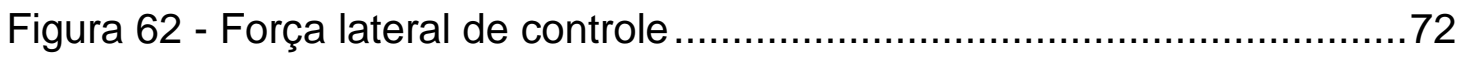

Figura 63 - Posição e aproamento do navio sob a condição brasileira típica \#1

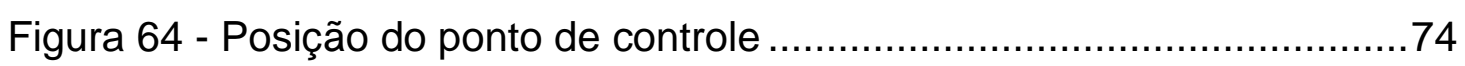

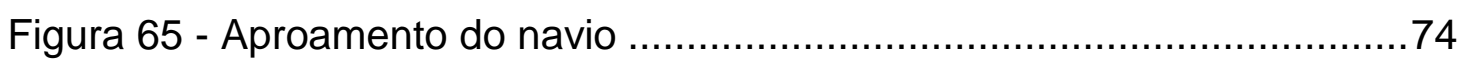

Figura 66 - Força lateral de controle .......................................................

Figura 67 - Posição e aproamento do navio sob a condição brasileira típica \#2

Fing

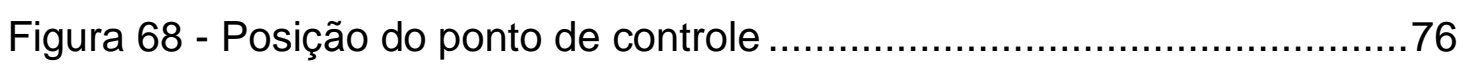

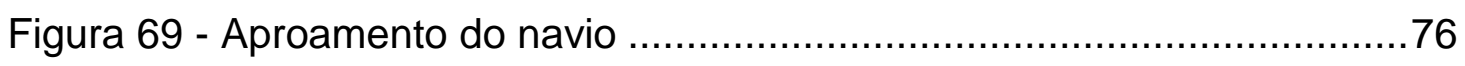


Figura 70 - Força lateral de controle...... .76

Figura 71 - Posição e aproamento do navio sob a condição brasileira típica \#3 .78

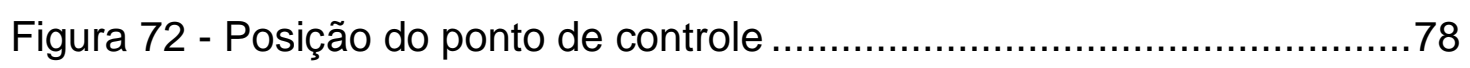

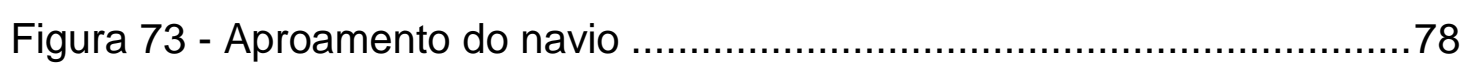

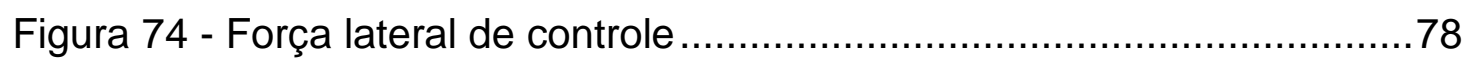

Figura 75 - Modelo utilizado durante ensaios no tanque de provas numérico 80

Figura 76 - Propulsor principal e propulsor túnel de popa do modelo..............80

Figura 77 - Propulsor túnel de proa do modelo utilizado durante ensaio .........81

Figura 79 - Geradores de vento instalados no tanque de provas ...................82

Figura 80 - Detalhe da transmissão de ângulo do sistema de geração de vento .83

Figura 81 - Transmissão que ajusta o ângulo de cada ventilador....................83

Figura 82 - Diagrama de funcionamento do gerador de ondas........................84

Figura 83 - Atuador e controlador do flap gerador de ondas ............................ 85

Figura 84 - Câmeras Qualisys utilizadas para detecção da posição do modelo utilizado para ensaios.

Figura 85 - Alvos reflexivos acoplados ao modelo (disponível em diversos tamanhos) .86

Figura 86 - Sistema rastreando o posicionamento do modelo em tempo real 87

Figura 88 - Módulo RF conectado ao modelo. .89

Figura 89 - Utilização do sistema propulsor (a) considerando propulsor principal (b) desconsiderando propulsor principal ............................................90

Figura 90 - Ensaio 1 - Posicionamento do navio ao longo do tempo ..............92

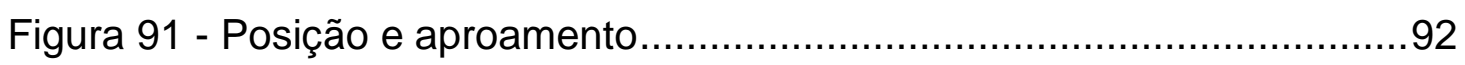

Figura 92 - Erro do Sistema DP .............................................................

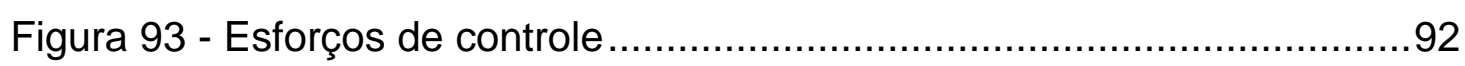

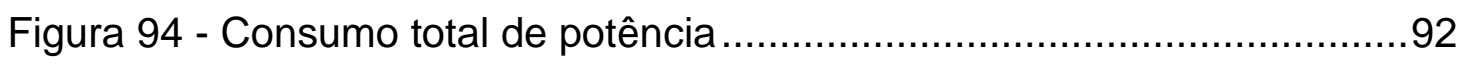

Figura 95 - Ensaio 2 - Posicionamento do navio ao longo do tempo ..............94

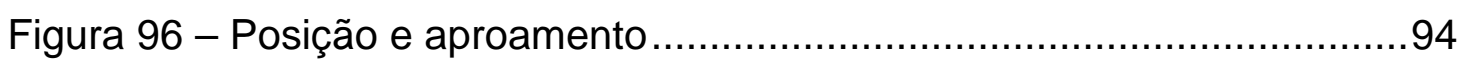

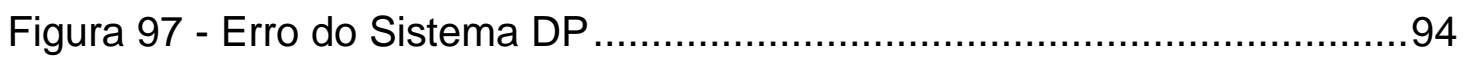

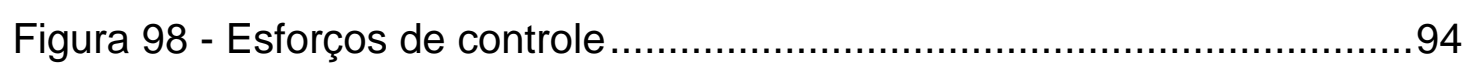

Figura 99 - Consumo total de potência.....................................................94 
Figura 100 - Ensaio 3 - Posicionamento do navio ao longo do tempo ............96

Figura 101 - Posição e aproamento .......................................................96

Figura 102 - Erro do Sistema DP ....................................................... 96

Figura 103 - Esforços de controle ..................................................96

Figura 104 - Consumo total de potência ................................................96

Figura 105 - Ensaio 4 - Posicionamento do navio ao longo do tempo ...........98

Figura 106 - Posição e aproamento ....................................................98

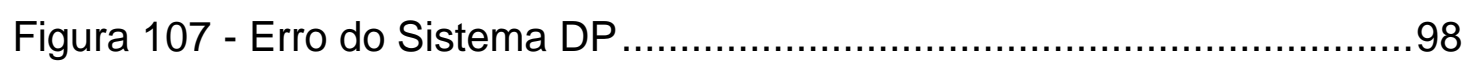

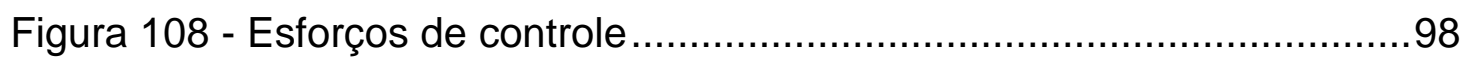

Figura 109 - Consumo total de potência ..............................................98

Figura 110 - Ensaio 5 - Posicionamento do navio ao longo ........................100

Figura 111 - Posição e aproamento ................................................... 100

Figura 112 - Erro do Sistema DP ..................................................... 100

Figura 113 - Esforços de controle ..................................................... 100

Figura 114 - Consumo total de potência ........................................... 100 


\section{LISTA DE TABELAS}

Tabela 1 - Propriedades físicas das embarcações simuladas...................................39

Tabela 2 - Sistema de propulsão da barcaça .........................................................39

Tabela 3 - Sistema de propulsão do aliviador .........................................................

Tabela 4 - Conjunto de condições ambientais utilizadas para análise ......................40

Tabela 5 - Resultados da análise da primeira combinação ambiental......................41

Tabela 6 - Resultados da análise da segunda combinação ambiental.....................43

Tabela 7- Resultados da análise da terceira combinação ambiental........................45

Tabela 8- Resultados da análise da quarta combinação ambiental ..........................48

Tabela 9 - Principais dados físicos e geométricos do navio em escala real...............79

Tabela 10 - Dados do sistema de propulsão do navio DP em escala real (valores entre parênteses equivalem à escala de modelo) ................................................. 80

Tabela 11 - Condições de ensaio dos cinco casos .............................................89 


\section{LISTA DE ABREVIATURAS E SIGLAS}

ANP

ASME

BEN

DP

FPSO

IFAC

IR

ITTC

JONSWAP

LQG

Maglev

MCMC

OCIMF

OMAE

$\mathrm{RF}$

PID

PM

$\mathrm{TL}$

TLP

TPN

USP

WAMIT

WOH

WOPC

W-ZPC

ZPC
Agência Nacional do Petróleo

American Society of Mechanical Engineers

Balanço Energético Nacional

Dynamic Positioning

Floating Production Storage and Offloading System

International Federation of Automatic Control

Infra Red

International Towing Tank Conference

Joint North Sea Wave Project

Linear Quadratic Gaussian

Magnetic Levitation

Maneuvering and Control of Marine Craft

Oil Companies International Marine Forum

International Conference on Ocean, Offshore and Arctic Engineering

Radio Frequência

Proporcional Integral Derivativo

Thruster Assisted Position Mooring

Tension Leg

Tension Leg Platform

Tanque de Provas Numérico

Universidade de São Paulo

Wave Analysis Massachusetts Institute of Technology

Weather Optimal Heading

Weather Optimal Positioning Control

Weathervane Zero Power Control

Zero Power Control 


\section{LISTA DE SÍMBOLOS}

Em geral, utiliza-se negrito para representar parâmetros ou funções vetoriais ou matriciais. Utilizam-se também as letras $i$ e $j$ para representar índices.

Alfabeto romano:

$\boldsymbol{A}$

$A_{1}$

$A_{2}$

$A_{F}$

$A_{L}$

B

C

$C_{i}$

$C_{j i}$

$D_{\mathrm{j}}$

E

$F_{j i}$

$g$

$H_{S}$

$I_{z}$

$K_{a m b}$

$K_{a m b}^{i}$

$K_{D}$
Matriz correlacionando empuxos e esforços de propulsores Matriz correlacionando empuxos e esforços de propulsores, decompondo propulsores azimutais em dois propulsores fixos

Matriz correlacionando empuxos e esforços de propulsores, considerando conhecidos os ângulos de azimute

Área emersa projetada frontal do navio

Área emersa projetada lateral do navio

Boca do navio

Matriz de amortecimento linear equivalente

Cosseno do azimute do i-ésimo propulsor

Coeficiente adimensional estático da condição ambiental j ( $j=$ vento ou correnteza) no grau de liberdade $\mathrm{i}(\mathrm{i}=\mathrm{x}, \mathrm{y}$ ou $\Psi$ )

Coeficiente de deriva média no grau de liberdade $\mathrm{j}(\mathrm{j}=\mathrm{x}, \mathrm{y}$ ou $\Psi)$

Erro de posição do navio, coordenadas no sistema de coordenadas 3

Força equivalente da condição ambiental j $(j=$ onda, vento ou correnteza) no i-ésimo GLD i ( $\mathrm{i}=\mathrm{x}$ ou y)

Constante gravitacional

Altura significativa de onda

Momento de inércia total do navio em torno do eixo $Z$

Matriz de ganhos da condição ambiental equivalente

Ganho da condição ambiental equivalente no i-ésimo grau de liberdade ( $\mathrm{i}=\mathrm{x}, \mathrm{y}$ ou $\Psi)$

Matriz de ganhos derivativos do Sistema DP 


\begin{tabular}{|c|c|}
\hline$K_{D}^{i}$ & Ganho derivativo relativo ao i-ésimo GDL ( $\mathrm{i}=\mathrm{x}$, y ou $\Psi$ ) \\
\hline$K_{I}$ & Matriz de ganhos Integrativos do Sistema DP \\
\hline$K_{I}^{i}$ & Ganho derivativo relativo ao i-ésimo GDL ( $\mathrm{i}=\mathrm{x}$, y ou $\Psi$ ) \\
\hline$K_{\text {int }}$ & Ganho de adaptação \\
\hline$K_{P}$ & Matriz de ganhos proporcionais do Sistema DP \\
\hline$K_{P}^{i}$ & Ganho proporcional relativo ao i-ésimo GDL ( $\mathrm{i}=\mathrm{x}, \mathrm{y}$ ou $\Psi)$ \\
\hline$L$ & Comprimento da embarcação \\
\hline$L_{P P}$ & Distância entre perpendiculares \\
\hline$M$ & Massa da embarcação \\
\hline$M$ & Matriz de massa \\
\hline$M_{11}, M_{22}, M_{26}, M_{66}$ & $\begin{array}{l}\text { Massas adicionais em baixa frequência (relativas ao ponto sistema } \\
\text { de coordenadas } o_{3}, x_{3}, y_{3} \text { ) }\end{array}$ \\
\hline$M_{j}^{\Psi}$ & $\begin{array}{l}\text { Momento em yaw devido à condição ambiental j ( } \mathrm{j}=\text { onda, vento ou } \\
\text { correnteza) }\end{array}$ \\
\hline$n_{\text {azim }}$ & Número de propulsores azimutais \\
\hline$n_{\text {fixo }}$ & Número de propulsores fixos \\
\hline$n_{\text {prop }}$ & Número total de propulsores do navio \\
\hline$n_{\text {prop }}^{\prime}$ & Número de propulsores não saturados \\
\hline$n_{\text {sat }}$ & Número de propulsores saturados nesta iteração \\
\hline$o_{i}$ & Origem do sistema de coordenadas $\mathrm{i}(\mathrm{i}=2,3)$ \\
\hline$Q$ & Medida de consumo de potência do sistema de propulsão \\
\hline$Q_{i}$ & Medida de consumo de potência do sistema de propulsão \\
\hline $\boldsymbol{R}$ & $\begin{array}{l}\text { Matriz de rotação, passando pontos do sistema de coordenadas } 1 \\
\text { para o sistema de coordenadas } 2\end{array}$ \\
\hline$S$ & Espectro de frequência de onda \\
\hline$s_{i}$ & Seno do azimute do i-ésimo propulsor \\
\hline$T$ & Calado da embarcação \\
\hline
\end{tabular}


$V_{C}$

$V_{w}$

$W_{a m b}$ $W_{a m b}^{i}$

$W_{c t r l}$

$W_{c t r l}^{i}$

$W_{j D M}$

$W_{\text {prop }}$

$W_{\text {prop }}^{i}$

$W_{\text {res }}$

$W_{\text {res }}^{\Psi}$

$W_{\text {sat }}$

$x_{B}$

$X_{E}$

$x_{G}$
Vetor contendo o empuxo dos propulsores

Empuxo exercido pelo i-ésimo propulsor

Empuxo exercido pelo i-ésimo propulsor azimutal

Empuxo exercido pelo i-ésimo propulsor fixo

Período de pico de onda

Empuxo longitudinal exercido pelo i-ésimo propulsor azimutal

Empuxo transversal exercido pelo i-ésimo propulsor azimutal

Função candidata de Lyapunov

Velocidade relativa de correnteza

Velocidade relativa de vento

Esforços de ambientais agindo sobre o navio

Esforço de ambientais agindo sobre o navio no i-ésimo grau de liberdade $(\mathrm{i}=\mathrm{x}, \mathrm{y}$ ou $\Psi)$

Esforços de controle exercidos pelo navio

Esforço de controle exercido pelo sistema de propulsão no i-ésimo grau de liberdade do navio $(i=x, y$ ou $\Psi$ )

Esforço de deriva média no j-ésimo grau de liberdade $(j=x, y$ ou $\Psi)$

Esforços devidos ao sistema de propulsão

Esforços devidos ao i-ésimo propulsor

Esforço ambiental residual

Momento ambiental residual

Esforços exercidos pelos propulsores que estão saturados

Posição x da meia nau do navio no sistema de coordenadas 2

Posição X da meia nau do navio no sistema de coordenadas 1

Posição do centro de gravidade em relação à meia nau no sistema de coordenadas 3 


$\begin{array}{ll}x_{i} & \text { Eixo } \mathrm{x} \text { do sistema de coordenadas } \mathrm{i}(\mathrm{i}=1,2,3) \\ x_{\text {prop }}^{i} & \text { Posição } \mathrm{x} \text { do } \mathrm{i} \text {-ésimo propulsor, relativa à meia nau } \\ x_{\text {ref }} & \text { Ponto de controle do sistema de controle (na coordenada } \mathrm{x} \text { ), } \\ & \text { relativo ao sistema de coordenadas } 3 \\ X_{S P} & \text { Posição } \mathrm{X} \text { do set-point do sistema de controle, no sistema de } \\ & \text { coordenadas } 1 \\ y_{B} & \text { Posição y da meia nau do navio no sistema de coordenadas } 2 \\ Y_{E} & \text { Posição } \mathrm{Y} \text { da meia nau do navio no sistema de coordenadas } 1 \\ y_{i} & \text { Eixo y do sistema de coordenadas } \mathrm{i}(\mathrm{i}=1,2,3) \\ y_{p r o p}^{i} & \text { Posição y do i-ésimo propulsor, relativa à meia nau } \\ y_{\text {ref }} & \text { Ponto de controle do sistema de controle (na coordenada y), } \\ & \text { relativo ao sistema de coordenadas } 3 \\ Y_{S P} & \text { Posição } \mathrm{Y} \text { do set-point do sistema de controle, no sistema de } \\ & \text { coordenadas } 1\end{array}$

Alfabeto Grego

$\alpha$

$\alpha_{0}$

$\alpha_{a m b}$

$\alpha_{j r}$

$\alpha_{\text {prop }}^{i}$

$\gamma$

$\eta_{B}$

$\eta_{G}$

$\eta_{\text {ref }}$
Vetor contendo o azimute de todos os propulsores

Constante correlacionando vento e correnteza

Ângulo de incidência da condição ambiental resultante

Ângulo de incidência equivalente da condição ambiental $\mathrm{j}(\mathrm{j}$ = onda, vento ou correnteza)

Ângulo do i-ésimo propulsor do navio

Peakedness factor

Vetor que define as coordenadas de interesse do corpo no sistema de coordenadas 2

Vetor que define as coordenadas de interesse do corpo no sistema de coordenadas 1

Vetor que define as coordenadas do ponto de controle do corpo, no 
sistema de coordenadas 2

$\eta_{s p}$

$\rho_{a}$

$\rho_{w}$

$\sigma$

$\psi$

$\Psi_{a m b}$

$\psi_{S P}$

$\omega$

$\omega_{0}$

Vetor que define o set-point do sistema de controle, descrito no sistema de coordenadas 1

Densidade do ar

Densidade da água

Fator de forma

Aproamento do navio, relativo ao sistema de coordenadas $\left(O_{1}, X_{1}, Y_{1}\right)$

Aproamento que resulta em força lateral nula sobre o navio

Aproamento desejado pelo sistema de controle

Frequência

Frequência de pico de onda

\section{Simbologia Especial}

A

F

$m \times n$

$T$

.

\#
(Sobrescrito) Fator relativo a propulsores azimutais

(Sobrescrito) Fator relativo a propulsores fixos

(Sobrescrito) Matriz de $m$ linhas e $n$ colunas

(Sobrescrito) Transposição

(Sobre a variável) Derivada em relação ao tempo

(Sobre a variável) Derivada de segunda ordem em relação ao tempo

(Sobrescrito) Matriz pseudoinversa 


\section{SUMÁRIO}

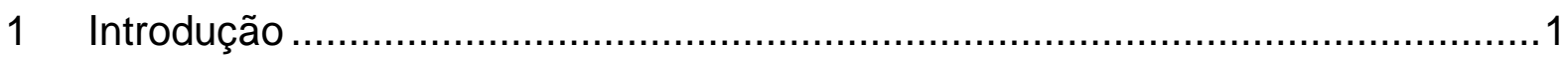

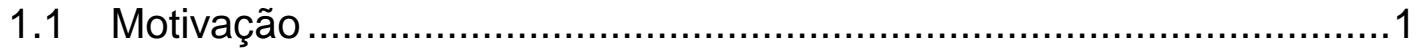

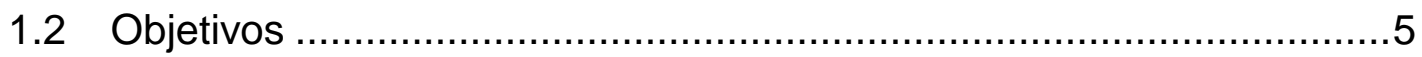

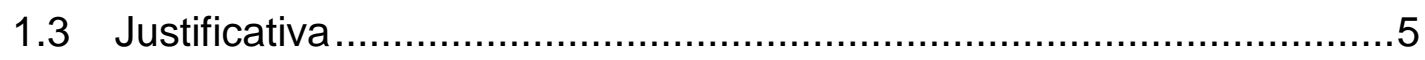

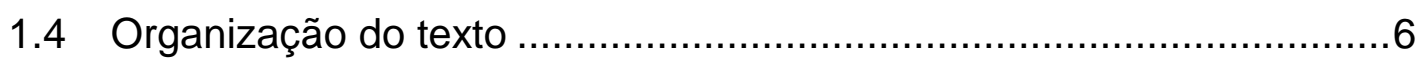

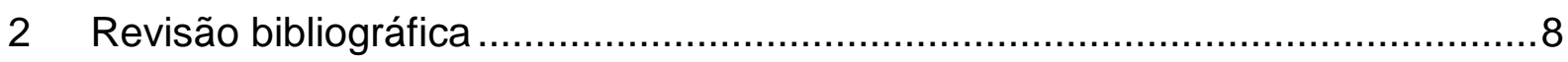

2.1 Métodos para posicionamento de corpos flutuantes no mar ................

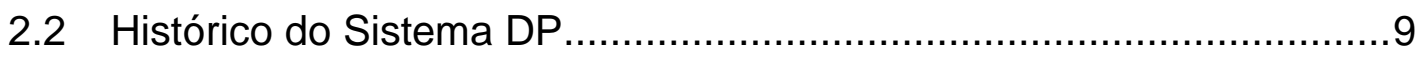

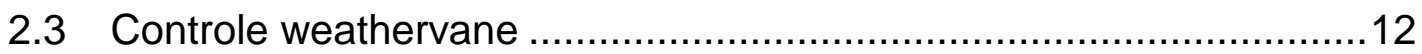

2.4 Controle de Potência Nula..........................................................16

2.4.1 Aplicação do controle de potência nula em sistemas navais........18

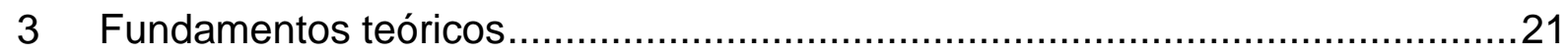

3.1 Dinâmica de sistemas oceânicos ....................................................21

3.2 Modelagem matemática de agentes ambientais ..............................24

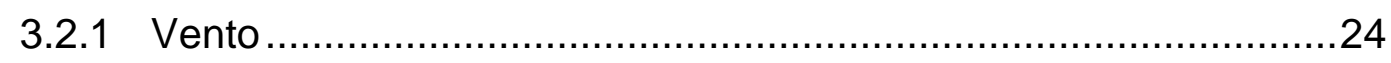

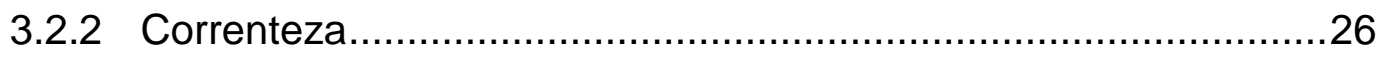

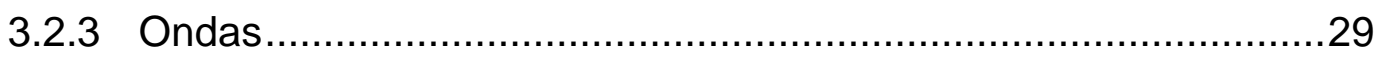

3.3 Controle de Posicionamento ……........................................................

3.4 Mensuração do consumo de potência...............................................32

3.5 Alocação de propulsão ..................................................................33

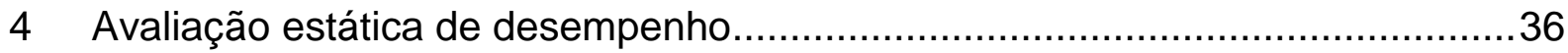

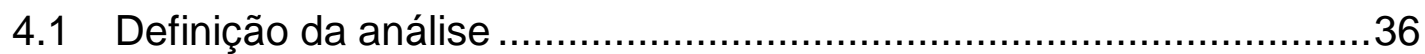

4.2 Definição de Aproamento Ótimo (Weather Optimum Heading) ...........36

4.3 Tipos de controle de aproamento de ótimo consumo ..........................37

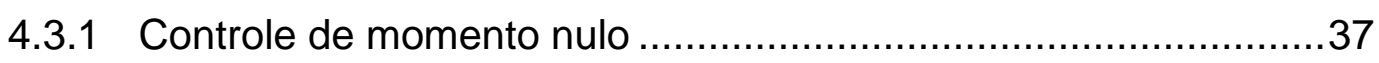

4.3.2 Controle de força lateral nula .................................................38 


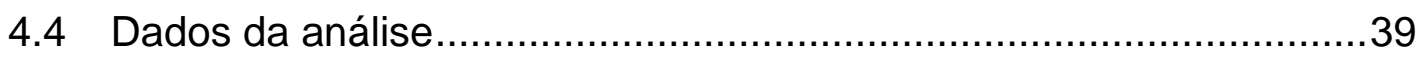

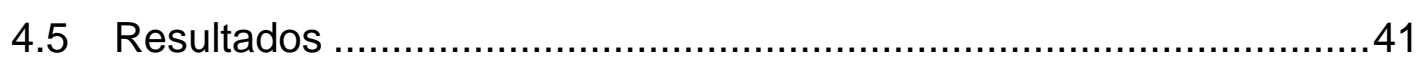

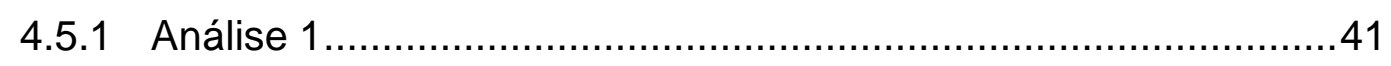

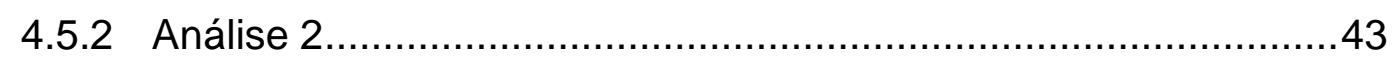

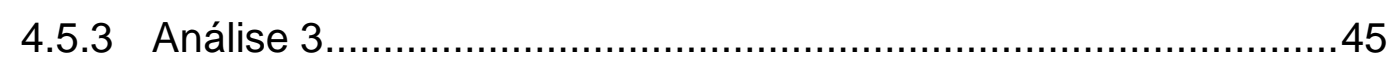

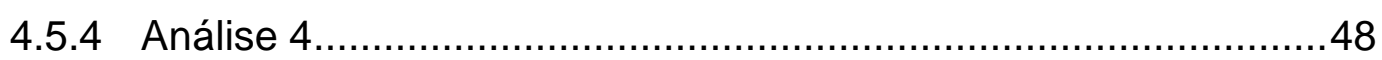

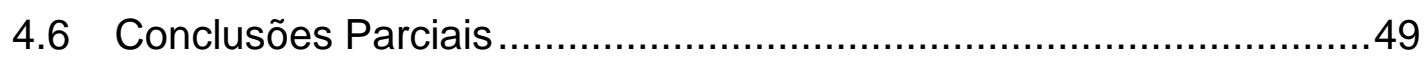

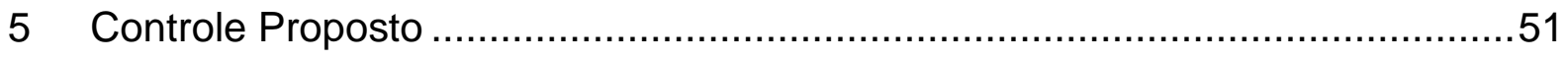

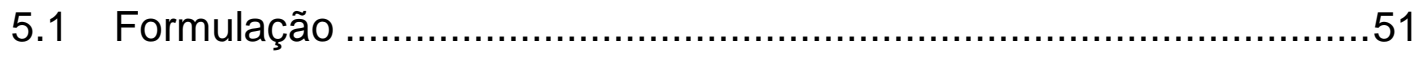

5.2 Análise de estabilidade....................................................... 53

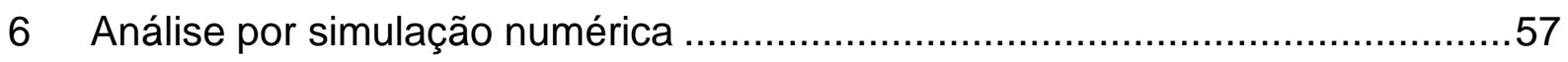

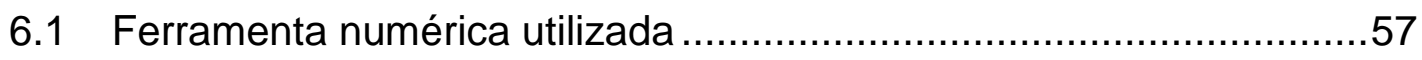

6.2 Descrição dos casos de simulação ........................................ 58

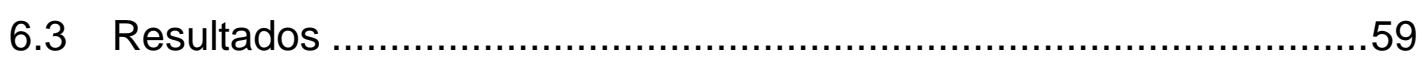

6.3.1 Sensibilidade ao ganho de integração..................................59

6.3.2 Controle da meia-nau .................................................60

6.3.3 Controle da proa.......................................................63

6.3.4 Controle de ponto no costado da embarcação ..........................65

6.3.5 Controle da popa .......................................................... 67

6.3.6 Caso com ondas bi-modais ..........................................69

6.3.7 Alteração do set-point ................................................ 71

6.3.8 Condição típica brasileira $\# 1$............................................. 73

6.3.9 Condição típica brasileira \#2 .......................................... 75

6.3.10 Condição típica brasileira \#3 ....................................... 77

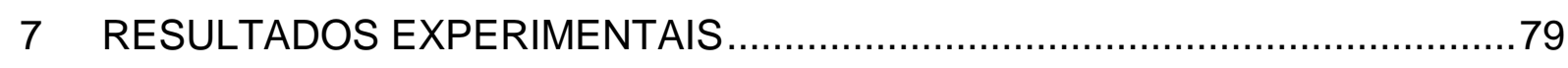

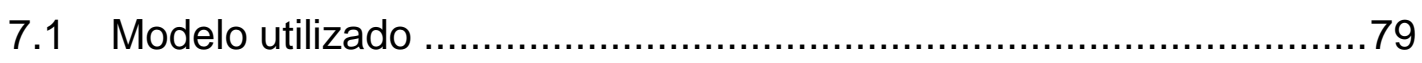

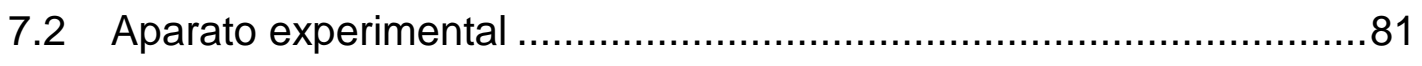




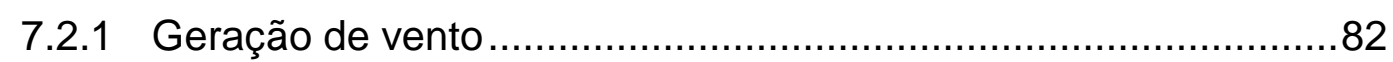

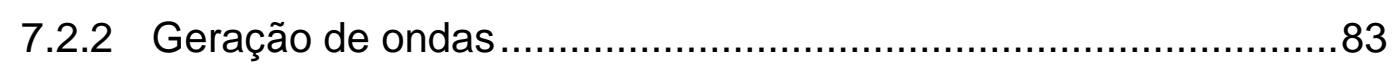

7.2.3 Sistema de medição de posição e aproamento.............................85

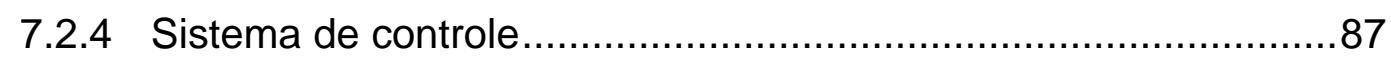

7.2.5

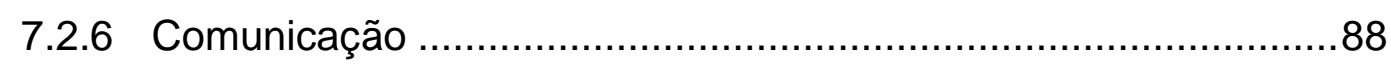

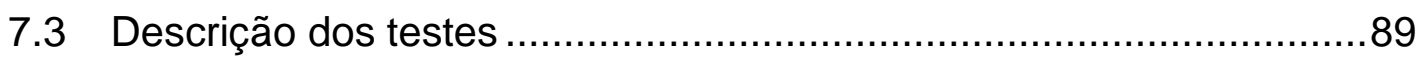

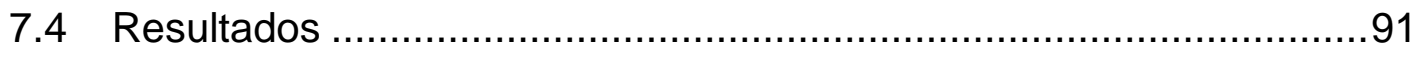

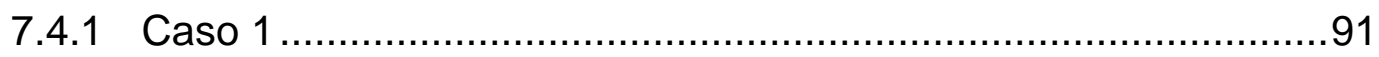

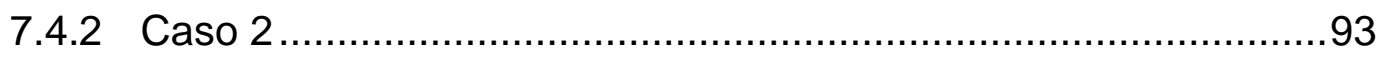

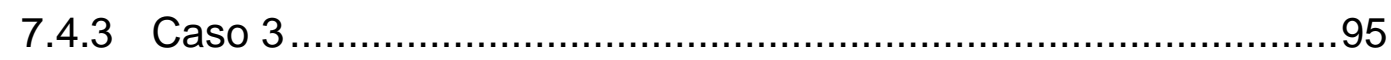

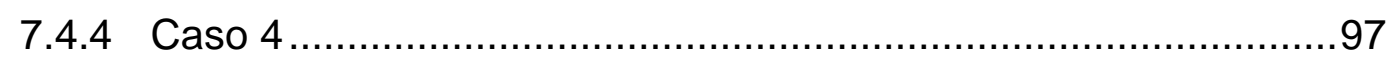

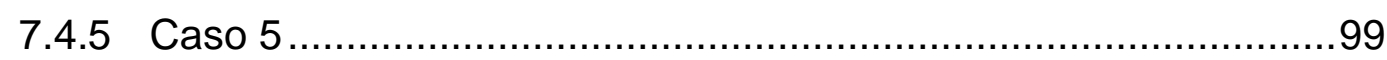

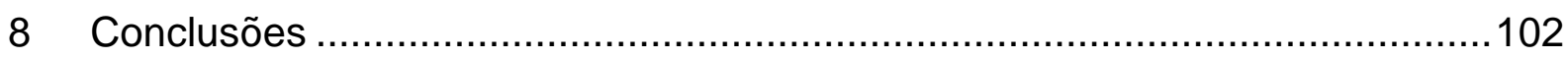

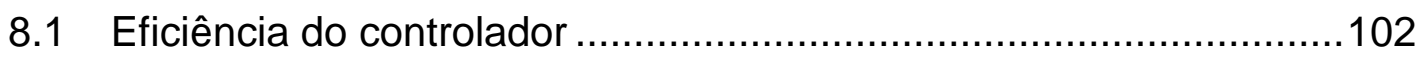

8.2 Estabilidade do controlador ......................................................103

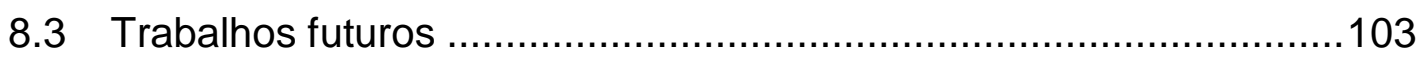

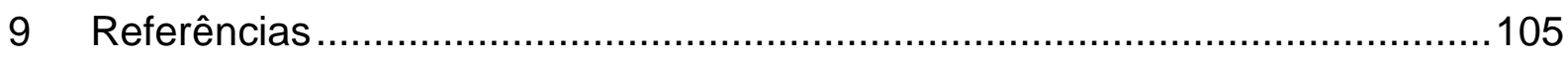




\section{INTRODUÇÃO}

Neste capítulo, será feita a contextualização do presente trabalho no cenário da indústria petrolífera de exploração em alto-mar, justificando-o e destacando-se os seus objetivos.

\subsection{Motivação}

Segundo a ANP (2011) (Agência Nacional do Petróleo, Gás Natural e Biocombustíveis), o Brasil possui reservas comprovadas de 14,2 bilhões de barris de petróleo, das quais apenas $6,4 \%$ estão localizadas em terra, e os 13.3 bilhões de barris restante estão localizadas em mar.

Ainda segundo dados da ANP (2011), as reservas mundiais de petróleo são da ordem de 1.383 bilhões de barris de petróleo, e Sandrea e Sandrea (2007) afirmam que em 2007 as reservas comprovadas de petróleo em campos em alto mar (offshore) eram da ordem de 300 bilhões de barris.

Dados do último BEN (2011) (Balanço Energético Nacional) informam que $41,9 \%$ da matriz energética de consumo brasileira baseiam-se na utilização de petróleo e 7,2\% baseiam-se em gás natural, evidenciando a importância destas fontes energéticas para a economia nacional.

Desta forma, fica clara a importância do desenvolvimento de tecnologias para exploração do petróleo em campos offshore. O estudo de QuestOffshore(2011) mostra que os investimentos para a exploração até 2010 somam $\$ 145.7$ bilhões de dólares.

A necessidade de altos investimentos para exploração de petróleo offshore é decorrência de os campos explorados estarem localizados a distâncias cada vez maiores da costa, e em águas cada vez mais profundas.

Devido às crescentes distâncias entre o ponto de extração de petróleo e os terminais costeiros, o transporte de petróleo por dutos pode apresentar altos custos. Nestes casos, é necessário buscar alternativas para alívio das plataformas em águas profundas. 
A operação de alívio auxiliada por Sistema DP possui diversas particularidades, dentre elas, a possibilidade de escolher arbitrariamente 0 aproamento do navio aliviador dentro de uma zona de segurança definida nas proximidades da plataforma, conforme afirmado em Sphaier et. al. (2009). A Figura 1 exemplifica esta zona de segurança dentro da qual o navio deve se posicionar durante a operação de alívio, exemplificando a possibilidade de alterar o aproamento durante a operação.

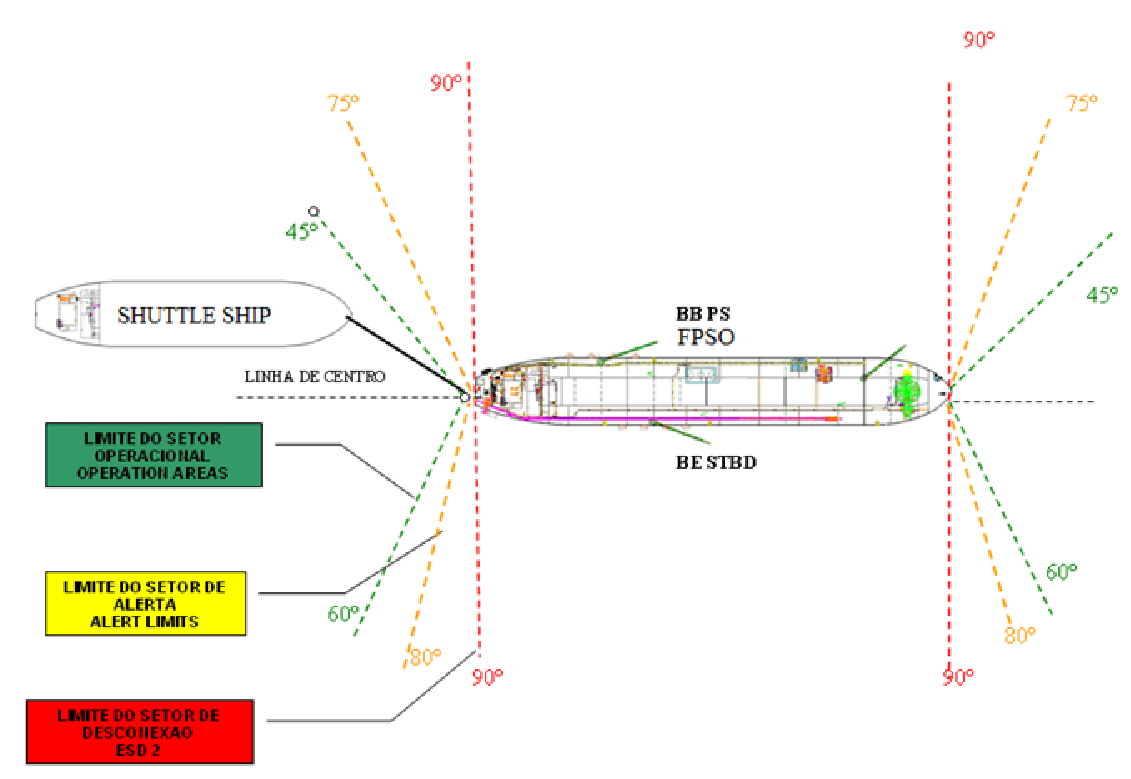

Figura 1 - Exemplo de limites de aproamento para operação de alívio (fonte: Tannuri et. al (2009))

Estudos atestam as vantagens da escolha correta do aproamento do navio aliviador, minimizando o consumo de potência e ampliando a janela operacional. Para ilustrar a diferença que o aproamento exerce sobre a utilização do Sistema DP, apresenta-se na Figura 2 um estudo conduzido por Tannuri et. al (2009), que mostra que a mudança de aproamento de uma embarcação em condições específicas diminuiria a utilização média de potência. Nesta figura apresentam-se dados monitorados em uma operação real de alívio de uma plataforma monocoluna no litoral do nordeste brasileiro. As figuras superiores mostram o início do alívio, durante a fase de aproximação e conexão, enquanto as figuras inferiores apresentam o aproamento após uma alteração de $30^{\circ}$ no mesmo. A força média de 
cada propulsor para ambos os aproamentos se encontra na Figura 3, atestando que houve uma redução significativa na potência e empuxo demandados.

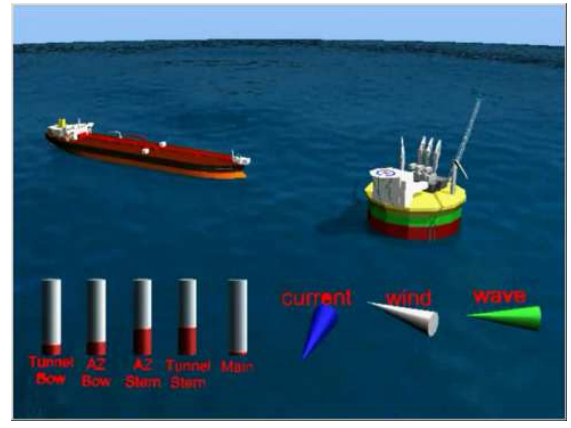

Inicial

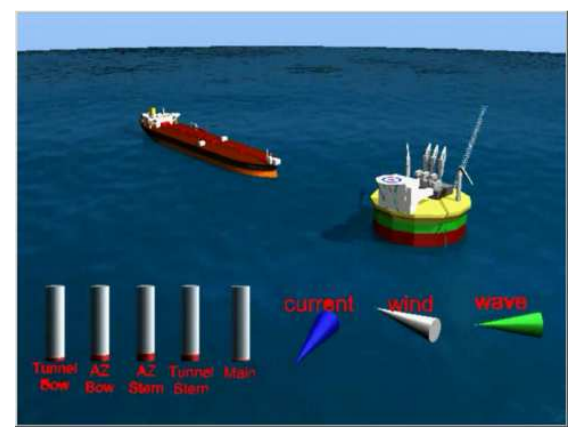

Final

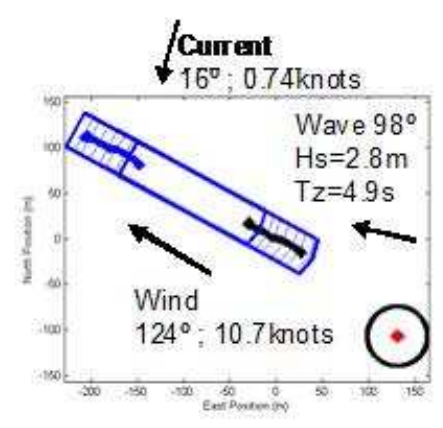

Inicial

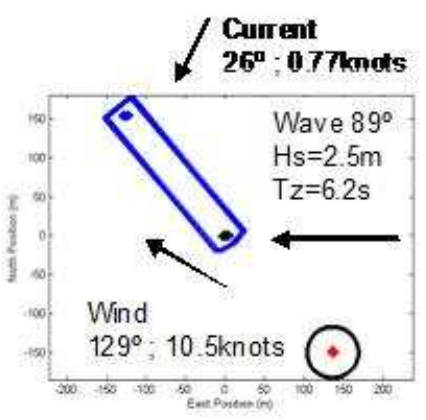

Final

Figura 2 - Alteração de aproamento para mitigar o consumo do Sistema DP em operação de alívio. (fonte: Tannuri et. al (2009))

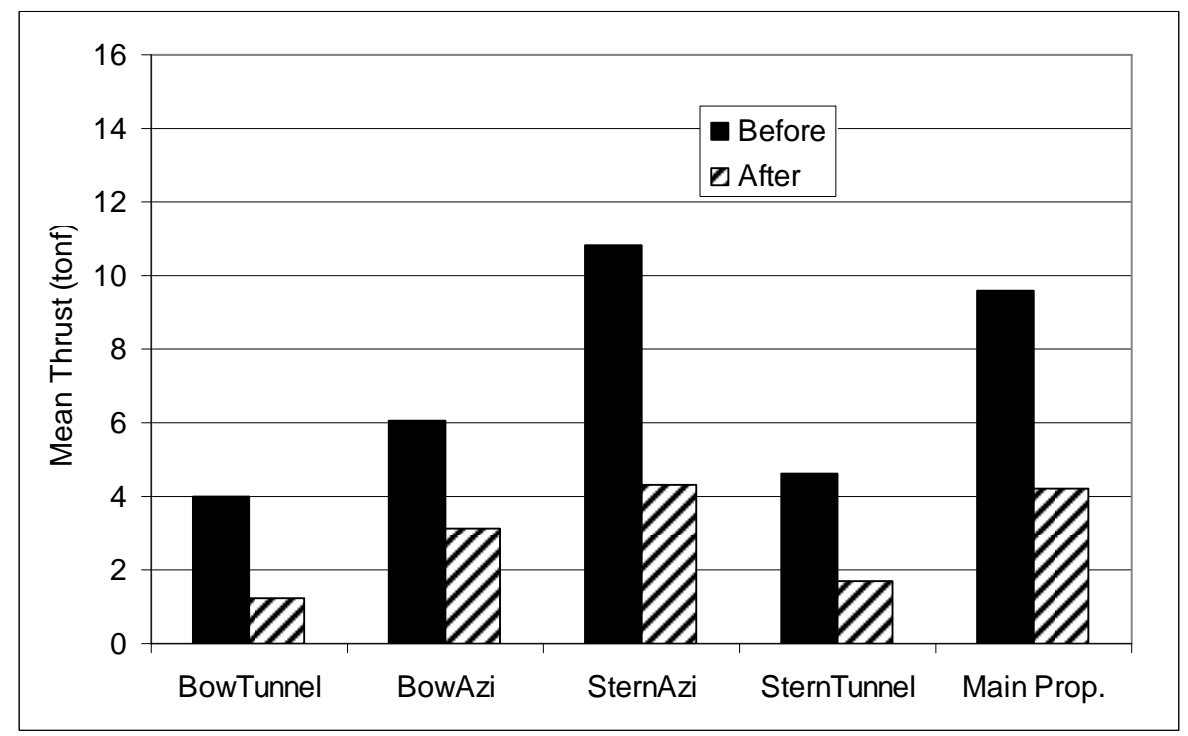

Figura 3 - Força média aplicada por cada propulsor (fonte: Tannuri et, al. (2009)) 
O alívio de petróleo não é o único caso em que há certa liberdade para alteração de aproamento a fim de minimizar o consumo de potência. Plataformas de perfuração também possuem tal propriedade, assim como FPSOs (Floating Production Storage and Offloading System) utilizados para produção antecipada em campos de exploração novos.

Plataformas de perfuração requerem o posicionamento do ponto no qual o riser de perfuração está posicionado (em geral, próximo à meia nau) para não haver rompimento dos elementos de perfuração. Por outro lado, o aproamento pode assumir qualquer valor dentro de um amplo intervalo.

Sistemas DP modernos possuem o chamado "modo weathervane", no qual o aproamento do navio controlado é alterado automaticamente, buscando o aproamento ótimo, no qual se minimizam os esforços exercidos sobre o navio.

Em teoria, basta medirem-se com precisão todos os agentes incidindo sobre o navio e calcular o ângulo de aproamento que resultasse em menor consumo de potência (denominado como jargão da área como ângulo de weathervane). Porém, não é possível medir diretamente as forças e momentos agindo sobre uma embarcação. É necessário mensurar os esforços através de medições de grandezas indiretas como velocidade e direção do vento, para posteriormente estimarem-se esforços devidos a cada agente ambiental, baseando-se em modelos validados previamente.

Nota-se também que as condições ambientais variam ao longo do dia, tanto em magnitude quanto em direção, e desta forma, o controlador deve se adaptar em tempo real levando em conta o conjunto de carregamentos ambientais variáveis incidindo sobre a embarcação.

Em operações em que a condição de carregamento do navio é alterada ao longo do tempo (como operações de alívio), a complexidade do problema de cálculo de ângulo weathervane é aumentada, pois com a variação da massa, consequentemente o calado do navio é alterado, e desta forma, todas as propriedades hidrodinâmicas e aerodinâmicas.

Em suma, o cálculo de ângulo weathervane se torna inviável devido a todas as incertezas envolvidas e alta dependência da qualidade de modelagem. Desta 
maneira, outra forma de inferir o ângulo weathervane deve ser encontrada, sendo este o escopo deste trabalho.

\subsection{Objetivos}

Existem problemas tecnológicos presentes nos atuais controladores weathervane existentes. $O$ presente trabalho propõe solucionar o problema de aproamento automático de navios com Sistemas DP, de forma a não apresentar as restrições atuais de outros controladores weathervane.

A solução deve ser aplicável para qualquer arranjo do sistema de propulsão, além de permitir a utilização de qualquer ponto de controle, seja de simples implementação e sem grandes modificações no sistema de controle base sobre o qual o controlador weathervane é implementado.

Também é necessário que o controlador desenvolvido seja viável fisicamente, se aproximando do aproamento ótimo, em tempo aceitável e de forma estável.

O método proposto deve comprovar sua funcionalidade de forma analítica, numérica e através de ensaios em tanque físico.

\subsection{Justificativa}

A primeira metodologia para adaptação do aproamento de navios com Sistemas DP foi apresentada por Pinkster e Nienhuis (1986), porém apresenta limitações, como sua estabilidade estar limitada ao controle de pontos a frente da meia nau da embarcação.

Outro grande fator limitante importante do controle desenvolvido por Pinkster reside na configuração do sistema de propulsão, pois para o controle é utilizado apenas um único propulsor azimutal, que deve estar posicionado na proa da embarcação.

Há controladores desenvolvidos posteriormente, que comprovadamente buscam soluções de aproamento ótimo, porém são patenteados. Pode-se citar o 
WOPC (Weather Optimal Positioning Control), desenvolvido por Fossen e Strand (2001) e patenteado pela $A B B$ Industri AS.

Outras empresas que desenvolvem Sistemas DP também possuem módulos que aproam automaticamente o navio, como é o caso da Kongsberg Maritime (Kongsberg (2006)), porém a metodologia utilizada por cada empresa não é divulgada.

Portanto, verificou-se a necessidade da criação de uma metodologia para tal fim, que pudesse ser implementada em ferramentas de simulação numérica tal como o simulador TPN (Tanque de Provas Numérico), desenvolvida no laboratório de mesmo nome, da Escola Politécnica da Universidade de São Paulo. Embora esta tenha sido a motivação, o presente trabalho irá mostrar que a metodologia apresentada possui grandes vantagens e excelente desempenho, o que permite que seja aplicada em sistemas reais, e não apenas em ambiente de simulação.

\subsection{Organização do texto}

Ao longo do desenvolvimento desta dissertação, é feita a descrição de forma aprofundada da estrutura do controlador e dos conceitos envolvidos. Devido à alta interdisciplinaridade deste tema, esta foi escrita de forma a fornecer o embasamento teórico necessário para o leitor, tanto na área de controle, quanto na área de sistemas navais e oceânicos, com detalhamento suficiente para o entendimento do trabalho.

O capítulo 2 contém uma revisão sobre as metodologias desenvolvidas até o momento para solução do problema de minimização de esforços ambientais sobre navios e plataformas em função de seu aproamento. Também é feita a revisão do histórico de Sistemas DP. Finalmente é introduzida a técnica ZPC, a qual é utilizada neste trabalho para resolução do problema de aproamento automático.

Os fundamentos teóricos presentes no capitulo 3 contam com a apresentação da dinâmica de sistemas oceânicos, desde a sua formulação matemática até métodos para estimar forças devido à ação de agentes ambientais. Também encontra-se neste capítulo descrições mais detalhadas sobre o sistema de 
propulsão do navio, como métodos para estimar o consumo de potência de cada propulsor e a metodologia utilizada para alocar propulsão.

O capítulo 4 contém a comparação dentre diversas estratégias para se encontrar o aproamento que leva ao consumo de potência mínimo, e justificando a metodologia presente neste trabalho.

O controlador desenvolvido, foco principal desta dissertação, é apresentado no capítulo 5, incluindo-se sua formulação e análise de estabilidade.

O capítulo 6 apresenta resultados de simulações numéricas contendo uma breve descrição do simulador utilizado, dos modelos matemáticos considerados e a discussão sobre os resultados.

O capítulo 7 apresenta os resultados dos ensaios efetuados, além da descrição do aparato utilizado.

Ao final, o capítulo 8 apresenta as conclusões deste estudo e sugestões de continuidade. 


\section{REVISÃO BIBLIOGRÁFICA}

Inicialmente, é feita uma breve discussão sobre posicionamento de corpos no mar, para ambientação do leitor sobre as tecnologias existentes, e sob qual conjunto de condições operacionais cada solução deve ser adotada.

Em seguida, as teorias e técnicas desenvolvidas até o momento, tanto na área de controle weathervane quanto de ZPC serão discutidas neste capítulo, bem como a explicação das características e desvantagens de cada controlador desenvolvido.

\subsection{Métodos para posicionamento de corpos flutuantes no mar}

Há um grande número de operações em alto mar que necessitam que um corpo permaneça em uma posição constante, devido a restrições físicas da operação a ser realizada. Um exemplo típico é a operação de perfuração, que exige que uma plataforma esteja em uma posição fixa para que não haja o rompimento de nenhum elemento envolvido no processo.

Diversas metodologias existem para manutenção da posição de corpos flutuantes. Desta forma, a escolha da solução deve levar em conta todas as variáveis e restrições de cada processo, tanto operacionais quanto financeiras.

Os aspectos operacionais incluem os carregamentos agindo sobre a estrutura, enquanto aspectos financeiros lidam com os custos de instalação e manutenção de cada operação.

Os sistemas atuais podem ser classificados em dois grupos distintos:

- Estruturas ancoradas ao leito do mar

- Estruturas posicionadas dinamicamente

As estruturas ancoradas são amarradas ao leito do mar através de linhas em catenária ou pernas tensionadas (TL - Tension Leg). Corpos amarrados com linhas em catenária limitam principalmente os movimentos no plano horizontal, sendo que há pouca influência nos demais movimentos (jogo - roll, afundamento - heave e 
arfagem - pitch). Podem-se citar como exemplo os FPSOs, que são navios convertidos em plataformas.

As plataformas com pernas tensionadas possuem tubulações verticais que ligam a estrutura da embarcação ao leito, porém, de forma que o volume de água deslocado seja maior do que a massa da plataforma. Desta forma, forças verticais de restauração estão sempre presentes, o que além de posicionar a plataforma no plano horizontal, também limita os movimentos verticais. $O$ exemplo mais comum de plataforma que utiliza este conceito são as plataformas chamadas TLP (Tension Leg Platform).

O último método para manutenção da posição de corpos sobre o mar é conhecido como Sistema DP, que consiste na utilização do sistema de propulsão do navio para compensar os esforços externos. Sistemas DP são constituídos por um conjunto complexo de subsistemas interligados e interdependentes, destacando-se geração de energia, sensores de posição e de aproamento, sistema computacional de controle e de filtragem e finalmente elementos de propulsão.

O foco deste trabalho está no desenvolvimento de um novo sistema de controle para Sistemas DP, de forma que este não deve alterar os demais sistemas (ex: não requer a instalação de propulsores ou sensores extras).

\subsection{Histórico do Sistema DP}

Em 1908, o primeiro girocompasso foi patenteado, iniciando uma nova fase em que controladores foram aplicados a navios. Inicialmente o uso dos controladores estava limitado ao aproamento automático de navios. Apenas três anos após a patente do primeiro girocompasso, foi desenvolvido o "Metal Mike", o primeiro sistema de aproamento automático de navios (em relação a um referencial fixo), porém apenas o aproamento era controlado, enquanto a posição do navio ainda era controlada manualmente, conforme mencionado em Fossen (2000).

Segundo Bray (1998), o primeiro navio equipado com Sistemas DP data de 1961, chamado de "Eureka", que utilizava o sistema taut-wire para referenciamento e um controlador analógico para cálculo das forças de cada propulsor. O navio "Eureka" também contava com dois propulsores azimutais além do propulsor 
principal, sendo capaz de controlar efetivamente todos os graus de liberdade horizontais.

Com a evolução do hardware utilizado, controladores mais complexos foram desenvolvidos, como controladores LQG, $\mathrm{H}_{\infty}$ e finalmente métodos não lineares como backstepping e modos deslizantes (sliding mode).

A Figura 4, extraída de Fossen (2000), apresenta de forma visual a evolução de controladores aplicados a embarcações. Em seu estudo sobre a evolução dos sistemas de controle, Fossen aborda aspectos ligados não somente sobre Sistemas DP, mas também sobre sistemas de aproamento, controle de trajetória e controle de sistemas sub-atuado para navios que possuem menos propulsores do que graus de liberdade controlados.

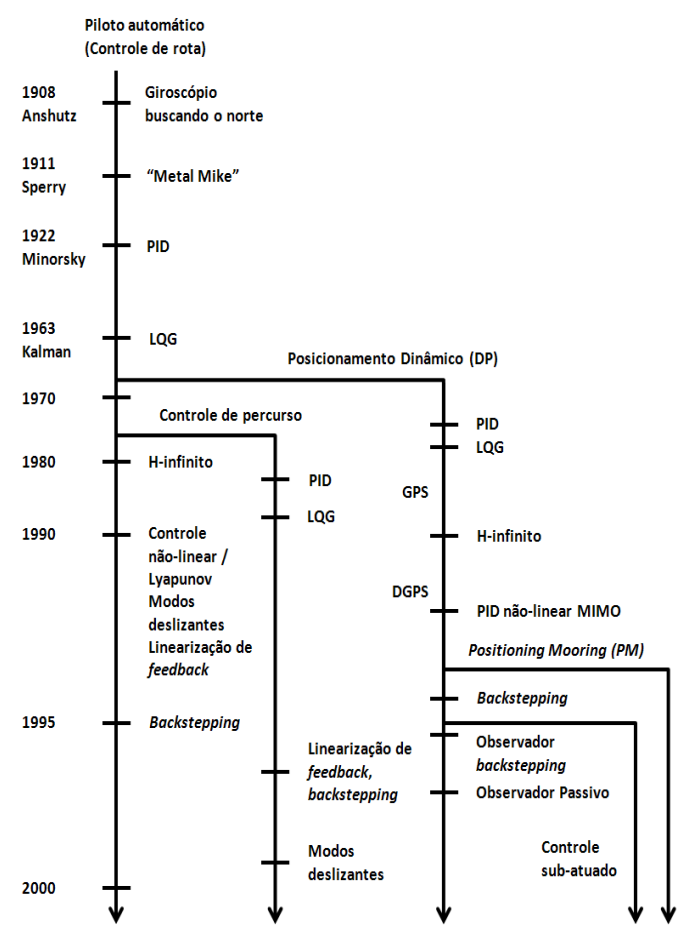

Figura 4 - Evolução de controladores navais (fonte: Fossen (2000))

Após o ano 2000, outras linhas de pesquisa surgiram nas mais diversas áreas. Um exemplo é o controle aplicado a navios amarrados utilizando-se linha em catenária e que possuam Sistema DP. Esta configuração é denominada "posicionamento via amarração assistido por propulsão" (PM - Thruster Assisted Position Mooring).

Hespanha (2001) e outros autores passaram a explorar técnicas de controle híbrido, que consistem na inclusão de uma lógica de chaveamento de controladores, 
em função das condições ambientais presentes. Desta forma, o mesmo navio pode possuir diferentes tipos de controladores, um aplicável em cada condição ou operação. Sørensen et. al.(2005) e estudos posteriores propuseram a utilização de controle híbrido para chaveamento de um banco de controladores variando de condições ambientais amenas até condições extremas, além de condições estacionárias a condições em navegação.

Um estudo sobre posicionamento ótimo de plataformas de perfuração em águas profundas pode ser visto em Sørensen et. al. (2001), que mostra a escolha do set-point de um navio em função de parâmetros como os esforços nas ferramentas de perfuração. O mesmo conceito se estende em Berntsen et. al. (2006), que aplica controle DP em navios amarrados ao leito do mar através de linhas em catenária, pois em condições ambientais severas, o posicionamento do navio faz com que as linhas estejam em condições sub-ótimas. $O$ trabalho de Berntsen também utiliza técnicas de confiabilidade em função do conjunto de condições ambientais incidentes.

A aplicação de técnicas de controle não linear robusto baseado em modos deslizantes é apresentada em Tannuri et. al. (2010). Os resultados indicaram vantagens desta técnica em relação a controladores convencionais no que concerne à robustez e facilidade de ajuste de parâmetros.

Técnicas avançadas para filtragem de ondas também estão sendo estudadas em relação ao Filtro de Kalman aplicado nos controladores atuais. Cita-se, por exemplo, o trabalho de Morishita et al (2011), que aplica a técnica de decomposição por modos empíricos (empirical mode decomposition) para esta função.

Os trabalhos citados são apenas alguns dos muitos estudos em andamento. Mais referências sobre os tópicos em estudo podem ser encontrados em Sørensen (2011).

Graças à grande quantidade de desenvolvimento científico e tecnológico em Sistemas DP, diversas operações foram viabilizadas com auxílio dos mesmos. Isto é visível, pois durante os 50 anos que se seguiram após o primeiro navio DP ser desenvolvido, diversas operações nas mais diferentes áreas, utilizando este sistema já foram realizadas. Bray (1998) apresenta uma longa lista de operações, 
destacando-se: perfuração, suporte a mergulho, instalação de dutos, alívio de petróleo, navios de cruzeiro, entre outras.

\subsection{Controle weathervane}

Conforme mencionado na seção 2.2, os primeiros Sistemas DP foram projetados para controlar os três graus de liberdade horizontais da embarcação (movimentação longitudinal e lateral, além do aproamento), porém, ao se desconsiderar o controle direto do aproamento, desenvolveu-se a primeira abordagem registrada de controlador de aproamento automático, buscando 0 aproamento que resulta em mínimos esforços de controle. O controlador desenvolvido por Pinkster e Nienhuis (1986) e aprofundado por Davidson et. al. (1987), sugere que o operador não defina uma referência fixa para o aproamento, apenas a posição da proa da embarcação.

A abordagem baseia-se na existência de um propulsor azimutal na proa do navio, que controla a posição do ponto de controle, posicionado a frente da meia nau. Desta forma, o propulsor consegue controlar dois graus de liberdade, correspondente à posição longitudinal e transversal do ponto de cotrole.

O aproamento não é controlado, porém os agentes ambientais que atuam sobre o navio tendem a aproá-lo naturalmente em uma posição em que o momento devido aos agentes ambientais é equivalente ao momento devido ao propulsor único, de certa forma similar a uma bandeira sob a ação do vento.

A Figura 5 apresenta o primeiro controlador weathervane proposto, na qual a marcação "•" representa a posição do ponto de controle do navio.

Nota-se que o navio tende a alinhar com as condições ambientais incidentes, graças ao momento sobre o navio causado pelos agentes ambientais. 


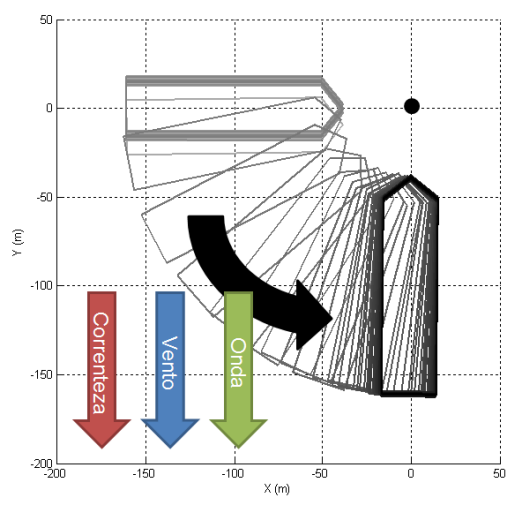

Figura 5 - Proposta desenvolvida por Pinkster e Nienhuis (1986)

Esta metodologia possui duas grandes desvantagens, ambas relacionadas ao fato de que não há qualquer controle do aproamento (yaw), e a embarcação busca seu aproamento natural.

A primeira relativa ao ponto de controle, que deve obrigatoriamente estar próximo à proa do navio para garantir este aproamento de equilíbrio natural (estável) seja de fato alinhado com a condição ambiental incidente resultante. Uma análise semelhante para o caso em que há incidência apenas de correnteza é mostrada em Pesce e Tannuri (1998).

A segunda desvantagem é que o navio é livre para alcançar o aproamento de equilíbrio, não sendo possível definirem-se limites seguros para o mesmo. Isto é critico em operações para as quais este ângulo deve estar restrito a um determinado intervalo, como operações de perfuração ou operações que envolvam diversas embarcações, como a de alívio.

Navios dotados de Sistema DP são geralmente superatuados, e é possível efetuar o controle de qualquer ponto de controle. Ao controlar a proa do navio e desativar o controle em yaw, cria-se um controlador que gera momento nulo em relação à meia nau, similar a ideia inicialmente proposta por Pinkster e Nienhuis (1986). Em alguns casos, pode-se incluir lógica apenas derivativa no controle de aproamento, aumentando o amortecimento neste movimento e evitando oscilações em torno do ângulo de weathervane.

Fossen e Strand (2001) afirmam que navios com ponto de controle à frente da proa do navio se comportam de forma similar a um pêndulo sob a ação da gravidade. Neste mesmo trabalho, Fossen e Strand (2001) também comprovam que 
se o set-point for alterado dinamicamente em função do aproamento do navio, dentro de uma trajetória circular, é possível posicionar outros pontos além da proa, por exemplo, a meia nau. O set-point depende das coordenadas do ponto de controle e o raio sobre a qual se deve posicionar o ponto de controle do sistema de controle.

A esta abordagem se deu o nome de WOPC (Weather Optimal Position Control), que é interessante por eliminar os problemas inerentes à abordagem simplista de controle weathervane desenvolvida por Pinkster e Nienhuis. Porém, uma desvantagem do WOPC é o fato desta abordagem ser patenteada pela $A B B$ Industri AS.

A Figura 6 representa o controle proposto por Fossen e Strand (2001), no qual o set-point (representado pelo "X") do navio é alterado em função do aproamento, para manter a meia nau fixa e encontrar o ângulo que minimiza os esforços ambientais. Vale ressaltar que este controlador possui comportamento similar ao apresentado na Figura 5, porém com a alteração dinâmica do set-point, a meia nau permanece estática.

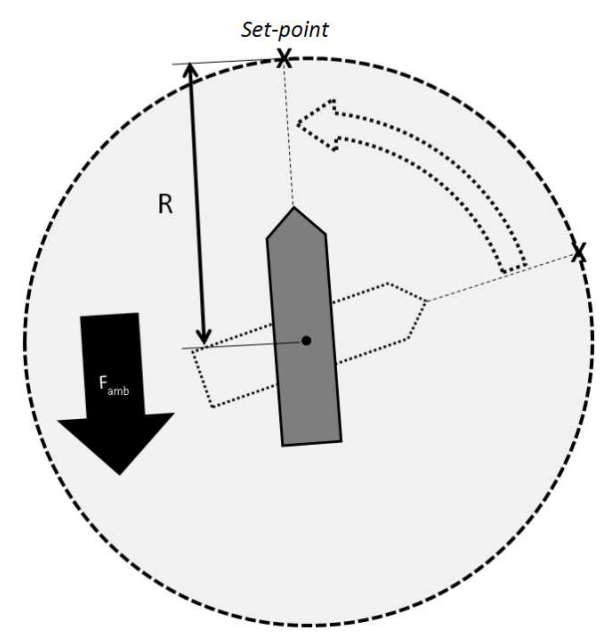

Figura 6 - Controlador proposto pelo WOPC (baseado em Fossen e Strand (2001))

Um ponto importante abordado por Kaasen et. al. (2005) é o fato de que em casos com condições ambientais desalinhadas, a definição de aproamento ótimo fica comprometida. A Figura 8 apresenta a simulação contida em Kaasen et al. (2005), que prova que nem sempre existe um aproamento em que a força lateral e o momento são simultâneamente nulos. Para esta simulação, a condição ambiental incidente é a apresentada na Figura 7. Indica-se na figura a altura significativa de 
onda, seu período de pico e as velocidades de vento e correnteza, além da direção de todos os agentes ambientais.

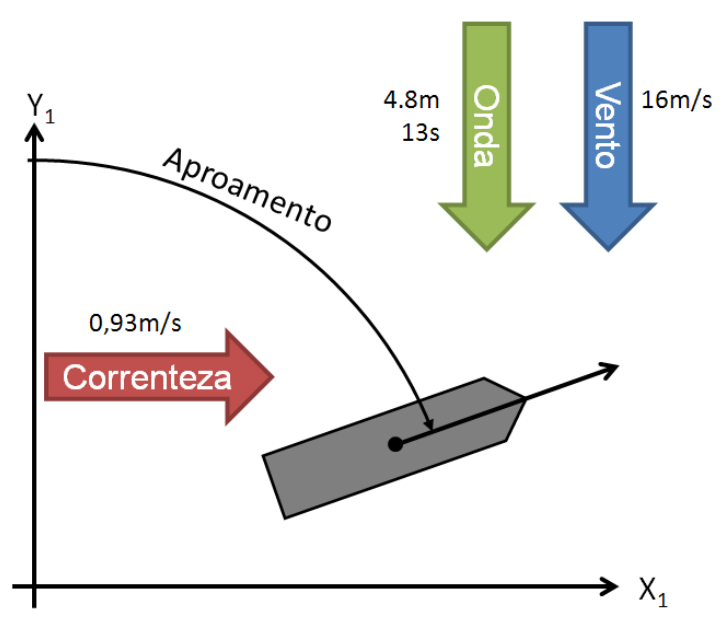

Figura 7 - Condição ambiental para a simulação apresentada em Kaasen et al. (2005)

O capítulo 4 desta dissertação discute a existência de aproamentos com força lateral e momento simultaneamente nulos, além de discutir qual variável deve ser preferencialmente anulada para minimizar o consumo de potência.
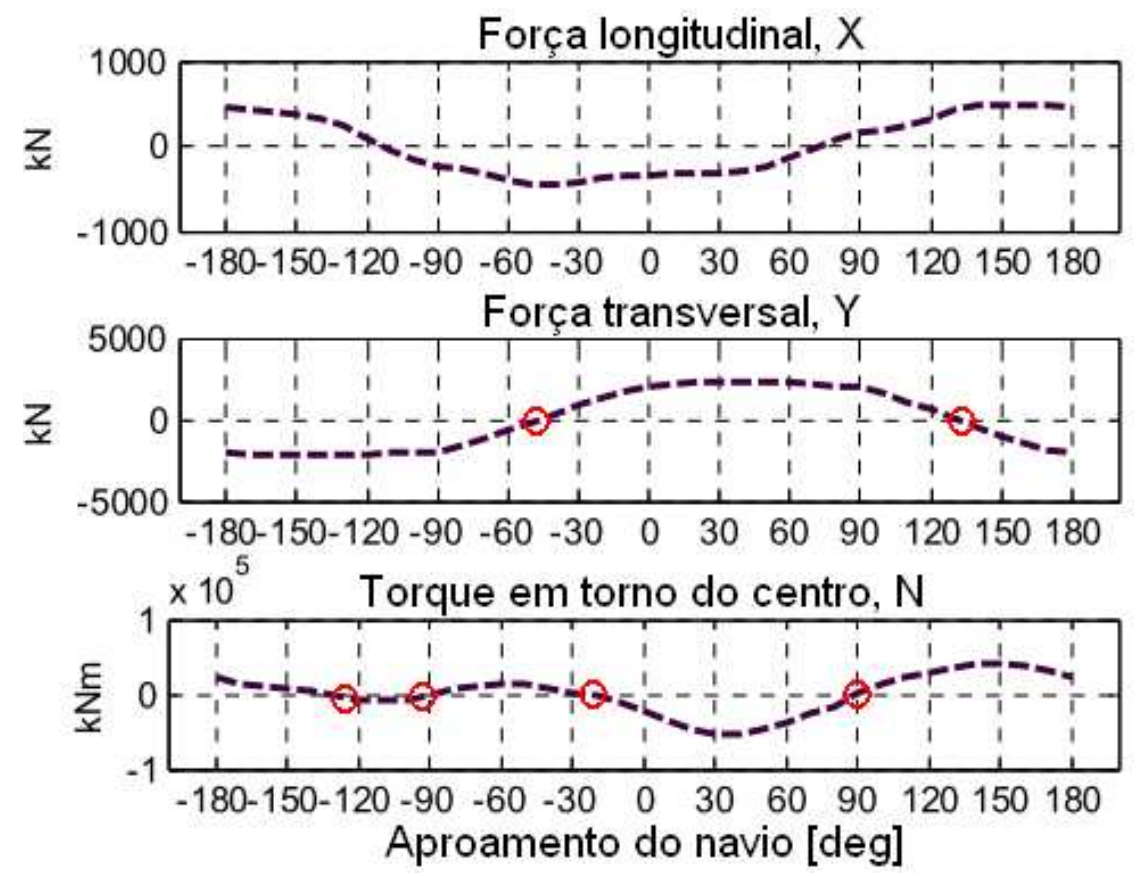

Figura 8 - Gráfico mostrando esforços ambientais agindo sobre navio aliviador em função de seu aproamento, com condições ambientais exibidas na Figura 7 (fonte: Kaasen et. al. (2005))

Constata-se que em geral há apenas um ponto de máximo e um de mínimo das forças longitudinais e laterais em função do ângulo de incidência, como pode ser visto na Figura 8. Nota-se que a força lateral é nula para aproameno de 
aproximadamente $135^{\circ}$ e $-50^{\circ}$, que equivale a incidência de proa e de popa (respectivamente) com a resultante dos agentes ambientais. Na mesma figura, notase que o momento de yaw, por outro lado, tende a apresentar extremos locais e múltiplos pontos de cruzamento por zero, podendo convergir para um ponto subótimo. O mesmo comportamento é verificado para o momento em torno de outros pontos que não o centro (meia nau) da embarcação.

\subsection{Controle de Potência Nula}

A abordagem utilizada para encontrar o ângulo weathervane é inspirada por controladores de potência nula (ZPC - Zero Power Control), comumente empregados para levitação magnética.

No início do desenvolvimento de sistemas maglev (magnetic levitation), todos os controladores eram projetados para manter uma distância fixa entre imãs e um trilho ferroso.

Para tentar minimizar o consumo de energia do sistema, imãs permanentes foram inseridos em paralelo com os eletroímãs (chamados sistemas híbridos, mostrados na Figura 9). Desta forma, a força magnética média era exercida de forma passiva. Assim, o consumo de potência foi reduzido drasticamente em casos nos quais o set-point foi ajustado corretamente.

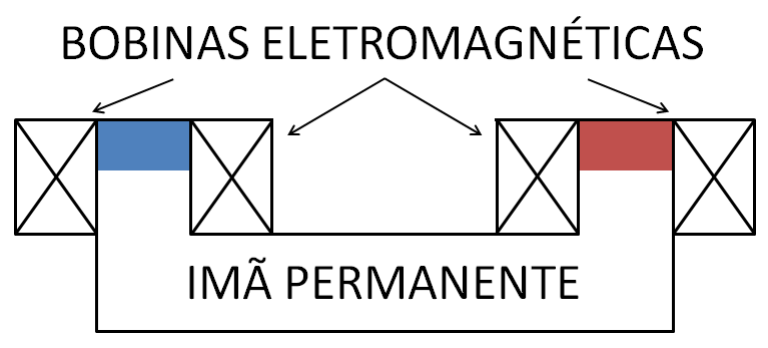

Figura 9 - Sistema maglev híbrido, constituído por um ímã permanente e bobinas eletromagnéticas.

Um novo tipo de controlador para levitação magnética foi desenvolvido por Morishita et. al. (1989), alterando dinamicamente o set-point do controlador em função do carregamento do sistema. A aplicação de tal controle, com foco em controle por levitação magnética em mancal uniaxial, pode ser visto em Mello (2011). 
A ideia central é alterar o set-point do sistema de forma a minimizar os esforços de controle. Desta forma, o ZPC pode ser interpretado como um controlador que possui como foco minimizar os esforços de controle ao invés de minimizar o erro de posição de um objeto.

Ainda tendo em mente a levitação magnética, é intuitivo que uma forma de compensar um aumento na carga levitada é aproximar o imã e a carga levitada. Desta forma, a força magnética aumenta sem necessariamente haver aumento do consumo de potência do sistema.

Na Figura 10, extraída de Mizuno (2002), é feita a comparação entre o setpoint de um sistema massa-mola e um sistema maglev. Ainda na Figura 10, nota-se que conforme se aumenta a carga sobre a mola, maior deve ser a força média exercida por esta, por isso a nova posição de equilíbrio. O mesmo ocorre com o sistema magnético, pois conforme se aumenta a carga, maior deve ser a força média, por isso o set-point deve ser alterado para diminuir o vão entre os imãs. Destaca-se, entretanto, que as posições de equilíbrio indicadas para o sistema magnético são instáveis, portanto, demandando um sistema de controle.

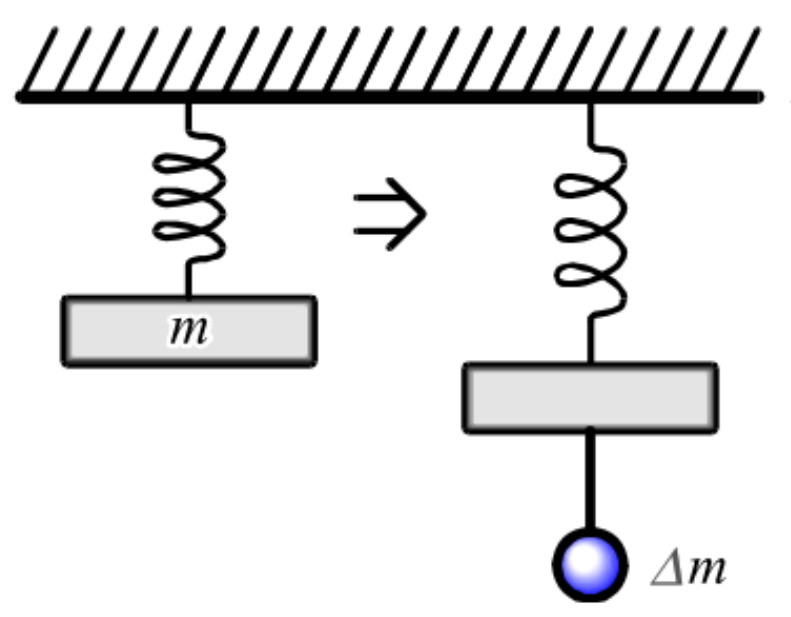

(A)

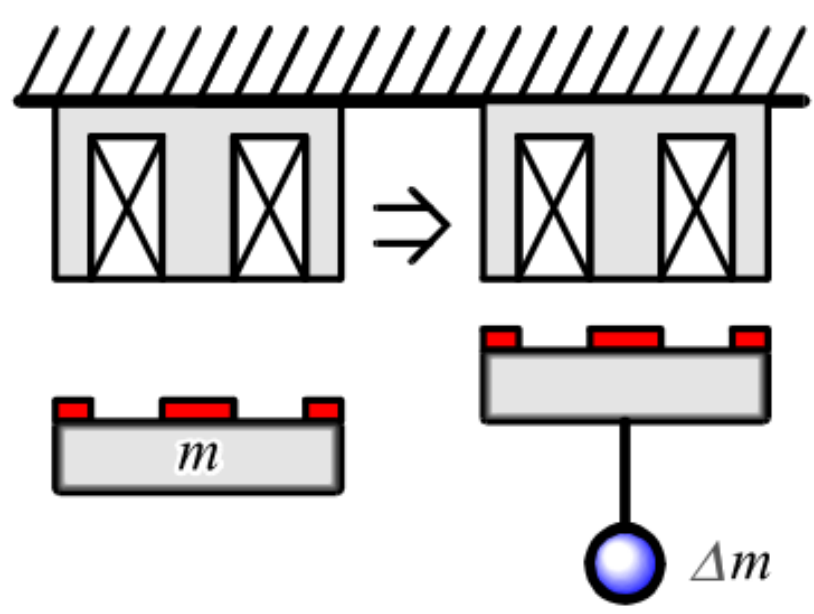

(B)

Figura 10 - Posição de equilíbrio do sistema para suspensão utilizando (A) Mola simples e (B) suspensão magnetica ZPC (fonte: Mizuno (2002))

O sistema de controle proposto por Morishita et. al. (1989) pode ser resumido pela modificação entre os sistemas da Figura 11 e da Figura 12. Esta metodologia consiste em somar a integral da saída do sistema com o set-point atual. 


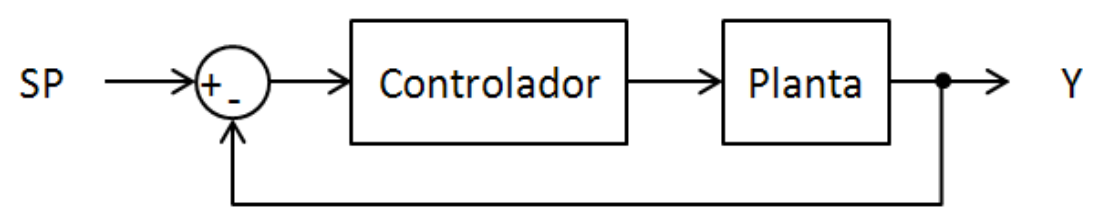

Figura 11 - Diagrama de blocos de um sistema com controle e realimentação unitária

0

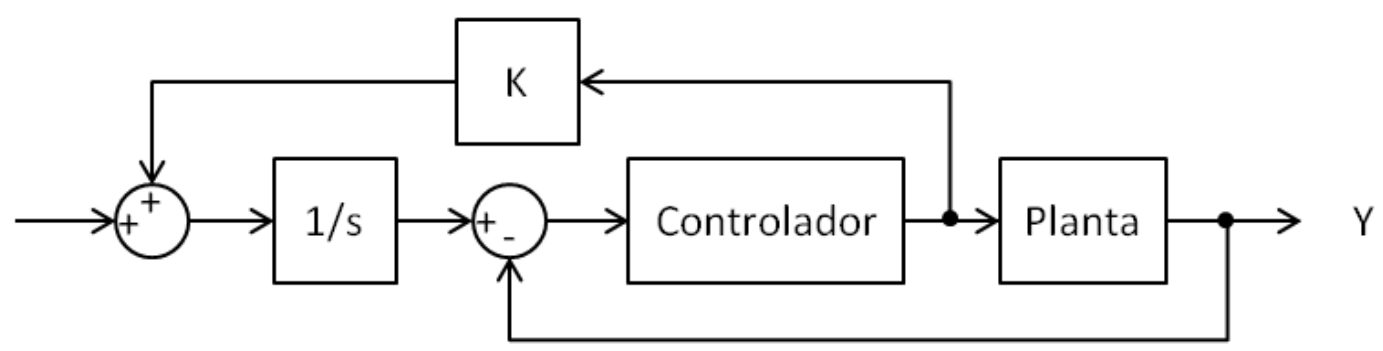

Figura 12 - Diagrama de blocos de um sistema de controle ZPC (baseado em Morishita et. al. (1989)).

Existem hoje diversas técnicas para minimização de esforços de controle Como exemplo, pode-se citar a utilização de observadores, integral da realimentação ou estimação de parâmetros da planta, conforme descrito em Sun e Oka (2009). Na Figura 12, a representação é de um sistema utilizando integral da realimentação.

Em suma, o controlador ZPC, independentemente de qual metodologia for utilizada, visa alterar dinamicamente o set-point do controlador base, levando 0 sistema a uma posição com consumo mínimo de energia.

\subsubsection{Aplicação do controle de potência nula em sistemas navais}

A integral de realimentação, técnica do ZPC, apresenta um ponto de estabilidade para cada par de mudanças de sinal na força de realimentação. A Figura 13 apresenta o coeficiente de força lateral ${ }^{1}$ de um navio e o aproamento de equilíbrio estável. Aplicando a integral de realimentação a este caso, há convergência para aproamento relativo de $180^{\circ}$ para qualquer condição inicial ] $0^{\circ}, 360^{\circ}$ [. Como será mostrado adiante na definição dos ângulos e sistemas de coordenadas, o aproamento relativo de $180^{\circ}$ corresponde à incidência ambiental de proa. 


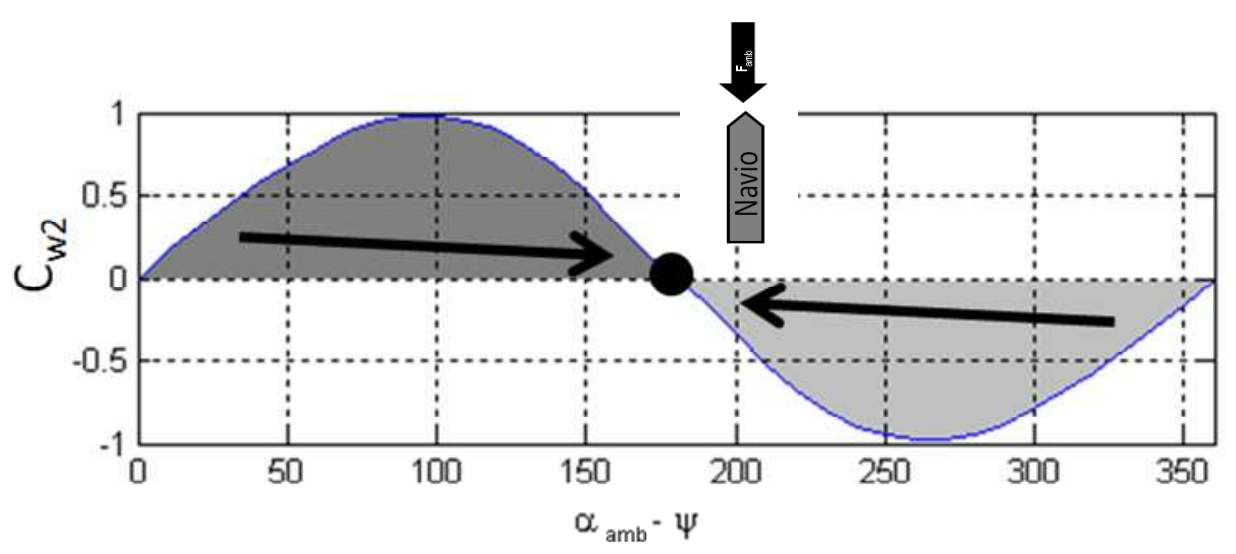

Figura 13 - Coeficiente de forças laterais devido ao vento, conforme será definido pela seção 3.2.1

Ilustrativamente, o ZPC aplicado às forças laterais atuantes sobre o navio é representado pela Figura 14, que mostra a evolução do aproamento e seu set-point ao longo do tempo. Nesta figura, os ângulos indicados são dados em relação ao eixo horizontal, ou seja, um ângulo de aproamento de $90^{\circ}$ corresponde ao alinhamento com a correnteza incidente.

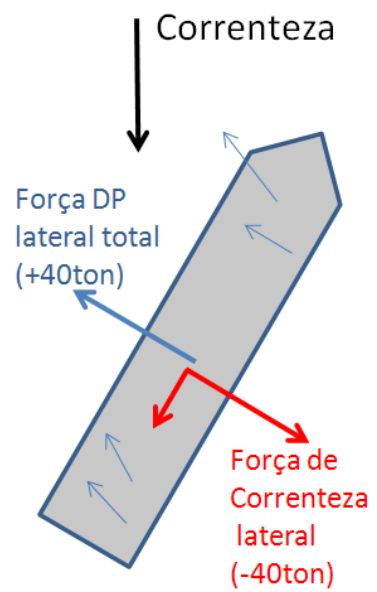

Início:

$\psi=60^{\circ}$

$\Psi_{\mathrm{SP}}=60^{\circ}$

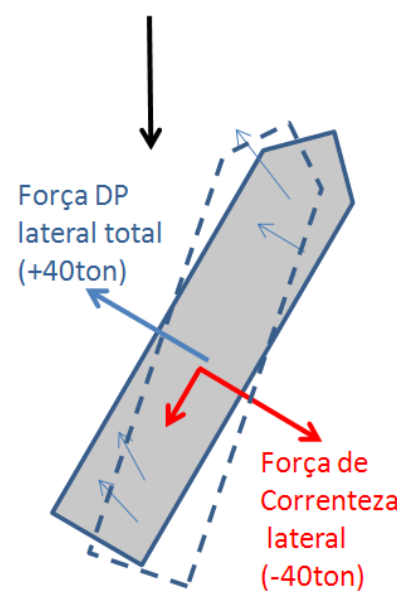

Após $t_{1}$ :

$\Psi=60^{\circ}$

$\Psi_{\mathrm{SP}}=70^{\circ}$

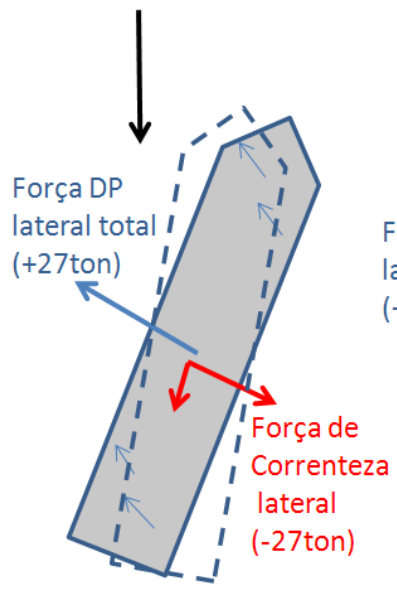

Após $t_{2}$ :

$\Psi=69^{\circ}$

$\Psi_{\mathrm{SP}}=80^{\circ}$

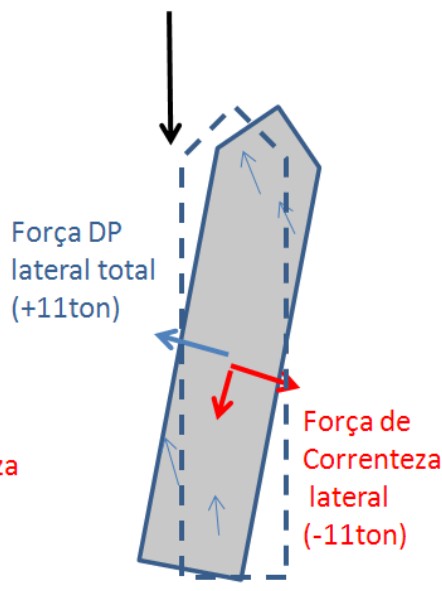

Após $t_{3}$ :

$\Psi=79^{\circ}$

$\Psi_{\mathrm{SP}}=90^{\circ}$

Figura 14 - Atuação do ZPC sobre um navio

Por outro lado, ao analisar o coeficiente de momento ${ }^{2}$ de vento do mesmo navio, apresentado na Figura 15, observam-se dois pontos de estabilidade, conforme exibido no diagrama na parte inferior da imagem. Este sistema converge para aproamento relativo de $180^{\circ}$ para condição inicial $] 100^{\circ}, 260^{\circ}$ [ e converge para $0^{\circ}$ para o intervalo de condições iniciais de $] 0^{\circ}, 100^{\circ}[$ ou $] 260^{\circ}, 360^{\circ}$ [. Antecipa-se

${ }^{2}$ Coeficiente de momento representa o momento lateral que será aplicado sobre a meia nau navio em função do ângulo de incidência da condição ambiental 
novamente que um aproamento relativo de $0^{\circ}$ equivale à incidência ambiental de popa, o que é indesejável em termos operacionais.

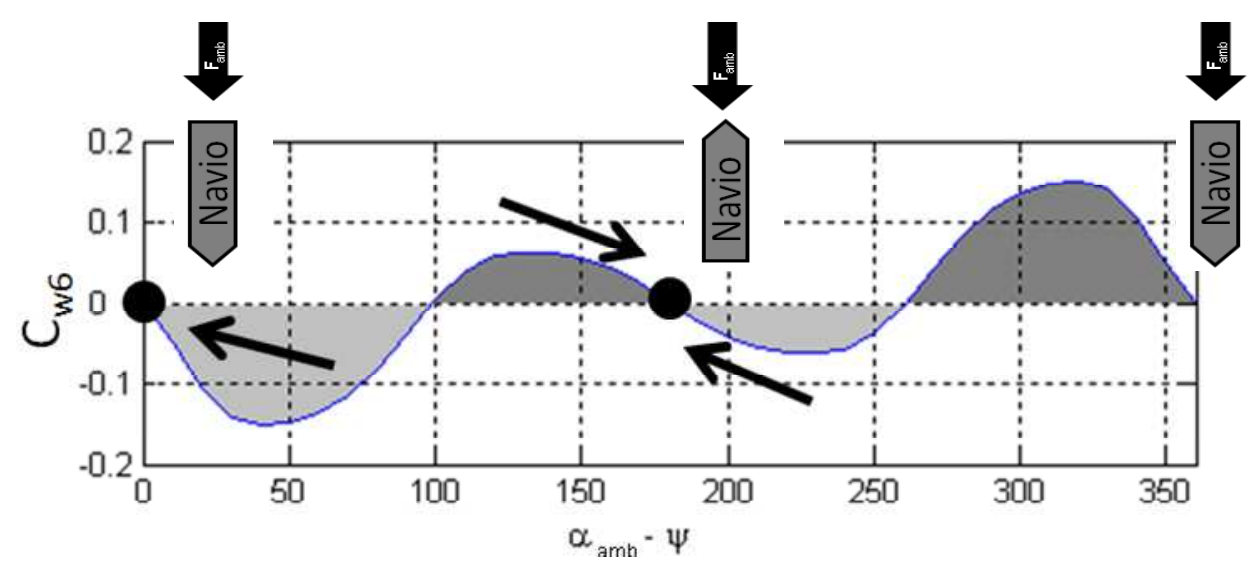

Figura 15 - Coeficiente momento devido ao vento, conforme será definido pela seção 3.2.1

O ZPC será utilizado para encontrar dinamicamente qual o set-point que levará a menor utilização do Sistema DP, ampliando janelas operacionais, minimizando desgaste e consumo de combustível. 


\section{FUNDAMENTOS TEÓRICOS}

Neste capítulo será feita uma breve descrição dos conceitos utilizados para desenvolvimento do presente trabalho. Primeiramente, serão discutidos aspectos referentes a sistemas oceânicos, seguido pela estimação de esforços ambientais e por fim serão apresentados os conceitos de controle.

\subsection{Dinâmica de sistemas oceânicos}

Primeiramente, serão definidos três diferentes sistemas de coordenadas para facilitar a descrição dos efeitos ambientais e esforços de controle.

$O$ primeiro sistema de coordenadas (definido por $O_{1}, X_{1}$ e $Y_{1}$ ) consiste no referencial fixo, ou seja, coordenadas fixas e constantes ao longo do tempo, independentes da posição do navio. Neste sistema de coordenadas, em geral, é descrita tanto a posição do navio como o set-point de seu Sistema DP. Figura 16 apresenta a definição do primeiro sistema de coordenadas:

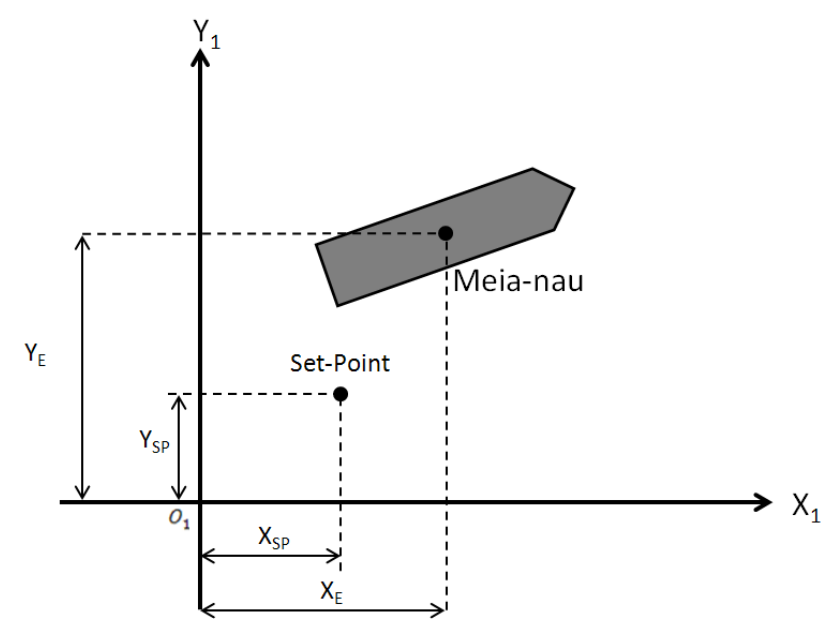

Figura 16 - Primeiro sistema de coordenadas

Posteriormente, define-se o segundo sistema de coordenadas $\left(o_{2}, x_{2}\right.$ e $\left.y_{2}\right)$, com mesma origem, porém rotacionado $\Psi$ em torno do eixo vertical. $O$ ângulo $\Psi$ coincide com o aproamento em que o navio se encontra, descrito no primeiro sistema de coordenadas. As projeções das coordenadas da meia nau sobre o segundo sistema de coordenadas são utilizadas para medir a posição do navio em 
coordenadas locais, usado para o cálculo do Sistema DP. A Figura 17 apresenta a definição deste sistema de coordenadas:

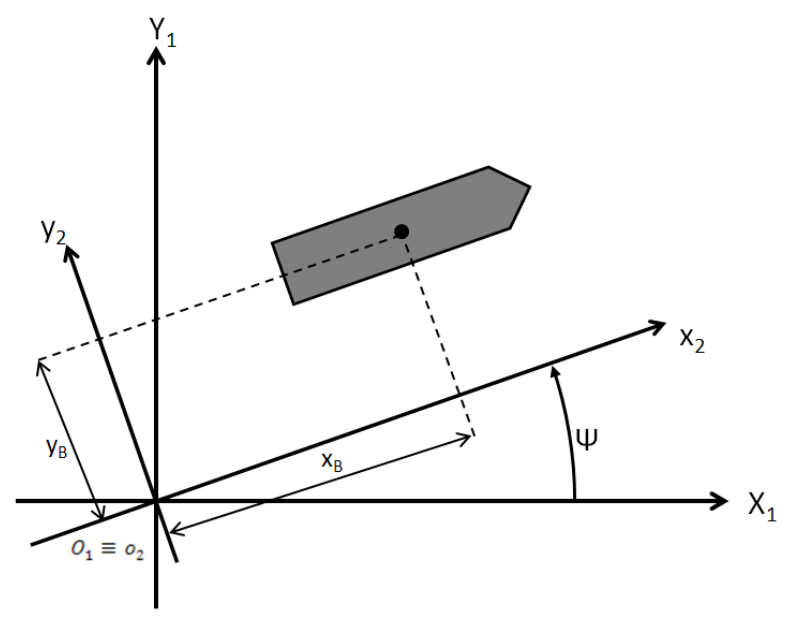

Figura 17 - Segundo sistema de coordenadas

Finalmente, 0 terceiro sistema de coordenadas $\left(o_{3}, x_{3}\right.$ e $\left.y_{3}\right)$, geralmente chamado de sistema de coordenadas local, é solidário ao navio. A origem deste sistema de coordenadas $\left(o_{3}\right)$ se desloca ao longo do tempo. É neste sistema de coordenadas em que as características físicas da embarcação são descritas, como a posição de cada propulsor e seu ângulo de azimute. Também se define o ponto de controle do navio utilizando-se o sistema de coordenadas local. A definição deste sistema de coordenadas está apresentada na Figura 18. Os movimentos na direção $x_{3}$ e $y_{3}$ são conhecidos como avanço (ou surge) e deriva (ou sway) respectivamente. O ângulo de rotação no plano horizontal é conhecido como aproamento (ou yaw, $\Psi$ ).

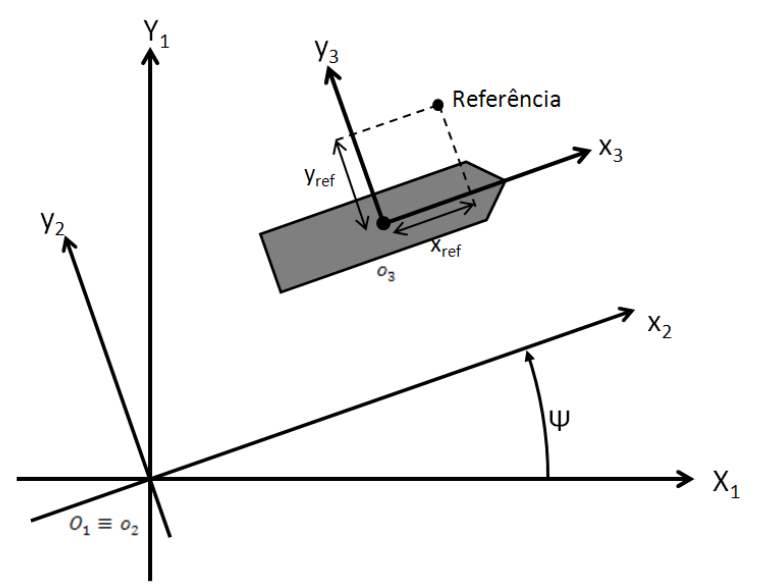

Figura 18 - Terceiro sistema de coordenadas 
A embarcação modelada é considerada um corpo rígido flutuante sob influência de carregamento devido aos agentes ambientais $\boldsymbol{W}_{\boldsymbol{a m b}}(\Psi)=\left[\begin{array}{lll}W_{a m b}^{x} & W_{a m b}^{y} & W_{a m b}^{\Psi}\end{array}\right]^{T}$, descrito no sistema de coordenadas solidário ao corpo. Supõe-se aqui, por simplificação, que os esforços ambientais dependem apenas do ângulo de aproamento, e não da velocidade do corpo. Além disso, há os esforços devido ao sistema de propulsão e controle $\boldsymbol{W}_{\text {prop }}=\left[\begin{array}{lll}W_{\text {prop }}^{x} & W_{\text {prop }}^{y} & W_{\text {prop }}^{\psi}\end{array}\right]$, também descritos no sistema de coordenadas solidário ao corpo $\left(o_{3}, x_{3}\right.$ e $\left.y_{3}\right)$.

A posição da meia nau do corpo e sua orientação em relação às coordenadas globais podem ser descritas pela equação (1):

$$
\boldsymbol{\eta}_{\boldsymbol{G}}=\left[\begin{array}{c}
X_{E} \\
Y_{E} \\
\Psi
\end{array}\right]
$$

O vetor $\boldsymbol{\eta}_{\boldsymbol{B}}$ é composto pela posição da meia nau no sistema de coordenadas paralelo ao corpo $\left(x_{B}, y_{B}\right)$ e pela rotação do sistema de coordenadas em relação ao referencial fixo segundo a equação (2):

$$
\boldsymbol{\eta}_{\boldsymbol{B}}=\left[\begin{array}{l}
x_{B} \\
y_{B} \\
\psi
\end{array}\right]
$$

A matriz de rotação $\boldsymbol{R}$ que rotaciona as coordenadas do sistema de coordenadas solidário ao corpo para o sistema de coordenadas solidário ao referencial fixo pode ser deduzida como:

$$
\boldsymbol{R}(\Psi)=\left[\begin{array}{ccc}
\cos (\Psi) & -\operatorname{sen}(\Psi) & 0 \\
\operatorname{sen}(\Psi) & \cos (\Psi) & 0 \\
0 & 0 & 1
\end{array}\right]
$$

Além disso, o ponto de controle e o set-point no sistema de coordenadas local estão descritos nas equações (4) e (5) respectivamente:

$$
\begin{gathered}
\boldsymbol{\eta}_{\boldsymbol{s} \boldsymbol{p}}=\boldsymbol{R} \cdot\left[\begin{array}{c}
X_{S P} \\
Y_{S P} \\
\Psi_{S P}
\end{array}\right] \\
\boldsymbol{\eta}_{\text {ref }}=\boldsymbol{\eta}_{\boldsymbol{B}}+\left[\begin{array}{c}
x_{\text {ref }} \\
y_{\text {ref }} \\
0
\end{array}\right]
\end{gathered}
$$

Finalmente, a dinâmica do navio pode ser descrita pelas equações (6) a (8), extraídas de Tannuri (2002): 


$$
\begin{gathered}
\left(M+M_{11}\right) \ddot{x}-\left(M+M_{22}\right) \dot{y} \dot{\Psi}-\left(M x_{G}+M_{22}\right) \dot{\Psi}^{2}=W_{a m b}^{x}+W_{\text {prop }}^{x} \\
\left(M+M_{22}\right) \ddot{y}+\left(M x_{G}+M_{26}\right) \ddot{\Psi}+\left(M+M_{11}\right) \dot{x} \dot{\Psi}=W_{a m b}^{y}+W_{\text {prop }}^{y} \\
\left(I_{z}+M_{66}\right) \ddot{\Psi}+\left(M x_{G}+M_{26}\right) \ddot{y}+\left(M x_{G}+M_{26}\right) \dot{x} \dot{\Psi}=W_{a m b}^{\Psi}+W_{\text {prop }}^{\Psi}
\end{gathered}
$$

Os esforços ambientais $\boldsymbol{W}_{\boldsymbol{a m b}}(\Psi)$ e os esforços de controle $\boldsymbol{W}_{\text {prop }}$ serão detalhados nas seções subsequentes.

\subsection{Modelagem matemática de agentes ambientais}

Diversos estudos estimam esforços ambientais incidentes sobre o navio. Nesta seção será exibida a modelagem utilizada durante as simulações, porém este tema não se restringe ao que será exibido nas seções 3.2.1 a 3.2.3.

Primeiramente, será definido o ângulo de incidência relativo de uma condição ambiental $\left(\alpha_{j r}\right)$, apresentada na Figura 19. Esta variável é medida em relação à popa do navio, e aumenta conforme a condição ambiental é rotacionada em sentido anti-horário.

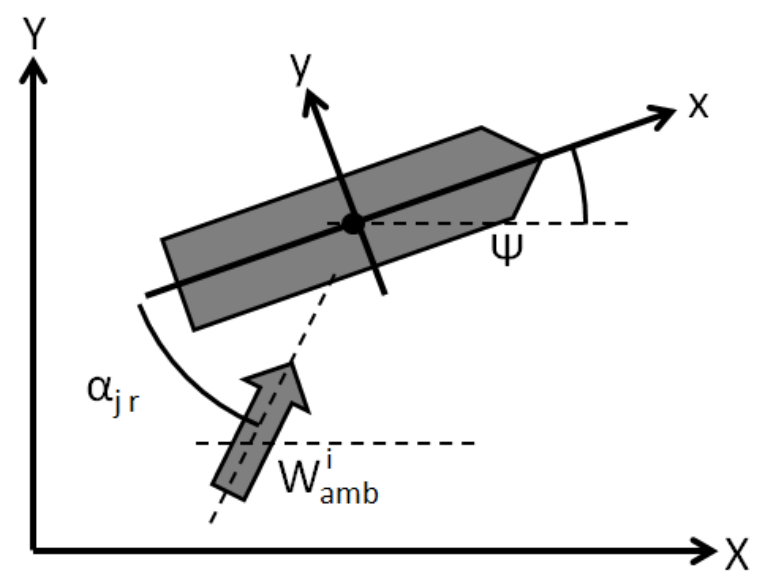

Figura 19 - Definição do ângulo de incidência

\subsubsection{Vento}

No fórum internacional OCIMF (1994) foi apresentada uma estimativa para cálculo de esforços de vento incidindo sobre tankers ${ }^{3}$, definido pelas equações (9) a (11). Esta formulação leva em conta os parâmetros geométricos do navio,

\footnotetext{
${ }^{3}$ Tanker é a denominação de uma embarcação que possui como objetivo o transporte de líquidos/gases.
} 
parâmetros físicos, parâmetros do vento incidente e coeficientes previamente calculados (experimentalmente ou numericamente). Ela pode ser aplicada de forma genérica para qualquer tipo de navio, e não apenas navios tankers, e é dada por.

$$
\begin{gathered}
F_{w x}=\frac{\rho_{a} \cdot V_{w}^{2} \cdot A_{F}}{2} \cdot C_{w x} \cdot\left(\alpha_{w r}\right) \\
F_{w y}=\frac{\rho_{a} \cdot V_{w}^{2} \cdot A_{L}}{2} \cdot C_{w y} \cdot\left(\alpha_{w r}\right) \\
M_{w \Psi}=\frac{\rho_{a} \cdot V_{w}^{2} \cdot L \cdot A_{L}}{2} \cdot C_{w \Psi} \cdot\left(\alpha_{w r}\right)
\end{gathered}
$$

Na qual:

- $F_{w x}, F_{w y}, M_{w \Psi}$ : Força na direção de surge e sway e momento de yaw devidos ao vento respectivamente

- $\rho_{a}$ : Densidade do ar

- $V_{w}$ : Velocidade relativa de vento

- $\quad L$ : Comprimento do navio

- $A_{F}, A_{L}$ : Área emersa projetada frontal e lateral do navio

- $C_{w i}$ : Coeficiente adimensional estático de vento no i-ésimo grau de liberdade (sendo $\mathrm{i}=\mathrm{x}$, y ou $\Psi$ )

- $\alpha_{w r}$ : Ângulo de incidência do vento, definido conforme mostrado na Figura 19

A Figura 20 apresenta as curvas dos coeficientes adimensionais $C_{w i}$ de um navio petroleiro típico em condição de lastro. É possível notar como estes parâmetros variam em função do ângulo relativo de incidência da condição ambiental incidente. 

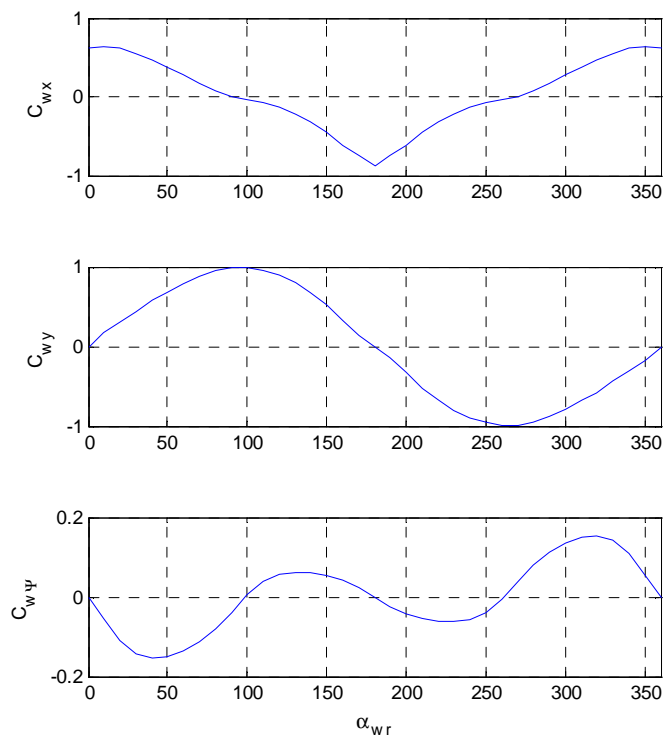

(a)
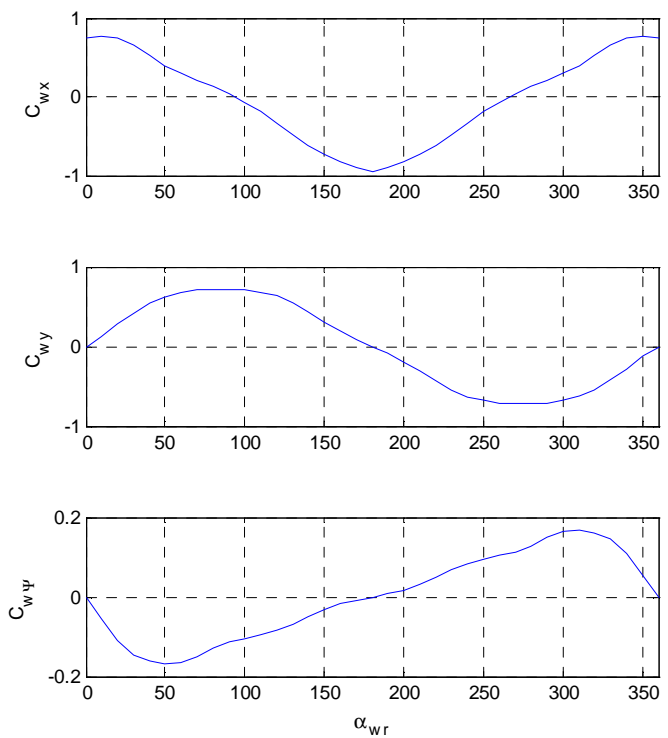

(b)
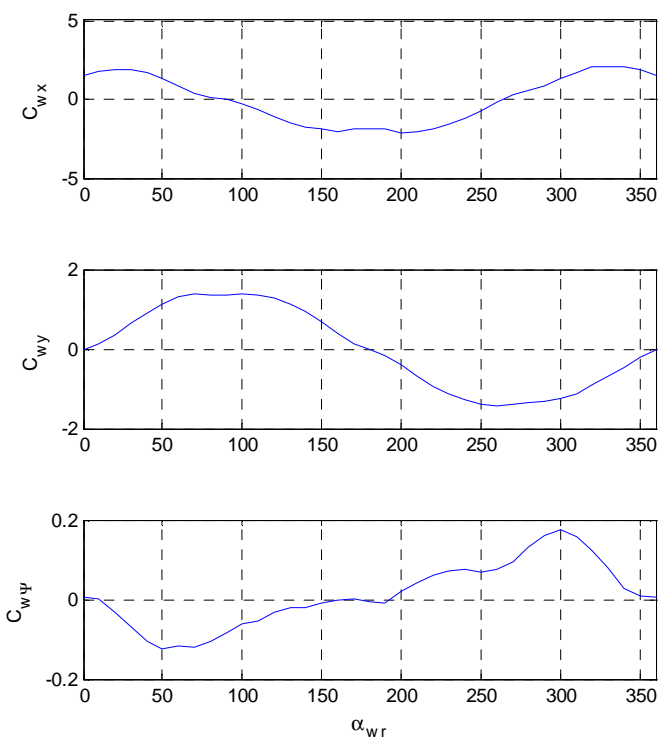

(c)

Figura 20 - Coeficientes adimensionais de vento dos navios (a) aliviador em condição de lastro, (b) aliviador cheio e (c) barcaça DP

\subsubsection{Correnteza}

No mesmo fórum em que foi apresentada a formulação para estimativa de calculo de esforços de vento (OCIMF (1994)), também foi apresentada uma estimativa similar para cálculo de esforços de correnteza incidindo sobre tankers. Para calcularem-se os esforços ambientais agindo sobre o navio, o modelo de carregamentos utilizado é o definido pelas equações (12) a (14). 
Esta formulação utiliza os mesmos parâmetros geométricos do navio e parâmetros físicos, além de parâmetros da correnteza incidente e coeficientes previamente calculados (experimentalmente ou numericamente):

$$
\begin{aligned}
F_{c x} & =\frac{\rho_{w} \cdot V_{c}^{2} \cdot L \cdot T}{2} \cdot C_{c x} \cdot\left(\alpha_{c r}\right) \\
F_{c y} & =\frac{\rho_{w} \cdot V_{c}^{2} \cdot L \cdot T}{2} \cdot C_{c y} \cdot\left(\alpha_{c r}\right) \\
M_{c \Psi} & =\frac{\rho_{w} \cdot V_{c}^{2} \cdot L^{2} \cdot T}{2} \cdot C_{c \psi} \cdot\left(\alpha_{c r}\right)
\end{aligned}
$$

Na qual:

- $F_{c x}, F_{c y}, M_{c \psi}$ : Força na direção de surge e sway e momento de yaw devidos à correnteza respectivamente

- $\rho_{w}$ : Densidade da água

- $V_{c}$ : Velocidade relativa de correnteza

- T: Calado do navio

- $C_{c i}$ : Coeficiente adimensional estático de correnteza no i-ésimo grau de liberdade

- $\alpha_{c r}$ : Ângulo de incidência da correnteza, definido conforme mostrado na Figura 19

A Figura 21 apresenta as curvas dos coeficientes adimensionais $C_{c i}$ de navio petroleiro típico em condição de lastro. É possível notar como estes parâmetros variam em função do ângulo relativo de incidência da condição ambiental incidente. 

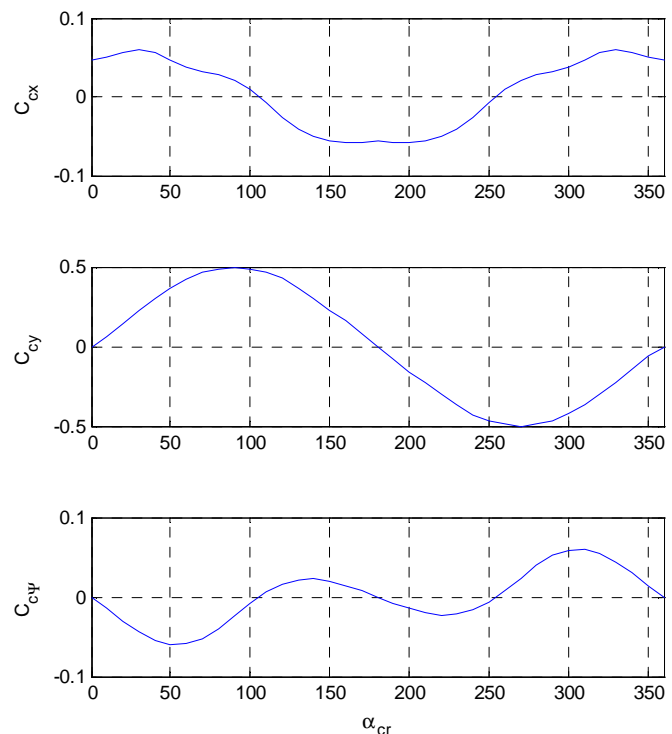

(a)
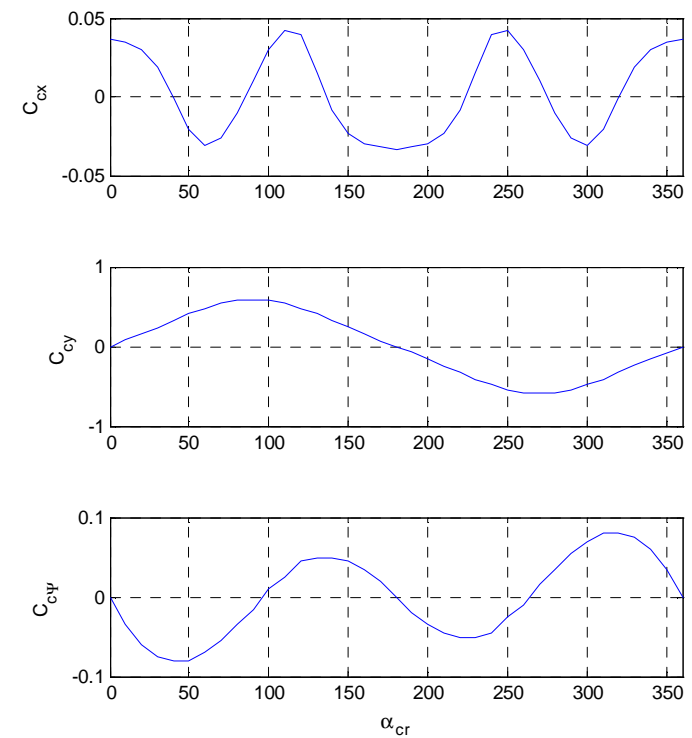

(b)
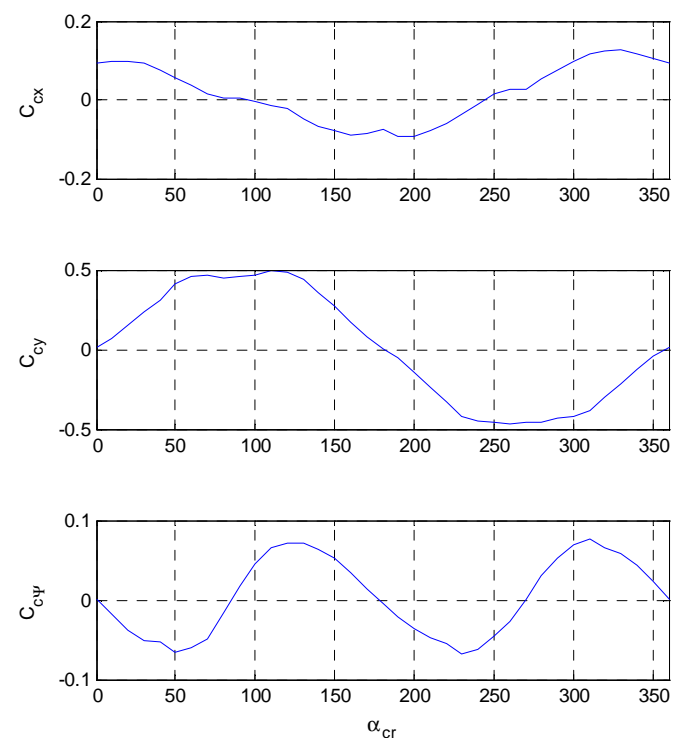

(c)

Figura 21 - Coeficientes adimensionais de correnteza dos navios (a) aliviador em condição de lastro, (b) aliviador cheio e (c) barcaça DP

Um ponto importante é que a correnteza é considerada constante ao longo do tempo (ou com variações lentas comparadas aos tempos típicos do navio). Ademais, velocidade de correnteza utilizada na formulação corresponde à velocidade média do perfil de correnteza ao longo do calado do navio. 


\subsubsection{Ondas}

A interação entre ondas e o casco de uma embarcação é complexa, com inúmeros fenômenos envolvidos. Nesta seção, será feita a descrição de ondas de gravidade em regime linear, que são responsáveis pela maior parcela de esforços em embarcações de grande porte em condições ambientais usuais nas quais a operação DP é possível.

Ondas podem ser classificadas como regulares (ondas que possuem energia em uma única frequência), ou irregulares (que possuem espectro de energia em diversas frequências).

Ondas regulares são mais simples de serem modeladas matematicamente, além de serem geradas em tanques físicos com maior facilidade. Por outro lado, as ondas que representam o comportamento do mar real são as irregulares.

A formulação mais utilizada para descrever mares irregulares em desenvolvimento é denominada JONSWAP (Joint North Sea Wave Project), sendo introduzida na conferência 17th International Towing Tank Conference (ITTC,1984), e é formulada da seguinte forma:

$$
\begin{gathered}
S(\omega)=\frac{\alpha_{0} g^{2}}{\omega^{5}} \cdot \exp \left[-\frac{5}{4}\left(\frac{\omega_{0}}{\omega}\right)^{4}\right] \gamma^{\exp \left[-\left(\omega-\omega_{0}\right)^{2} /\left(2 \sigma^{2} \omega_{0}^{2}\right)\right]} \\
\sigma=\left\{\begin{array}{l}
0,07 \text { se } \omega \leq \omega_{0} \\
0,09 \text { se } \omega>\omega_{0}
\end{array}\right. \\
\alpha_{0}=\frac{5}{16 g^{2}} H_{S}^{2} \omega_{0}^{4}[1-0.287 \cdot \ln (\gamma)]
\end{gathered}
$$

Sendo:

- $S$ : Espectro de energia $\left[\mathrm{m}^{2} \mathrm{rad} / \mathrm{s}\right]$

- $\omega_{0}$ : Frequência de pico de onda [rad/s]

- $\omega$ : Frequência de onda [rad/s]

- $g$ : Constante gravitacional $\left[\mathrm{m} / \mathrm{s}^{2}\right]$

- $\sigma$ : Fator de forma [ ]

- $\gamma$ : Peakedness factor, fator de forma que indica o quão concentrada está a energia de um dado espectro JONSWAP [ ] 
- $\alpha_{0}$ : Constante correlacionando velocidade do vento com comprimento de onda. [ ]

- $H_{s}$ : Altura significativa de onda ${ }^{4}[\mathrm{~m}]$

Para exemplificar o espectro de energia JONSWAP, a Figura 22 apresenta 0 espectro de energia em função da frequência para $\omega_{0}=55 \mathrm{rad} / \mathrm{s}, H_{s}=5,5 \mathrm{~m}, \gamma=2,5$.

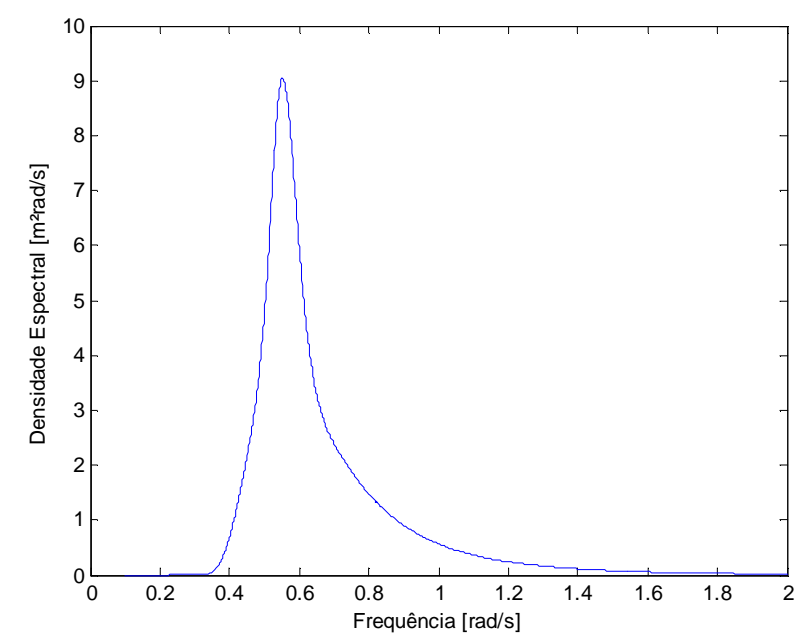

Figura 22 - Espectro de onda para $\omega_{0}=\mathrm{rad} / \mathrm{s}$ e $H_{s}=5,5 \mathrm{~m}$

Nesta dissertação será descrito o cálculo da força de deriva média, sendo esta a força utilizada para análise estática. Os demais esforços provenientes de ondas (forças de primeira ordem, forças de deriva lenta ou efeitos de ordens elevadas) são calculados no simulador utilizado conforme o modelo apresentado em Aranha; Fernandes (1995) e Aranha (1996).

\subsubsection{Forças de deriva média}

As forças de segunda ordem são forças proporcionais ao quadrado da altura da onda incidente. As componentes médias dos esforços de segunda ordem são conhecidos como "forças de deriva média", enquanto as demais componentes são conhecidas como "forças de deriva lenta".

A dedução do cálculo das forças de deriva média pode ser encontrada em Mei (1989) e é baseada na definição dos coeficientes de deriva, que representam a

\footnotetext{
${ }^{4}$ Representa o valor da altura média $1 / 3$ das ondas mais altas.
} 
força média atuante sobre o corpo para uma dada frequência de onda, normalizada pelo quadrado da amplitude da onda.

Os esforços de deriva média serão definidos pela seguinte fórmula:

$$
W_{j D M}\left(\omega, \alpha_{o r}\right)=2 \int_{0}^{\infty} S(\omega) D_{j}\left(\omega, \alpha_{o r}\right) d \omega, \quad \forall j=(x, y, \Psi)
$$

Sendo:

- $\alpha_{o r}=$ Ângulo relativo de incidência da onda incidente.

- $D_{j}=$ Coeficiente de deriva na direção j.

- $W_{j D M}\left(\omega, \alpha_{o r}\right)=$ Esforço de deriva média no j-ésimo grau de liberdade, para uma determinada frequência e ângulo relativo de incidência de onda.

\subsection{Controle de Posicionamento}

Neste trabalho são utilizados três controladores do tipo Proporcional-IntegralDerivativo (PID) desacoplados para controlar os movimentos no plano horizontal. Esta configuração é estável e pressupõe que o controlador esteja com os parâmetros que garantam desempenho adequado.

Vale ressaltar que qualquer controlador base poderia ser utilizado, desde um controlador linear com três graus de liberdade desacoplados, tal como aqui considerado, até um controlador não linear com termos acoplados entre os diferentes graus de liberdade, tal como proposto por Tannuri et al. (2010)

O controle PID é calculado baseado na diferença entre a posição desejada (set-point) e o ponto de controle, definidos pelas equações de (19) a (24)

$$
\begin{gathered}
\boldsymbol{E}=\boldsymbol{\eta}_{\boldsymbol{s p}}-\boldsymbol{\eta}_{\boldsymbol{r e f}} \\
\dot{\boldsymbol{E}}=-\dot{\boldsymbol{\eta}}_{\boldsymbol{r e f}} \\
\boldsymbol{K}_{\boldsymbol{P}}=\left[\begin{array}{ccc}
K_{p}^{1} & 0 & 0 \\
0 & K_{p}^{2} & 0 \\
0 & 0 & K_{p}^{6}
\end{array}\right]
\end{gathered}
$$




$$
\begin{gathered}
\boldsymbol{K}_{\boldsymbol{I}}=\left[\begin{array}{ccc}
K_{I}^{1} & 0 & 0 \\
0 & K_{I}^{2} & 0 \\
0 & 0 & K_{I}^{6}
\end{array}\right] \\
\boldsymbol{K}_{\boldsymbol{D}}=\left[\begin{array}{ccc}
K_{D}^{1} & 0 & 0 \\
0 & K_{D}^{2} & 0 \\
0 & 0 & K_{D}^{6}
\end{array}\right] \\
\boldsymbol{W}_{\boldsymbol{c t r l}}=\boldsymbol{K}_{\boldsymbol{P}} \cdot \boldsymbol{E}+\boldsymbol{K}_{\boldsymbol{I}} \cdot \int \boldsymbol{E}+\boldsymbol{K}_{\boldsymbol{D}} \cdot \dot{\boldsymbol{E}}
\end{gathered}
$$

As matrizes $K_{P}, K_{I}$ e $K_{D}$ são diagonais e contêm os ganhos dos termos proporcional, integral e derivativo de cada grau de liberdade respectivamente. É importante ressaltar que a força exercida pelo sistema de propulsão $\boldsymbol{W}_{\text {prop }}$ não necessariamente coincide com a força demandada pelo sistema de controle $\boldsymbol{W}_{\boldsymbol{c t r l}}$ devido às limitações físicas dos propulsores, como saturação, dinâmica, etc.

Nota-se que a derivada do set-point não foi considerada no cálculo do termo derivativo do controle. Esta medida serve para evitar derivadas de grande magnitude, que possivelmente desestabilizariam o sistema, no caso da aplicação de um degrau no set-point.

\subsection{Mensuração do consumo de potência}

Primeiramente, para se avaliar a eficiência de um controlador, é necessária uma medida de consumo de potência, para poder quantificar o desempenho obtido por cada diferente estratégia de controle.

Como medida de consumo será utilizada a grandeza $Q$, denominada "fator de desempenho". Segundo Tannuri (2002), o fator de desempenho serve como uma ferramenta para comparação entre diferentes configurações do Sistema DP, por ser proporcional à potência consumida pelo sistema de propulsão. Desta forma, é ideal para atestar a eficiência ou não de um controlador weathervane.

O fator de desempenho foi calculado como: 


$$
Q=\sum_{i=1}^{n_{\text {prop }}} T^{i^{3 / 2}}
$$

Sendo:

- $T_{i}$ : Força exercida pelo i-ésimo propulsor

- $n_{\text {prop }}$ : Número de propulsores ativos no navio

\subsection{Alocação de propulsão}

Após o Sistema DP calcular as forças e momento resultantes que devem agir sobre o navio pelo sistema de propulsão, é necessário encontrar a distribuição de forças e azimutes de cada propulsor. Esta tarefa é realizada pelo módulo de alocação de propulsão, efetuando a interface entre o Sistema DP e os propulsores.

Navios dotados de Sistemas DP são, em geral, sobre-atuados ${ }^{5}$. Desta forma, há diversas configurações diferentes de empuxos e azimutes que resultam nos mesmos esforços sobre o navio.

Dentre as diversas soluções, deseja-se encontrar a configuração que leva ao menor consumo de potência, e consequentemente, a situação com maior economia de combustível e emissão de poluentes mínima.

O método para otimização utilizado será dos mínimos quadrados (utilizandose a matriz pseudoinversa) e será feito em duas etapas devido à presença de propulsores azimutais, conforme apresentado a diante.

O seguinte sistema de coordenadas local $\left(o_{3}, x_{3}\right.$ e $\left.y_{3}\right)$ foi previamente definido e está exibido na Figura 23:

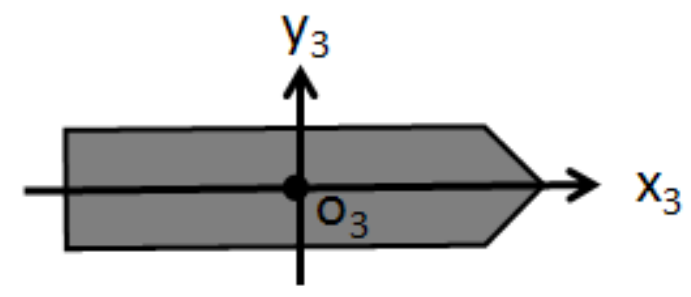

Figura 23 - Sistema de coordenadas local $\left(o_{3}, x_{3}\right.$ e $\left.y_{3}\right)$ previamente definido

\footnotetext{
${ }^{5} \mathrm{O}$ termo sobre-atuado se refere a um sistema de controle que possui mais atuadores do que graus de liberdade a serem controlados, de forma que há diversas soluções que resultam na mesma saída do sistema.
} 
O eixo coordenado $x_{3}$ está alinhado com a direção longitudinal do navio, o eixo coordenado $y_{3}$ com a direção transversal ao navio e a origem $o_{3}$ está localizada na meia-nau.

Primeiramente, as seguintes variáveis serão definidas:

- $x_{\text {prop }}^{i}$ : Coordenada do i-ésimo propulsor no eixo $o_{3} x_{3}$

- $y_{\text {prop }}^{i}$ : Coordenada do i-ésimo propulsor no eixo $o_{3} y_{3}$

- $\alpha_{\text {prop }}^{i}$ : Ângulo/Azimute do i-ésimo propulsor

- $T_{i}^{\max }$ : Empuxo máximo do i-ésimo propulsor

Para simplificar o problema de alocação de propulsão, o fator de desempenho $Q$ utilizado no algoritmo de otimização é proporcional ao quadrado do empuxo dos propulsores, e não à potência $3 / 2$. Desta forma, o funcional $Q$ pode ser minimizado através de otimização quadrática, obedecendo às condições de contorno. Os esforços demandados pelo sistema de controle $\left(W_{c t r l}\right)$ e exercidos pelo sistema de propulsão $\left(W_{c t r l}\right)$ devem obedecer:

$$
\boldsymbol{W}_{\text {ctrl }}=\boldsymbol{W}_{\text {prop }}
$$

O vetor $\boldsymbol{W}_{\text {prop }}$ é definido da seguinte forma:

$$
\boldsymbol{W}_{\text {prop }}=\left[\begin{array}{c}
\sum_{i=1}^{n_{\text {prop }}} T_{i} \cdot \cos \left(\alpha_{\text {prop }}^{i}\right) \\
\sum_{i=1}^{n_{\text {prop }}} T_{i} \cdot \sin \left(\alpha_{\text {prop }}^{i}\right) \\
\sum_{i=1}^{n_{\text {prop }}}-T_{i} \cdot \cos \left(\alpha_{\text {prop }}^{i}\right) \cdot y_{\text {prop }}^{i}+T_{i} \cdot \sin \left(\alpha_{\text {prop }}^{i}\right) \cdot x_{\text {prop }}^{i}
\end{array}\right]
$$

Para facilitar os cálculos, a notação matricial será adotada, com o seguinte equacionamento:

$$
\boldsymbol{A} \cdot \boldsymbol{T}=\boldsymbol{W}_{\text {prop }}
$$

$$
\text { Sendo } \begin{aligned}
\boldsymbol{T} & =\left[\begin{array}{lll}
T_{1} & \ldots & T_{n_{\text {prop }}}
\end{array}\right]^{T}, c_{i}=\cos \left(\alpha_{\text {prop }}^{i}\right), s_{i}=\operatorname{sen}\left(\alpha_{\text {prop }}^{i}\right) \mathrm{e}: \\
\boldsymbol{A} & =\left[\begin{array}{ccc}
c_{1} & c_{n_{\text {prop }}} \\
s_{1} & \ldots & s_{n_{\text {prop }}} \\
-c_{1} \cdot y_{\text {prop }}^{1}+s_{1} \cdot x_{\text {prop }}^{1} & -c_{n_{\text {prop }}} \cdot y_{\text {prop }}^{n_{\text {prop }}}+s_{n_{\text {prop }}} \cdot y_{\text {prop }}^{n_{\text {prop }}}
\end{array}\right]
\end{aligned}
$$


Finalmente, o problema de otimização se resume a:

$$
\min Q(\boldsymbol{T})
$$

Sujeito a:

$$
\begin{gathered}
\boldsymbol{A}(\boldsymbol{\alpha}) \cdot \boldsymbol{T}=\boldsymbol{W}_{c t r l} \\
T_{i} \leq T_{i}^{\max }
\end{gathered}
$$

Nota-se que na condição de contorno, representada pela equação (28), há dependência tanto do vetor de empuxos (vetor $\boldsymbol{T}$ ), quanto do ângulo de azimute dos propulsores (vetor $\boldsymbol{\alpha}$ ). A priori não se sabe qual o ângulo de azimute de cada propulsor azimutal, e estes também são variáveis a serem calculadas para otimização do problema.

A solução adotada consiste em dois passos: primeiro descobre-se o ângulo de azimute de cada propulsor, e posteriormente estes dados são tratados como valores fixos e resolve-se o problema considerando todos os propulsores como fixos. Esta abordagem faz com que o problema possua critério de optimalidade quadrático e restrições lineares de igualdade. Esta abordagem de solução foi proposta originalmente por Sørdalen (1997). 


\section{AVALIAÇÃO ESTÁTICA DE DESEMPENHO}

O objetivo deste capítulo é apresentar e discutir a definição do aproamento ótimo de uma embarcação, ou seja, aquela que minimiza seu consumo de potência. Cálculos foram efetuadas comparando os diversos controladores weathervane já estabelecidos, o controlador aqui proposto (denominado W-ZPC) e o aproamento ótimo teoricamente calculado. Este capítulo originou o trabalho Miyazaki et. al (2013)

\subsection{Definição da análise}

Esta análise considera que o sistema está em posição de equilíbrio, ou seja, que as forças do sistema de propulsão compensam o carregamento médio devido aos agentes ambientais, resultando em velocidade nula e aceleração nula, conforme mostra a equação a seguir:

$$
W_{c t r l}^{i}=-W_{a m b}^{i}, \quad i=(x, y, \Psi)
$$

Os esforços do sistema de propulsão foram calculados para todos os aproamentos no o intervalo $\left[0^{\circ}, 360^{\circ}[\right.$, com precisão de 1 grau (sendo interpolado para aproamentos intermediários).

\subsection{Definição de Aproamento Ótimo (Weather Optimum Heading)}

Fossen e Strand (2001) afirmam a existência de um aproamento ótimo em função do conjunto de condições ambientais agindo sobre o navio. Este aproamento, denominado WOH (Weather Optimum Heading), é o que leva a um consumo de potência mínimo e é identificado pelo seguinte conjunto de características:

- Força resultante lateral nula.

- Momento resultante em torno de Z nulo.

- Força longitudinal negativa, de grande amplitude.

Kaasen (2005) provou que para condições ambientais desalinhadas, é impossível encontrar o aproamento ótimo definido por Fossen e Strand. Desta 
forma, é necessário encontrar qual das metodologias desenvolvidas apresentam o consumo mínimo de energia. Independente da existência de WOH ou não, as diretrizes que definem este aproamento são as utilizadas pelos controladores weathervane para encontrar o aproamento ótimo.

\subsection{Tipos de controle de aproamento de ótimo consumo}

Neste item serão apresentados os modelos matemáticos de controladores existentes, focando na descrição do aproamento final resultante da utilização de cada um destes controladores. Todos os controladores que foram desenvolvidos até o presente momento podem se classificados em um dos seguintes grupos:

\subsubsection{Controle de momento nulo}

Controladores de momento nulo possuem um ponto de controle específico em torno do qual não há momento resultante dos propulsores. Este fato pode decorrer devido às restrições físicas do navio ou devido à lógica do controle.

Um exemplo de restrição física é o controlador de Pinkster e Nienhuis (1986), que conta com a presença de um único propulsor. Desta forma, o ponto do casco no qual o propulsor está instalado sempre possui momento zero devido ao sistema de propulsão.

O aproamento em sistemas de momento nulo está em equilíbrio ao atender a seguinte equação:

$$
W_{a m b}^{\Psi}(\Psi)-x_{r e f} W_{a m b}^{y}(\Psi)+y_{r e f} W_{a m b}^{x}(\Psi)=0
$$

O controlador de Pinkster e Nienhuis (1986), que historicamente é o primeiro controlador weathervane, utiliza um controlador de momento nulo, sendo nulo o momento em torno do ponto em que o propulsor é instalado em sua proa.

A mesma analogia é válida para o sistema apresentado em Kaasen (2005), acoplando um módulo DP em um navio convencional. Desta forma, o ponto médio definido pela localização dos propulsores do módulo DP é o ponto em que o momento é nulo. 
O último controlador de momento nulo que será estudado consiste no controle do momento da embarcação em relação à meia nau. Não há nenhum controlador weathervane divulgado que utilize o controle de momento nulo em relação à meia nau, porém, este controlador pode ser facilmente obtido ao se ajustar para zero todos os ganhos de controle de aproamento de um controlador convencional.

Nesta seção, serão analisados três controladores de momento nulo. Estes controladores serão denominados "meia nau", "proa" e "bombordo" deste ponto em diante, e são controladores de momento nulo em relação à meia nau, à proa ou a um ponto $15 \mathrm{~m}$ a bombordo do casco respectivamente.

\subsubsection{Controle de força lateral nula}

Fossen e Strand (2001) desenvolveram o controlador adaptativo backstepping denominado WOPC. Este controlador apenas aumenta o amortecimento lateral do navio. Desta forma, o controlador leva o navio ao aproamento em que a força lateral gerada pelos agentes ambientais é nula.

Kjerstad e Breivik (2010) inseriram modificações no controlador WOPC de Fossen e Strand, viabilizando a utilização do controlador em navios que não possuem atuação em sway (por exemplo, navios apenas com propulsor principal e leme).

Este trabalho apresenta um controlador do tipo weathervane que também é do tipo força lateral nula.

Todos os controladores de força lateral nula convergem para o aproamento em que:

$$
W_{a m b}^{y}(\Psi)=0
$$

Nesta seção será utilizados um controlador de força lateral nula, denominado "zero lateral" deste ponto em diante. 


\subsection{Dados da análise}

Nesta análise, as forças médias devido ao vento, correnteza e onda (tanto onda local quanto swell) são consideradas, conforme os modelos apresentados na seção 3.2 .

O algoritmo de alocação de propulsão utilizado é o método da pseudoinversa, conforme apresentado nos capítulos anteriores. A eficiência individual de cada propulsor não foi levada em conta, bem como foi desconsiderada saturação. Desta forma, os propulsores possuem sempre o mesmo peso no algoritmo de alocação de propulsão.

Dois navios distintos foram analisados. O primeiro é uma barcaça classe DP2, com seis propulsores e configuração peculiar do sistema de propulsão. $O$ segundo navio analisado é um aliviador DP-2. O navio aliviador será analisado em dois calados diferentes, lastro e totalmente carregado. Já a barcaça será considerada apenas em seu calado nominal.

A Tabela 1 apresenta as propriedades físicas principais dos navios considerados durante esta análise. Além disso, a Tabela 2 e a Tabela 3 apresentam as características do navio aliviador e da barcaça respectivamente.

Tabela 1 - Propriedades físicas das embarcações simuladas

\begin{tabular}{lccccc}
\hline Navio & $\begin{array}{c}\text { Comprimento } \\
(\mathbf{L})\end{array}$ & Boca (B) & Calado (T) & Massa (M) & $\begin{array}{c}\text { Momento de } \\
\text { inércia (Iz) }\end{array}$ \\
\hline Aliviador em lastro & $262 \mathrm{~m}$ & $46 \mathrm{~m}$ & $8 \mathrm{~m}$ & 77.000 ton & $3,6 \times 10^{8}$ ton $\mathrm{m}^{2}$ \\
Aliviador cheio & $262 \mathrm{~m}$ & $46 \mathrm{~m}$ & $15,9 \mathrm{~m}$ & 176.200 ton & $8,2 \times 10^{8}$ ton $\mathrm{m}^{2}$ \\
Barcaça & $121 \mathrm{~m}$ & $46 \mathrm{~m}$ & $5,2 \mathrm{~m}$ & 17.092 ton & $2,4 \times 10^{7}$ ton $\mathrm{m}^{2}$ \\
\hline
\end{tabular}

Tabela 2 - Sistema de propulsão da barcaça

\begin{tabular}{cccc}
\hline Propulsor & Posição X & Posição Y & Azimute \\
\hline Azim 1 & $64,6 \mathrm{~m}$ & $9,3 \mathrm{~m}$ & Livre \\
Azim 2 & $66,7 \mathrm{~m}$ & $-3,3 \mathrm{~m}$ & Livre \\
Azim 3 & $41,2 \mathrm{~m}$ & $-17,9 \mathrm{~m}$ & Livre \\
Azim 4 & $-46,3 \mathrm{~m}$ & $-17,9 \mathrm{~m}$ & Livre \\
Azim 5 & $-63,3 \mathrm{~m}$ & $-2,6 \mathrm{~m}$ & Livre \\
Azim 6 & $-66,4 \mathrm{~m}$ & $6,4 \mathrm{~m}$ & Livre \\
\hline
\end{tabular}

Tabela 3 - Sistema de propulsão do aliviador

\begin{tabular}{cccc}
\hline Propulsor & & & \\
& Posição X & Posição Y & Azimute \\
\hline Tun Proa & $128 \mathrm{~m}$ & $0 \mathrm{~m}$ & $90^{\circ}$ \\
Azim Proa & $122.2 \mathrm{~m}$ & $0 \mathrm{~m}$ & Livre \\
Azim Popa & $-91,4 \mathrm{~m}$ & $0 \mathrm{~m}$ & Livre \\
Tun Popa & $-111 \mathrm{~m}$ & $0 \mathrm{~m}$ & $90^{\circ}$ \\
Principal & $-124,6 \mathrm{~m}$ & $0 \mathrm{~m}$ & $0^{\circ}$ \\
\hline
\end{tabular}


Para calcular a eficiência de cada controlador, o fator de desempenho $Q$ será normalizado, sendo o valor unitário atribuído para o aproamento ótimo.

Os testes efetuados, representados pela Figura 24, são apresentados na Tabela 4, onde se apresenta a condição ambiental na qual a embarcação é simulada.

Tabela 4 - Conjunto de condições ambientais utilizadas para análise

\begin{tabular}{lcccc}
\hline Parâmetro & Análise 1 & Análise 2 & Análise 3 & Análise 4 \\
\hline Velocidade & & & & \\
Correnteza & $1 \mathrm{~m} / \mathrm{s}$ & $1 \mathrm{~m} / \mathrm{s}$ & $1,5 \mathrm{~m} / \mathrm{s}$ & $1 \mathrm{~m} / \mathrm{s}$ \\
Direção Correnteza & $\mathrm{S}$ (indo para) & $\mathrm{S}$ (indo para) & $\mathrm{S}$ (indo para) & $\mathrm{S}$ (indo para) \\
Velocidade Vento & $20 \mathrm{~m} / \mathrm{s}$ & $20 \mathrm{~m} / \mathrm{s}$ & $20 \mathrm{~m} / \mathrm{s}$ & $20 \mathrm{~m} / \mathrm{s}$ \\
Direção Vento & $\mathrm{N}($ vindo de) & $\mathrm{NE}($ vindo de) & $\mathrm{SE}$ (vindo de) & $\mathrm{NE}$ (vindo de) \\
Altura Onda & $3,5 \mathrm{~m}$ & $3,5 \mathrm{~m}$ & $3,5 \mathrm{~m}$ & $3,5 \mathrm{~m}$ \\
Período Onda & $8 \mathrm{~s}$ & $8 \mathrm{~s}$ & $8 \mathrm{~s}$ & $8 \mathrm{~s}$ \\
Direção Onda & $\mathrm{N}($ vindo de) & $\mathrm{NE}($ vindo de) & $\mathrm{SE}($ vindo de) & $\mathrm{NE}($ vindo de) \\
Altura Swell & - & - & - & $2 \mathrm{~m}$ \\
Período Swell & - & - & - & $12 \mathrm{~s}$ \\
Direção Swell & - & - & - & $\mathrm{SE}$ (vindo de) \\
\hline
\end{tabular}

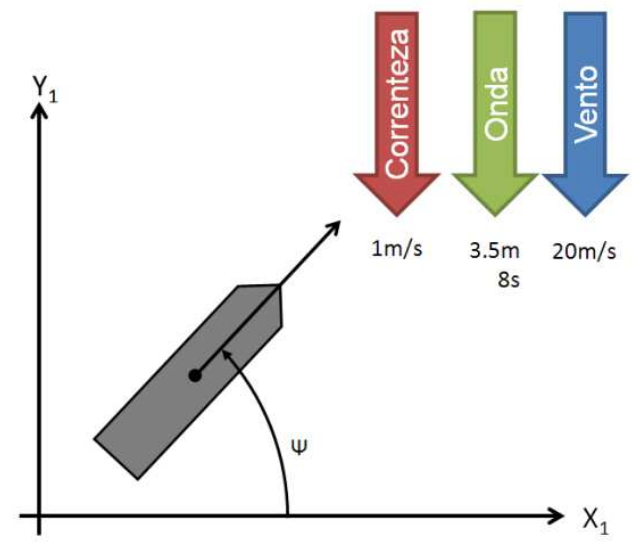

(a)

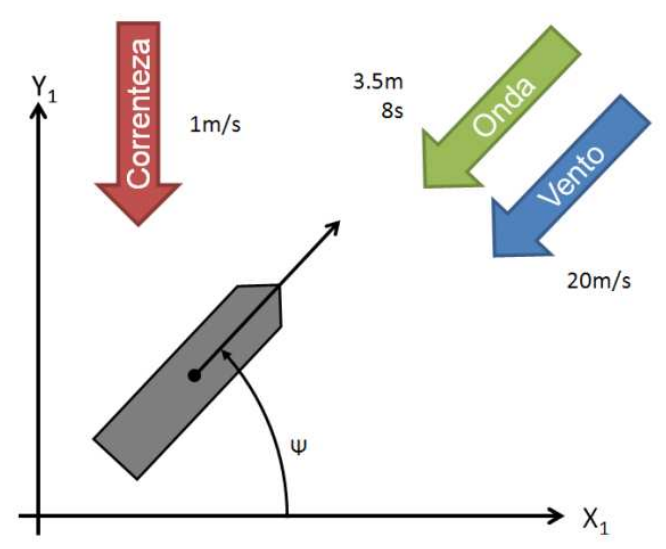

(b) 


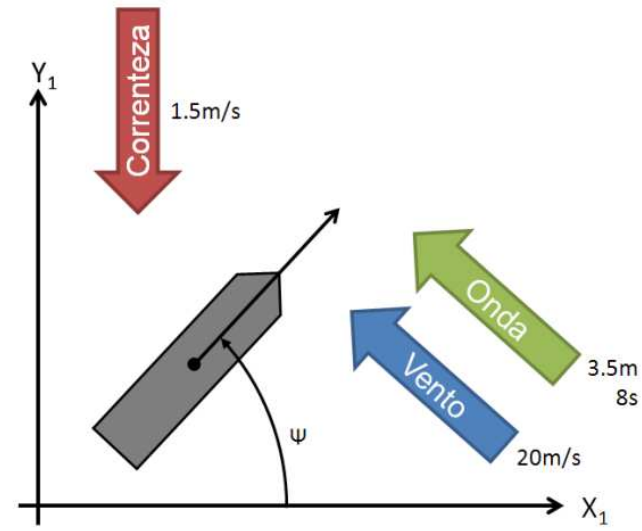

(c)

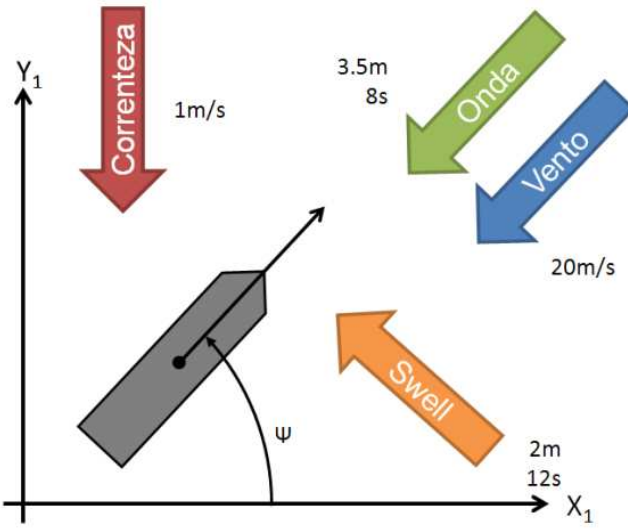

(d)

Figura 24 - Condições ambientais usadas nas análises 1 a 4 respectivamente

\subsection{Resultados}

Os resultados serão apresentados divididos por conjunto de condições ambientais.

\subsubsection{Análise 1}

Os resultados da primeira análise estão compilados na Tabela 5, considerando cada combinação navio - controlador.

Este caso em particular considera todas as condições ambientais incidentes alinhadas, e desta forma verifica-se que o aproamento ótimo é aquele em que o navio se aproa com os agentes ambientais. Este aproamento garante também força lateral e momentos (em relação à meia nau e à proa) nulos.

Tabela 5 - Resultados da análise da primeira combinação ambiental

\begin{tabular}{c|cc|cc|cc}
\hline Análise 1 & $\begin{array}{c}\text { Aproamento } \\
\text { Lastro }\end{array}$ & Q Lastro & $\begin{array}{c}\text { Aproamento } \\
\text { Carregado }\end{array}$ & $\begin{array}{c}\text { Q } \\
\text { Carregado }\end{array}$ & $\begin{array}{c}\text { Aproamento } \\
\text { Barcaça }\end{array}$ & Q Barcaça \\
\hline Zero Lateral & $90,0^{\circ}$ & 1,00 & $90,0^{\circ}$ & 1,00 & $90,0^{\circ}$ & 1,00 \\
Meia Nau & $90,0^{\circ}$ & 1,00 & $90,0^{\circ}$ & 1,00 & $92,8^{\circ}$ & 1,01 \\
Proa & $90,0^{\circ}$ & 1,00 & $90,0^{\circ}$ & 1,00 & 89,1 o & 1,00 \\
Bombordo & $78,9 \circ$ & 1,37 & $79,2^{\circ}-$ & 1,40 & $76,9 \circ$ & 1,15 \\
Mínimo & $90,0^{\circ}$ & 1,00 & $90,0^{\circ}$ & 1,00 & $90,0^{\circ}$ & 1,00 \\
\hline
\end{tabular}


Nota-se que todos os controladores levaram ao mesmo aproamento, e portanto, com o mesmo consumo de energia. A exceção é o controlador de bombordo, que teve um consumo de potência de $15 \%$ a $40 \%$ maior.

As figuras desta seção apresentam as forças (apresentadas de forma vetorial) atuando sobre o navio, sendo a força devido aos agentes ambientais representada pela seta azul-marinho enquanto as demais setas representam a força individual de cada propulsor. A posição da meia nau é representada pelo ponto preto central.

A Figura 25 apresenta a distribuição de empuxo pelos propulsores do navio aliviador em condição de lastro. É possível notar que os propulsores do tipo túnel não geram empuxo algum, devido à existência da condição de WOH.

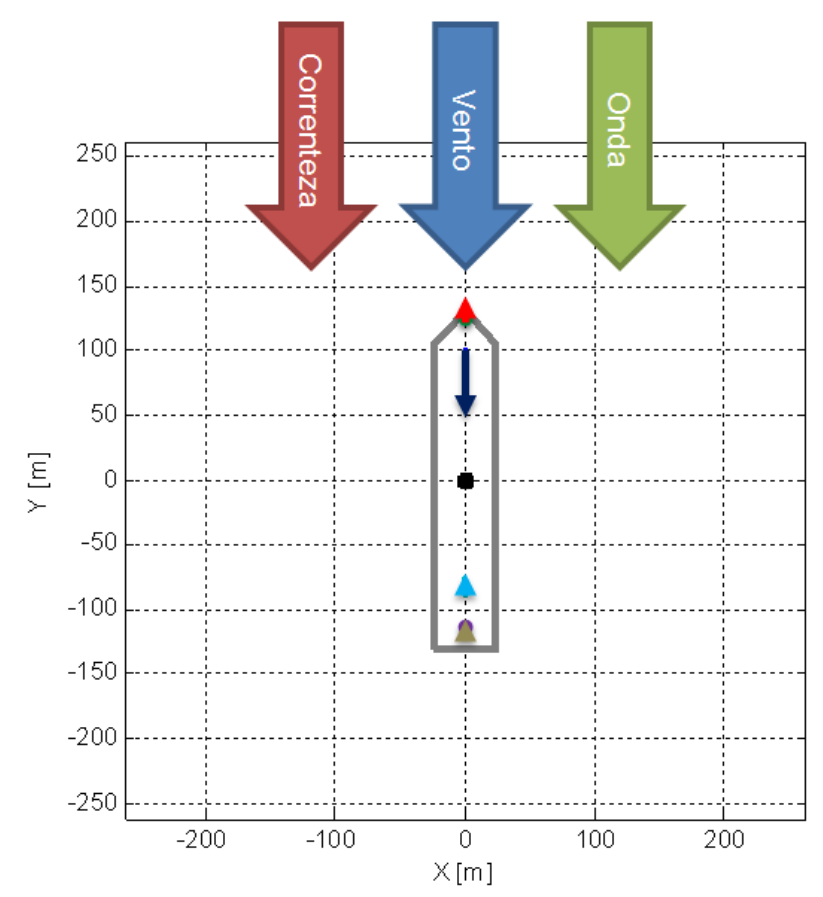

Figura 25- Aproamento ótimo do navio aliviador em condição de lastro sob a influência da combinação ambiental \#1

O gráfico de forças para a barcaça com o controle de bombordo está apresentado na Figura 26. Fica claro através desta figura que o aproamento resultante faz com que o ponto de controle (representado pelo círculo vermelho) se alinhe com a força ambiental resultante (representada pela seta azul central). 


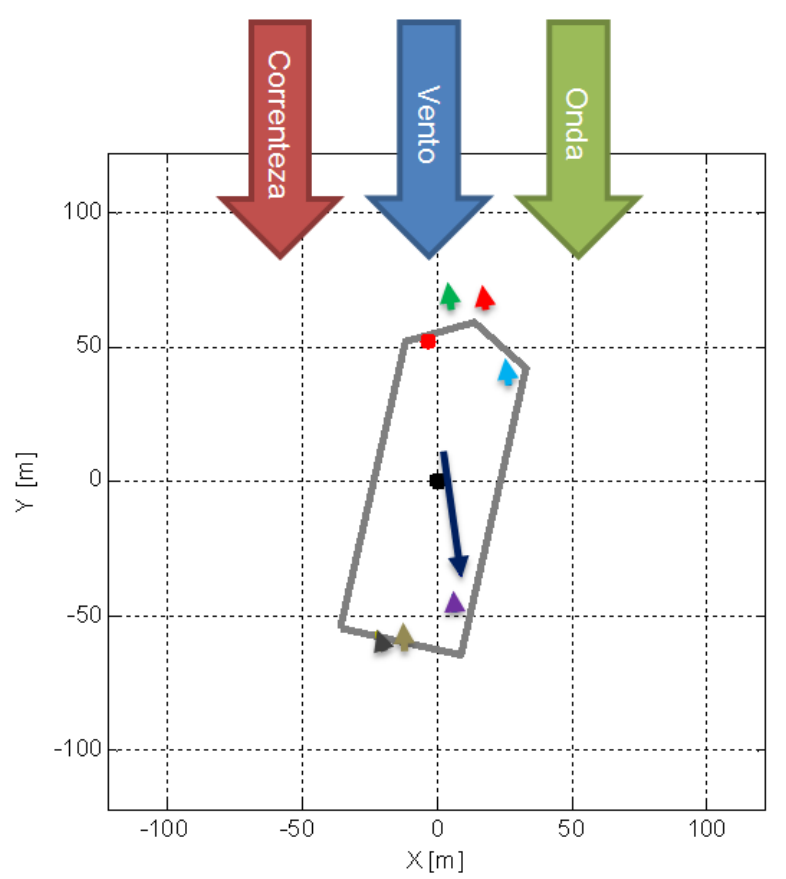

Figura 26 - Aproamento de equilíbrio da barcaça utilizando o controle de bombordo.

\subsubsection{Análise 2}

A Tabela 6 apresenta a compilação da combinação ambiental \#2, típica da Bacia de Campos.

Tabela 6 - Resultados da análise da segunda combinação ambiental

\begin{tabular}{c|cc|cc|cc}
\hline Análise 2 & $\begin{array}{c}\text { Aproamento } \\
\text { Lastro }\end{array}$ & Q Lastro & $\begin{array}{c}\text { Aproamento } \\
\text { Carregado }\end{array}$ & $\begin{array}{c}\text { Q } \\
\text { Carregado }\end{array}$ & $\begin{array}{c}\text { Aproamento } \\
\text { Barcaça }\end{array}$ & Q Barcaça \\
\hline Zero Lateral & $52,5^{\circ}$ & 1,00 & $62,4^{\circ}$ & 1,00 & $52,2^{\circ}$ & 1,00 \\
Meia Nau & $48,8^{\circ}$ & 1,11 & $96,5^{\circ}$ & 6,17 & $64,7^{\circ}$ & 1,28 \\
Proa & $53,9^{\circ}$ & 1,00 & $57,8^{\circ}$ & 1,07 & $50,8^{\circ}$ & 1,00 \\
Bombordo & $47,1^{\circ}$ & 1,19 & $48,3^{\circ}$ & 1,63 & $37,5^{\circ}$ & 1,10 \\
Mínimo & $53,0^{\circ}$ & 1,00 & $62,0^{\circ}$ & 1,00 & $51,0^{\circ}$ & 1,00 \\
\hline
\end{tabular}

Nota-se que o controle de força lateral nula leva o navio, em todos estes casos, a aproamento muito próximo do menor consumo de energia. O mesmo é verificado para o controle de momento nulo em relação à proa.

O controle da de momento nulo em relação à meia nau leva a um resultado interessante. Enquanto o navio está em condição de lastro, o controlador possui desempenho satisfatório, com o navio alinhado com os agentes ambientais, como pode ser visto na Figura 27. Conforme o processo de carregamento é finalizado, o controle de momento nulo leva a um aproamento com incidência de agentes 
ambientais de través, aumentando significativamente a utilização do Sistema DP, conforme mostra a Figura 28.

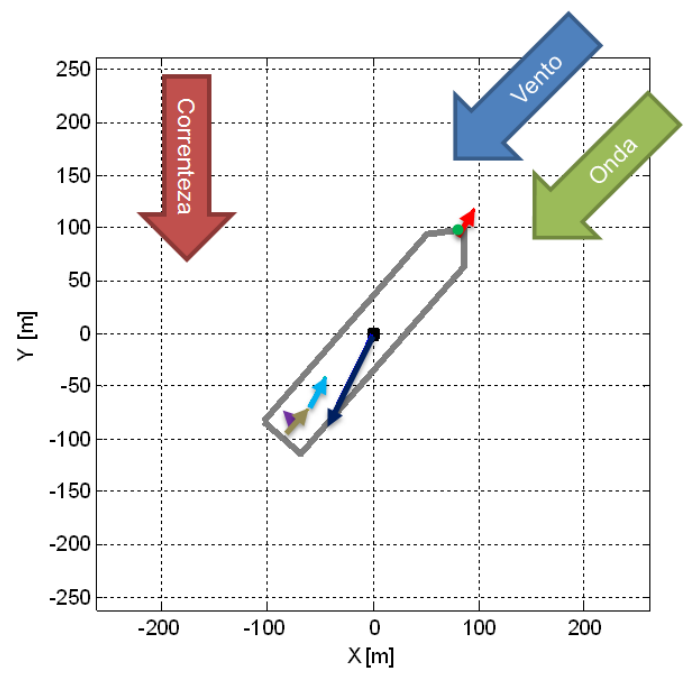

Figura 27 - Aproamento do navio aliviador em condição de lastro seguindo lógica de controle de momento nulo em relação à meia nau

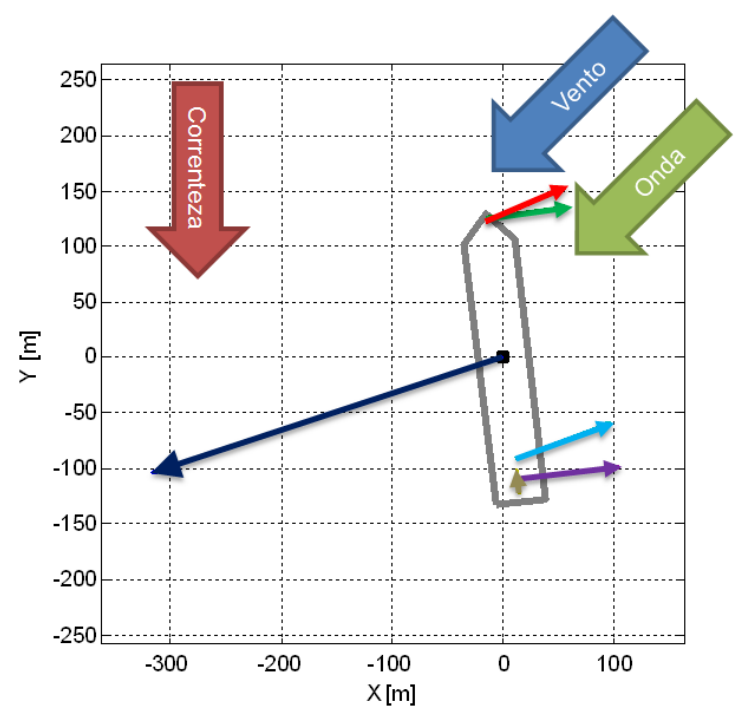

Figura 28 - Aproamento do navio aliviador carregado seguindo lógica de controle de momento nulo em relação à meia nau

Outro fato importante de se ressaltar é a diferença de aproamento entre o controle de força lateral e o controle de proa. Mesmo com diferença de até 5ำ entre ambos, o consumo de potência varia apenas 7\% em relação ao aproamento ótimo.

A Figura 29 apresenta o fator de desempenho do sistema em função do aproamento, para cada navio analisado. Nota-se que o mínimo valor de $Q$ se dá no

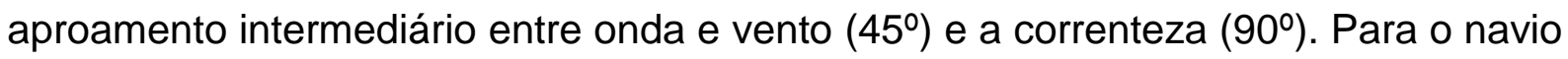


aliviador, há como esperado maior tendência ao alinhamento à correnteza para a condição totalmente carregada.
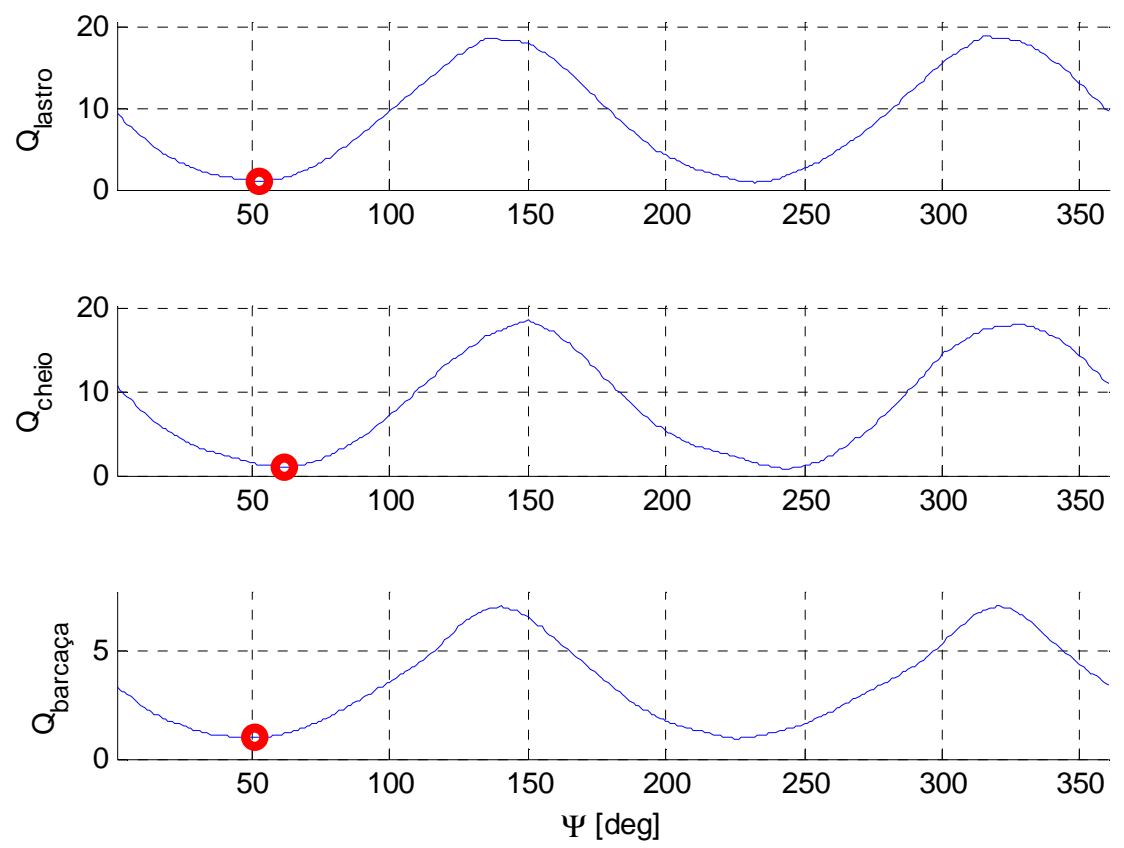

Figura 29 - Variação de Q em função do aproamento para a segunda análise

\subsubsection{Análise 3}

A Tabela 7 apresenta a compilação da combinação ambiental \#3, também típica da Bacia de Campos.

Tabela 7- Resultados da análise da terceira combinação ambiental

\begin{tabular}{c|cc|cc|cc}
\hline Análise 3 & $\begin{array}{c}\text { Aproamento } \\
\text { Lastro }\end{array}$ & Q Lastro & $\begin{array}{c}\text { Aproamento } \\
\text { Carregado }\end{array}$ & $\begin{array}{c}\text { Q } \\
\text { Carregado }\end{array}$ & $\begin{array}{c}\text { Aproamento } \\
\text { Barcaça }\end{array}$ & Q Barcaça \\
\hline Zero Lateral & $-18,3^{\circ}$ & 1,14 & $50,9^{\circ}$ & 1,11 & $-25,2^{\circ}$ & 1,00 \\
Meia Nau & $125,7^{\circ}$ & 2,30 & $104,9^{\circ}$ & 2,11 & $112,3^{\circ}$ & 1,84 \\
Proa & $-3,9^{\circ}$ & 1,03 & $37,3^{\circ}$ & 1,15 & $-19,0^{\circ}$ & 1,05 \\
Bombordo & $7,1^{\circ}$ & 1,30 & $27,9^{\circ}$ & 1,75 & $-22,1^{\circ}$ & 1,01 \\
Mínimo & $-8,0^{\circ}$ & 1,00 & $45,0^{\circ}$ & 1,00 & $-27,0^{\circ}$ & 1,00 \\
\hline
\end{tabular}

Este caso apresenta a única condição em que o controlador de força lateral não foi o controlador que mais se aproximou do aproamento ótimo, para o aliviador em condição de lastro. Conforme o processo de alívio de petróleo decorre, o controle de força lateral nula torna-se novamente o controlador que melhor estima $o$ aproamento ótimo. 
Devido ao grande desalinhamento entre os agentes ambientais incidentes, o controle de bombordo apresenta grande consumo de potência se comparado com o aproamento ótimo. Para o caso do controle do navio aliviador carregado, o consumo chega a $75 \%$ mais energia que o aproamento ótimo.

A configuração de equilíbrio do controle de bombordo é apresentado na Figura 30, em comparação à de aproamento ótimo, apresentada na Figura 31. Destaca-se que o aproamento ótimo em termos de energia leva à incidência de ondas a $90^{\circ}$, que pode ocasionar movimentos de rolagem excessivos. Entretanto, este aspecto não é avaliado na presente análise.

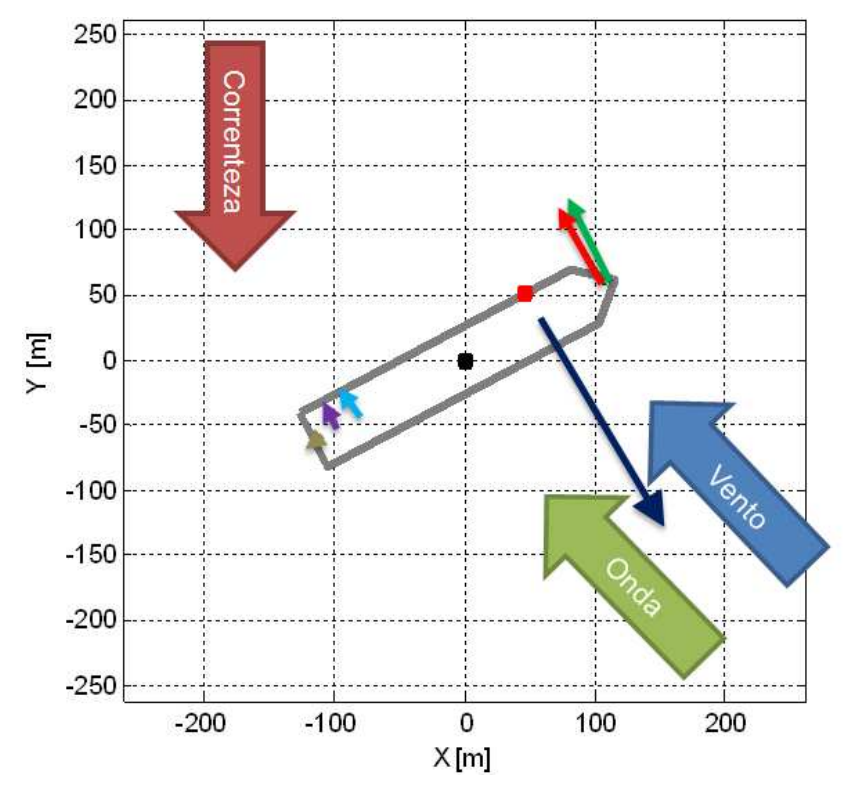

Figura 30 - Aproamento do navio aliviador carregado seguindo lógica de controle de bombordo 


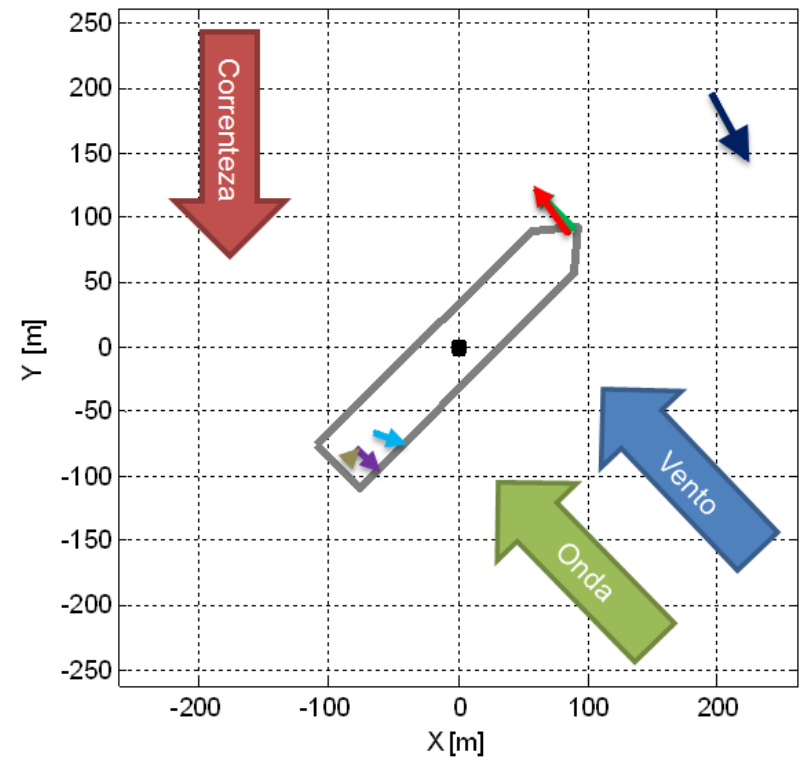

Figura 31 - Aproamento ótimo do navio aliviador carregado

Figura 32 de desempenho do sistema em função do aproamento, para cada navio analisado. Novamente, para o navio aliviador, verifica-se maior tendência ä se alinhar com a correnteza para a condição totalmente carregada.
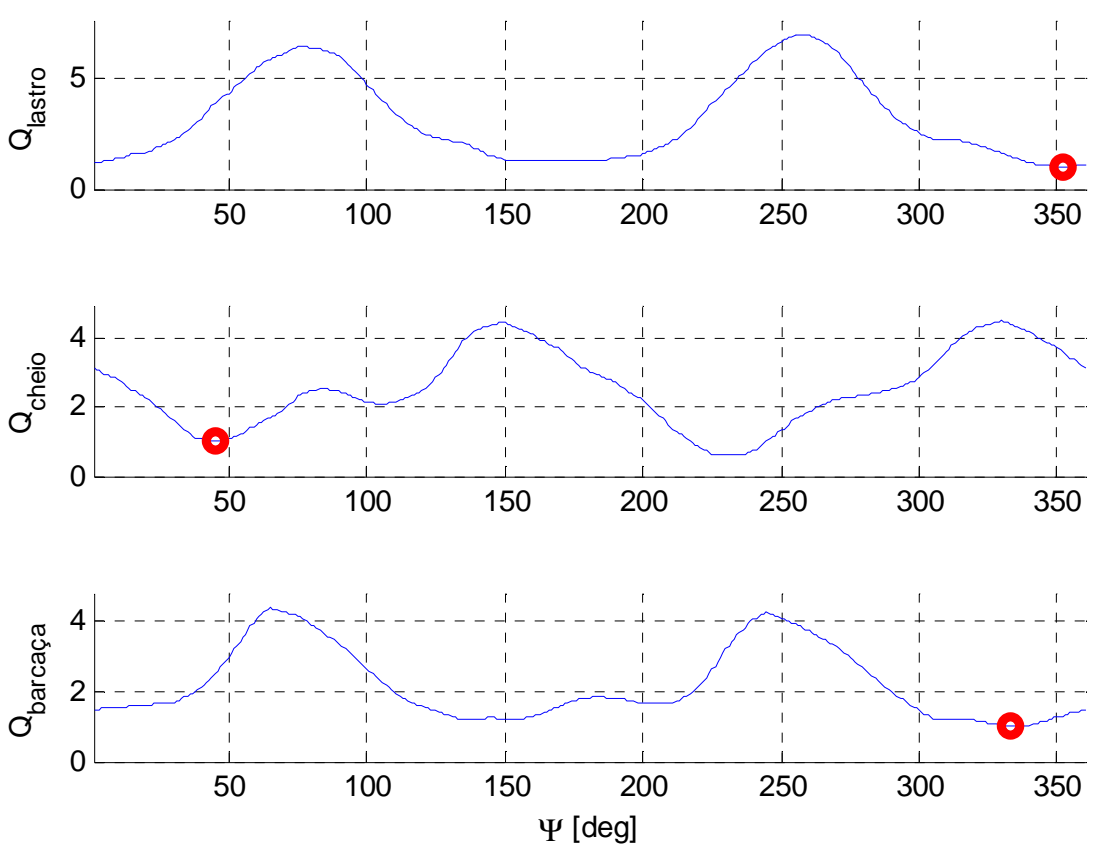

Figura 32 - Variação de Q em função do aproamento para a terceira análise 


\subsubsection{Análise 4}

Os resultados da última análise apresentada estão compilados na Tabela 8. Esta combinação de agentes ambientais também representa uma condição tipicamente encontrada na região offshore brasileira, incluindo a presença de mar bimodal com incidência de swell.

Tabela 8- Resultados da análise da quarta combinação ambiental

\begin{tabular}{c|cc|cc|cc}
\hline Análise 4 & $\begin{array}{c}\text { Aproamento } \\
\text { Lastro }\end{array}$ & Q Lastro & $\begin{array}{c}\text { Aproamento } \\
\text { Carregado }\end{array}$ & $\begin{array}{c}\text { Q } \\
\text { Carregado }\end{array}$ & $\begin{array}{c}\text { Aproamento } \\
\text { Barcaça }\end{array}$ & Q Barcaça \\
\hline Zero Lateral & $49,3^{\circ}$ & 1,00 & $57,1^{\circ}$ & 1,00 & $49,6^{\circ}$ & 1,00 \\
Meia Nau & $47,8^{\circ}$ & 1,04 & $100,7^{\circ}$ & 7,69 & $70,2^{\circ}$ & 1,56 \\
Proa & $49,7^{\circ}$ & 1,00 & $51,4^{\circ}$ & 1,07 & $47,7^{\circ}$ & 1,00 \\
Bombordo & $42,1^{\circ}$ & 1,25 & $42,8^{\circ}$ & 1,57 & $34,9^{\circ}$ & 1,10 \\
Mínimo & $50,0^{\circ}$ & 1,00 & $56,0^{\circ}$ & 1,00 & $48,0^{\circ}$ & 1,00 \\
\hline
\end{tabular}

Os resultados aqui apresentados se assemelham aos resultados obtidos na segunda análise, já que o swell, por apresentar menor amplitude $(2 \mathrm{~m})$ e maior período (12s), representa apenas uma pequena parcela das forcas médias sobre o navio.

O desempenho dos controladores de proa e de força lateral foi mantido, enquanto o controle de bombordo teve leve perda de desempenho, alcançando $57 \%$ mais consumo se comparado com o aproamento ótimo.

A Figura 33 apresenta o fator de desempenho $Q$ em função do aproamento dos navios. O gráfico aqui apresentado é muito semelhante ao da análise \#2 (Figura 29), porém com um leve deslocamento lateral. 

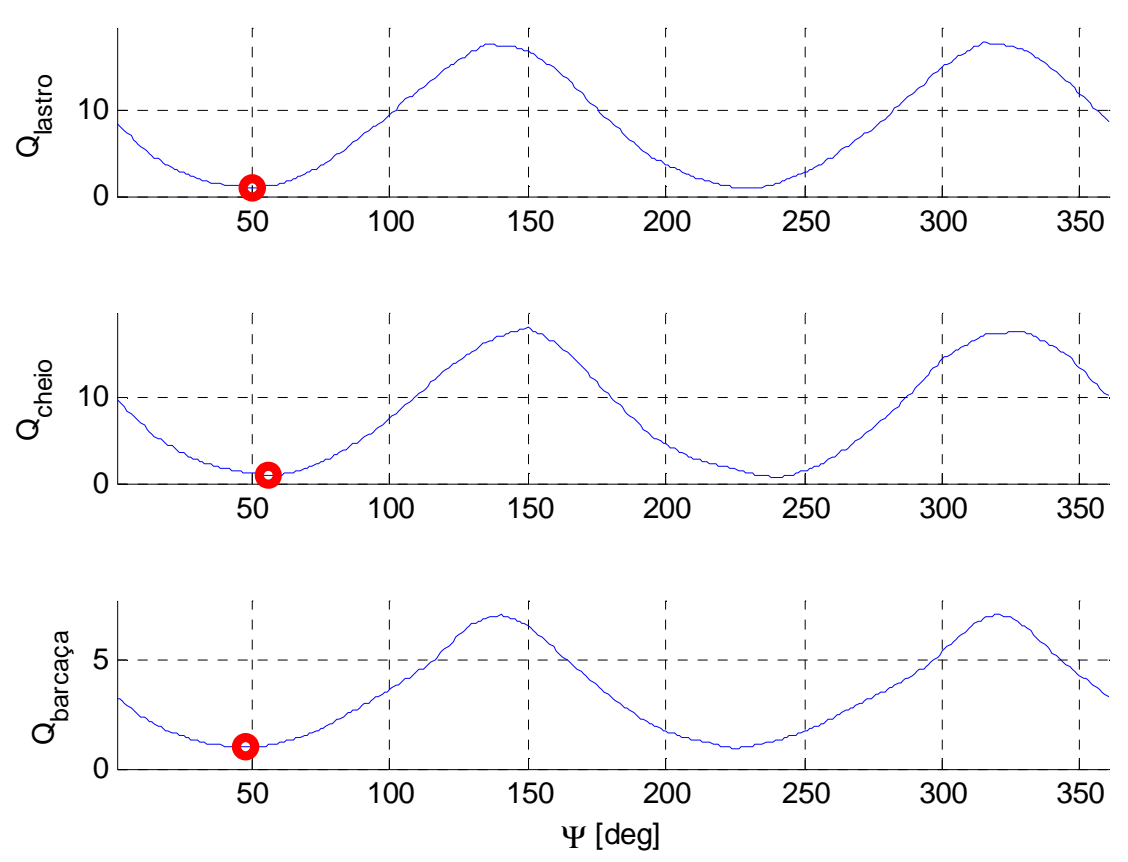

Figura 33 - Variação de $Q$ em função do aproamento para a quarta análise

\subsection{Conclusões Parciais}

Nesta seção foram analisados quatro controladores diferentes, atuando em três navios.

O primeiro resultado que se pode ressaltar é o fato de que para agentes ambientais desalinhados, nem sempre é possível encontrar o aproamento $\mathrm{WOH}$, definido por Fossen e Strand (2001). O conjunto de condições que garantem a existência do WOH são:

- $\Psi=\Psi_{a m b}+\pi$

- condições ambientais alinhadas

- navio possua simetria em torno do plano XZ

Com a possibilidade do aproamento $\mathrm{WOH}$ nem sempre ser verdadeiro, então se analisam os diferentes controladores existentes, para inferir qual o que apresenta o melhor desempenho.

O controle de força lateral apresentou maior proximidade com o aproamento ótimo. O pior caso apresentou consumo apenas $14 \%$ superior comparado com 0 aproamento ótimo, e apenas na análise \#3, onde grande desalinhamento ambiental está presente. 
Este resultado corrobora a escolha do controle de força lateral nula através da realimentação da mesma e da aplicação da técnica ZPC proposta no presente trabalho. 


\section{CONTROLE PROPOSTO}

Nesta seção será apresentada a formulação do controlador weathervane proposto, seguindo a metodologia de força lateral nula, conforme demonstrado na seção anterior. Também será feita uma análise de estabilidade do controlador resultante.

\subsection{Formulação}

Aplicando a metodologia ZPC a sistemas marítimos, a integral da força de controle aplicada sobre o movimento lateral do navio foi utilizada para adaptar o setpoint do aproamento. A integral da realimentação é mostrada naFigura 34 , ressaltada pela cor vermelha.

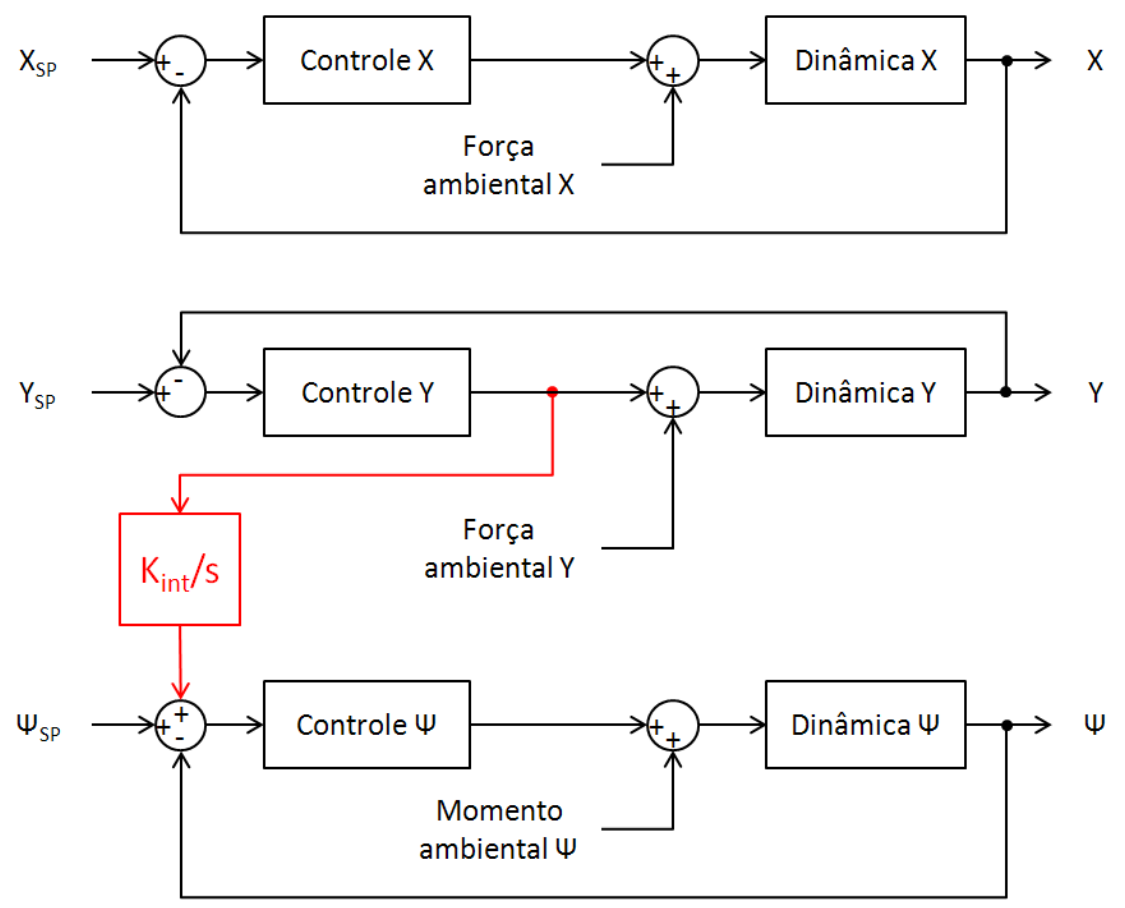

Figura 34 - Estrutura modificada do controlador para aplicação de técnicas de ZPC

Para simplificar a representação do controlador, consideraram-se as dinâmicas e controladores desacoplados para cada grau de liberdade.

Vale notar que caso o ganho de adaptação $K_{\text {int }}$ for nulo, o sistema é equivalente ao controlador original, antes da inserção do termo weathervane. Esta 
estratégia pode ser utilizada para desligar o termo adaptativo e manter o set-point do aproamento como o último valor válido.

Durante os testes efetuados, notou-se que uma lei de adaptação simples foi suficiente para que o sistema convergisse para o aproamento desejado. A equação (36) apresenta a lei de adaptação baseada na integral de realimentação de sistemas ZPC:

$$
\dot{\Psi}_{S P}=K_{i n t} \cdot W_{c t r l}^{y}
$$

O sistema foi capaz de chegar ao aproamento desejado, graças à existência de apenas dois zeros na força lateral. Tal comportamento está exemplificado na Figura 20 e na Figura 21, para o navio petroleiro.

A Figura 35 apresenta graficamente o sinal das forças laterais incidentes sobre o navio, em função do ângulo relativo de incidência ambiental. Esta lei de controle faz com que o set-point seja rotacionado no sentido horário em regiões escuras (forças laterais positivas) e em sentido anti-horário em regiões claras (forças laterais negativas). Desta forma, o controlador sempre tende a levar o navio para condição de incidência frontal (condição ótima).

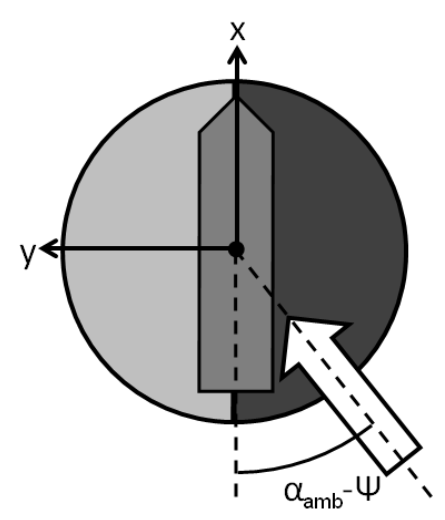

Figura 35 - Representação gráfica do sinal das forças laterais do navio

Em contrapartida, o momento de yaw em torno da meia nau apresenta o comportamento que pode ser visualizado na Figura 36. Verifica-se que as condições estáveis correspondem à incidência frontal das condições ambientais, ou à incidência pela popa. Este fato reforça a escolha do controlador utilizar forças laterais ao invés de momentos em yaw como variável controlada. 


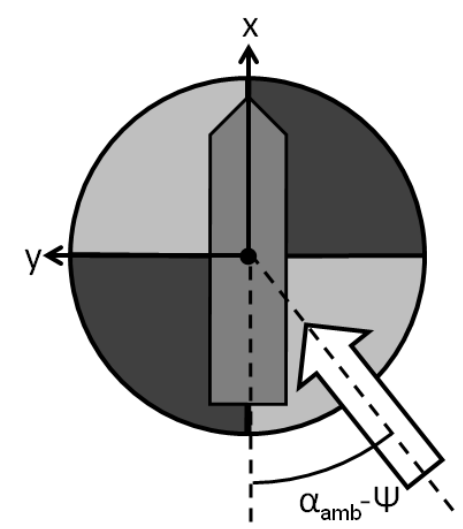

Figura 36 - Representação gráfica do sinal do momento de yaw em relação à meia nau

\subsection{Análise de estabilidade}

Para provar a estabilidade do sistema resultante após a inclusão do termo weathervane, será estudado o caso de um controlador PD atuando sobre o aproamento do navio. Além da dinâmica do aproamento do navio, será analisado o comportamento dos movimentos laterais e a influência devido à inserção do termo adaptativo.

A dinâmica do navio, considerando dois graus de liberdade (sway e yaw) pode ser descrita através da união das equações (7) e (8), da seguinte forma:

$$
M \ddot{x}=W_{a m b}+W_{\text {prop }}
$$

Sendo o vetor $\boldsymbol{x}$ redefinido como:

$$
\boldsymbol{x}=\left[\begin{array}{ll}
y & \Psi
\end{array}\right]^{T}
$$

e a matriz de massa para esse sistema sendo:

$$
\boldsymbol{M}=\left[\begin{array}{cc}
M+M_{22} & M x_{G}+M_{26} \\
M x_{G}+M_{26} & I_{z}+M_{66}
\end{array}\right]
$$

Considera-se que $\boldsymbol{W}_{\text {prop }}=\boldsymbol{W}_{\text {ctrl }}$ e que para esta análise o Sistema DP é definido pela seguinte equação, de um controlador PD:

$$
W_{c t r l}=K_{P}\left(x_{S P}-x\right)+K_{D}(-\dot{x})
$$

O set-point é definido pela variável $\boldsymbol{x}_{S P}=\left[\begin{array}{ll}y_{S P} & \Psi_{S P}\end{array}\right]^{T}$. Os ganhos do controle PD são dados pelas seguintes matrizes: 


$$
\begin{aligned}
\boldsymbol{K}_{\boldsymbol{P}} & =\left[\begin{array}{cc}
K_{P}^{y} & 0 \\
0 & K_{P}^{\psi}
\end{array}\right] \\
\boldsymbol{K}_{\boldsymbol{D}} & =\left[\begin{array}{cc}
K_{D}^{y} & 0 \\
0 & K_{D}^{\psi}
\end{array}\right]
\end{aligned}
$$

Os esforços ambientais serão linearizados em torno do ângulo no qual a força lateral devido aos agentes ambientais é nula, seguindo a seguinte formulação:

$$
W_{a m b}=K_{a m b}\left(x-x_{a m b}\right)^{T}+W_{r e s}
$$

Dado que $\quad \boldsymbol{x}_{\boldsymbol{a m b}}=\left[\begin{array}{ll}0 & \Psi_{a m b}\end{array}\right]^{T} \quad$ e $\quad \boldsymbol{K}_{\boldsymbol{a m b}}=\left[\begin{array}{cc}0 & K_{a m b}^{y} \\ 0 & K_{a m b}^{\Psi}\end{array}\right] \quad$ correspondem respectivamente ao ângulo de linearização e a derivada ao redor deste ângulo $\left(\Psi_{\text {amb }}\right)$ O termo constante $\boldsymbol{W}_{\text {res }}=\left[\begin{array}{ll}0 & W_{\text {res }}^{\psi}\end{array}\right]^{T}$ é incluído devido à possibilidade do ângulo ao redor do qual a força lateral é nula diferir do ângulo no qual o momento gerado é nulo. Esta possibilidade foi comprovada no capítulo 4.

A dinâmica do sistema apresentado na equação (37) é então descrita por:

$$
M \ddot{x}=K_{a m b}\left(x-x_{a m b}\right)^{T}+W_{r e s}+K_{P}\left(x_{S P}-x\right)+K_{D}(-\dot{x})
$$

O set-point do movimento lateral $\left(y_{S P}\right)$ é considerado constante e igual a zero. Por outro lado, o set-point do aproamento $\left(\Psi_{S P}\right)$ é desconhecido a priori, porém, devido à inclusão da lei de adaptação apresentada em (36), independente de seu valor inicial, esta variável converge para o valor desejado. Desta forma, o valor inicial do set-point do aproamento será considerado como nulo.

Será definido o vetor de estados:

$$
\boldsymbol{x}_{\boldsymbol{F}}=\left[\begin{array}{lllll}
y & \Psi & \dot{y} & \dot{\Psi} & \Psi_{S P}
\end{array}\right]^{T}
$$

Sua derivada pode ser deduzida como:

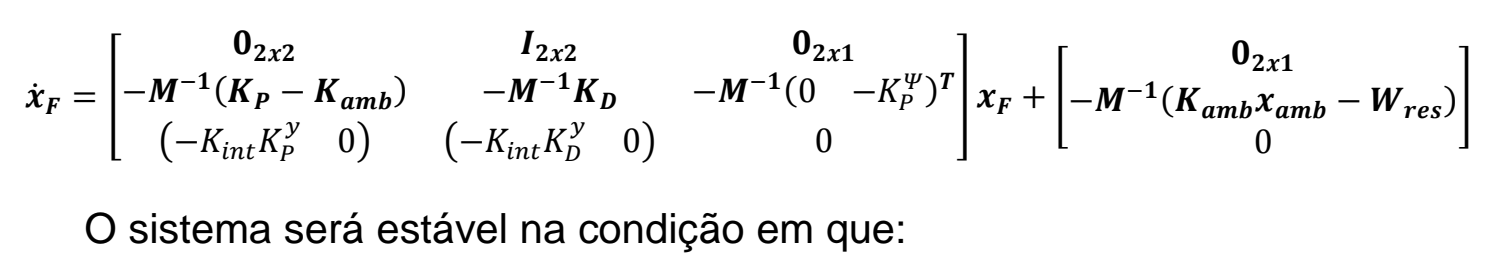

$$
\dot{\boldsymbol{x}}_{\mathrm{F}}=\mathbf{0}
$$

Resolvendo o sistema matricial anterior, nota-se que a única solução do problema proposto se encontra no ponto em que: 


$$
\boldsymbol{x}_{\boldsymbol{F}}=\left[\begin{array}{lllll}
0 & \Psi_{a m b} & 0 & 0 & \left(\Psi_{a m b}-W_{r e s}^{\Psi} / K_{P}^{\Psi}\right.
\end{array}\right]^{T}
$$

Desta forma, prova-se que o sistema irá convergir (caso seja estável) para o aproamento em que não há força lateral, na medida em que o valor de equilíbrio para $O$ estado $\Psi$ é $\Psi_{a m b}$.

A estabilidade do sistema é verificada pelos autovalores da matriz definida em (46). O sistema será estável se a parte real de todos os autovalores for negativa.

Devido à complexidade do cálculo de autovalores, não há solução analítica, sendo possível apenas estudar casos numericamente.

Como exemplo, considera-se o da barcaça assimétrica DP discutida no capítulo anterior. Vale ressaltar que os parâmetros $K_{a m b}^{y}$ e $K_{a m b}^{\Psi}$ são função da condição ambiental atuante, e neste caso considera-se a condição 1 apresentada na seção 0. Os parâmetros utilizados são:

- $K_{P}^{y}=26 \mathrm{kN} / \mathrm{m} ; K_{D}^{y}=2.01 \times 10^{3} \mathrm{kN} / \mathrm{m} / \mathrm{s}$

- $K_{P}^{\Psi}=3.3 \times 10^{5} \mathrm{kN} \cdot \mathrm{m} / \mathrm{rad} ; K_{D}^{\Psi}=2.5 \times 10^{6} \mathrm{kN} \cdot \mathrm{m} / \mathrm{rad} / \mathrm{s}$

- $I_{z}+M_{66}=3.04 \times 10^{7}$ ton $\cdot m^{2}$

- $M+M_{22}=2.4 \times 10^{4}$ ton

- $M x_{G}+M_{26}=-2.3 \times 10^{4}$ ton $\cdot \mathrm{m}$

- $K_{a m b}^{y}=2.1 \times 10^{2} \mathrm{kN} / \mathrm{rad} ; K_{a m b}^{\Psi}=4.3 \times 10^{3} \mathrm{kN} \cdot \mathrm{m} / \mathrm{rad}$

- $K_{\text {int }}=1.0 \times 10^{-5} \mathrm{rad} / \mathrm{s} / \mathrm{kN}$

Analisaram-se os autovalores do sistema da equação (46) com os parâmetros apresentados acima, e verificou-se que o sistema será estável para qualquer ganho $K_{\text {int }}<1.8 \cdot 10^{-4}$.

Através da simulação numérica da equação (46) é também possível estimar a influência do valor do ganho de adaptação $\left(K_{\text {int }}\right)$ na dinâmica do sistema. Conforme esperado, o tempo de assentamento é inversamente proporcional ao valor de $K_{\text {int }}$, conforme apresentado na Figura 37. Estes resultados serão comprovados na seção seguinte, na qual utiliza-se o modelo completo da dinâmica não linear da embarcação, e não apenas a dinâmica linearizada. 


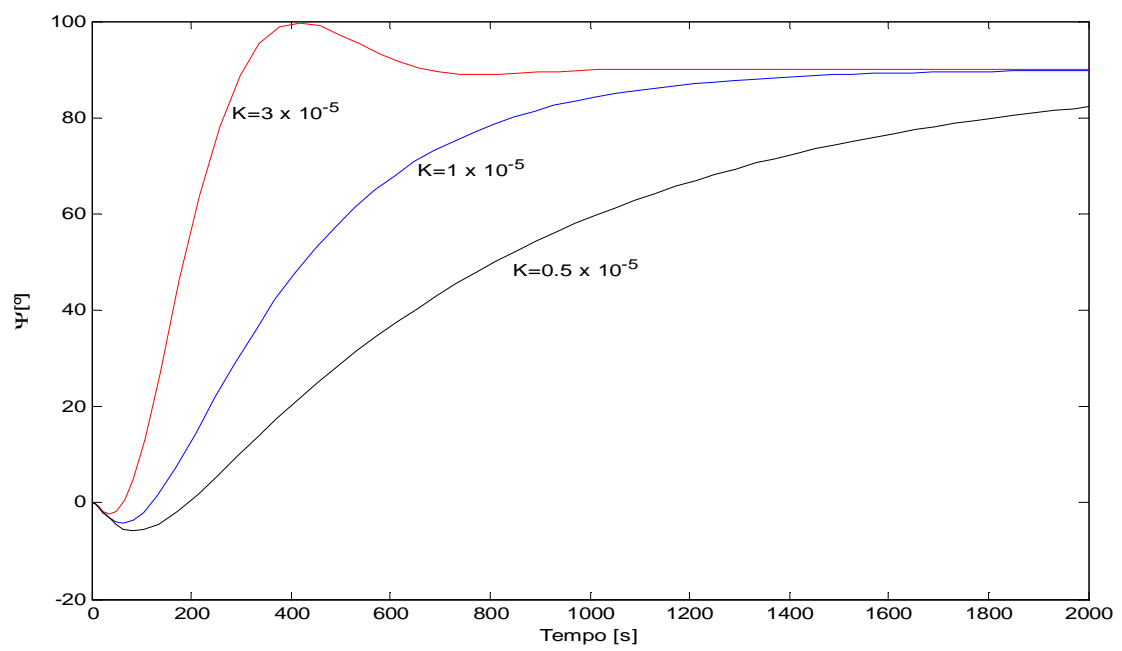

Figura 37 - Análise de estabilidade em função do ganho de adaptação 


\section{ANÁLISE POR SIMULAÇÃO NUMÉRICA}

Neste capítulo será descrita a simulação numérica efetuada para atestar a validade do controlador desenvolvido.

Primeiramente, será feita a descrição da ferramenta numérica que foi utilizada. Posteriormente, é feita a descrição dos parâmetros utilizados durante as simulações, seguidos pela apresentação e análise dos resultados.

Os dados e resultados presentes neste capítulo foram utilizados para a produção dos trabalhos apresentados em Miyazaki e Tannuri (2012a), Miyazaki e Tannuri (2012c) e Miyazaki e Tannuri (2013)

\subsection{Ferramenta numérica utilizada}

O simulador utilizado, denominado TPN (e desenvolvido pelo laboratório de mesmo nome), é uma ferramenta de análise numérica para análises no domínio do tempo de sistemas oceânicos ancorados ou com Sistema DP. A dinâmica em 6 graus de liberdade do navio é considerada, sendo portanto uma extensão do modelo descrito na seção 3.1, que se resumiu aos movimentos no plano horizontal. $O$ método de integração utilizado é o Runge-Kutta de $4^{\underline{a}}$ ordem.

Forças de correnteza são calculadas utilizando o modelo apresentado na seção 3.2.2, bem como forças de vento, que segue a formulação indicada na seção 3.2.1. Tanto a velocidade de vento quanto a de correnteza são consideradas constantes ao longo do tempo. As ondas consideradas são irregulares, ou seja, possuem espectro de energia JONSWAP. Efeitos de primeira e segunda ordem são modelados, bem como efeitos de deriva. Os coeficientes hidrodinâmicos são calculados utilizando o software WAMIT. Um resumo dos modelos de onda implementados foi apresentado na seção 3.2.3.

O Sistema DP apresenta filtro do tipo cunha, para separar componentes de alta frequência de componentes de baixa frequência. Desta forma, é possível atuar de forma a compensar componentes de baixa frequência, diminuindo 
significativamente o consumo de potência e ampliando a janela operacional em que o Sistema DP é utilizável.

O algoritmo de alocação de propulsão apresentado na seção 3.5 é responsável por distribuir esforços pelos propulsores distribuídos ao longo do navio. Estes esforços são calculados por três controladores PID independentes para cada grau de liberdade no plano horizontal (tal como descrito na seção 3.3). Considerase, tal como um Sistema DP real, a malha de feedforward de vento, que compensa os esforços devidos ao vento, antes de haver distúrbios sobre o posicionamento do navio, utilizando-se a medida de anemômetros.

Quanto ao sistema de propulsão, leva-se em conta a dinâmica de segunda ordem relativa ao eixo rotor dos propulsores para a geração de empuxo, e a limitação na velocidade de rotação para o ângulo de azimute.

\subsection{Descrição dos casos de simulação}

Inicialmente, avaliou-se a influência do ganho de adaptação do controlador $\left(K_{\text {int }}\right)$ e em seguida estudou-se o comportamento do controle para posições distintas do ponto de controle. Ao final, condições típicas encontradas em mares brasileiros foram testadas (inclusive múltiplas ondas incidentes). Para os testes, foi utilizado o modelo de uma barcaça típica. Os dados principais deste navio estão exibidos na Tabela 1

O sistema de propulsão, apresentado na Tabela 2 é composto por seis propulsores idênticos (três localizados na popa do navio e três localizados em sua proa), de $217 \mathrm{kN}$ de empuxo cada. Este navio foi escolhido devido à alta relação potência/massa presente no Sistema DP, e consequentemente, apresenta excelente manobrabilidade.

Todos os casos simulados possuem um período de 2000s iniciais para estabilização do sistema, durante o qual o controle weathervane está desligado. Após 2000s o controle weathervane é ativado, sendo que no restante da simulação o controlador estima qual o aproamento ideal para minimizar forças laterais de controle. 


\subsection{Resultados}

\subsubsection{Sensibilidade ao ganho de integração}

Como primeiro teste, foi feita a comparação do desempenho do sistema, em função do ganho utilizado. Além disso, por ser o primeiro teste efetuado, também serviu para analisar o comportamento do novo controlador. As condições de simulação foram as seguintes:

- Correnteza $S$ (indo para), com $V_{C}=0,7 \mathrm{~m} / \mathrm{s}$

- Vento $N$ (vindo de), com $V_{W}=9 \mathrm{~m} / \mathrm{s}$

- Onda $N$ (vindo de), com $T_{P}=8 s$ e $H_{S}=2 m$

- Set-point a meia nau

- $\Psi_{\text {inicial }}=0^{\circ}$

- $\Psi_{\text {desejado }}=90^{\circ}$

- $K_{\text {int }}$ Variável

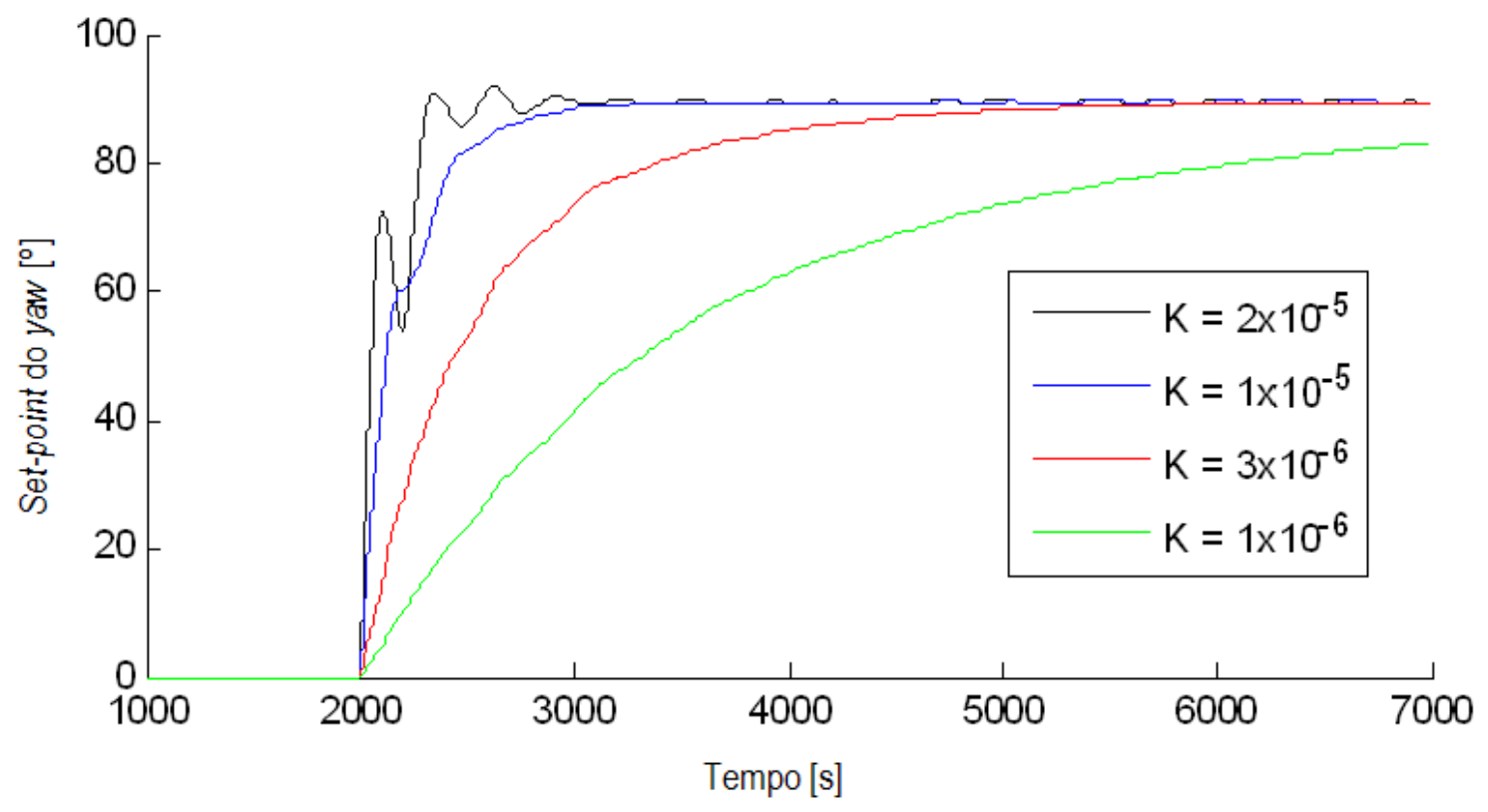

Figura 38 - Set-point do aproamento do navio em função do tempo para diferentes valores de $K_{\text {int }}$ analisados

Nota-se que todos os ganhos testados dentro desta faixa apresentaram resultados satisfatórios, porém o ganho de maior magnitude parece oscilar, fato que os outros ganhos utilizados não apresentaram. Como esperado, quanto maior o 
valor do ganho, mais rápida a resposta do controlador, então ganhos muito baixos, apesar de estáveis, levam mais tempo para alcançar equilíbrio. Embora as condições ambientais apresentem intensidade diferente do teste anterior apresentado em 5.2, verifica-se, comparando-se a Figura $38 \mathrm{com}$ a Figura 37, que os resultados são qualitativamente equivalentes.

Com o estudo do comportamento do ganho de integração concluído, passouse a estudar o comportamento do navio em função do ponto de controle escolhido.

\subsubsection{Controle da meia-nau}

O controle de meia nau, de grande importância para operações como perfuração DP, é um caso instável em operações com controladores weathervane tradicionais, e de grande utilidade. As condições de simulação foram as seguintes:

- Correnteza S(indo para), com $V_{C}=0,7 \mathrm{~m} / \mathrm{s}$

- Vento $N$ (vindo de), com $V_{W}=9 \mathrm{~m} / \mathrm{s}$

- Onda $\mathrm{N}$ (vindo de), com $\mathrm{T}_{\mathrm{P}}=8 \mathrm{~s}$ e $\mathrm{H}_{\mathrm{S}}=2 \mathrm{~m}$

- Ponto de controle na meia nau

- Set-point na coordenada [0, 0]

- $\Psi_{\text {inicial }}=0^{\circ}$

- $\Psi_{\text {desejado }}=90^{\circ}$

- $K_{\text {int }}=1 \times 10^{-5} \mathrm{rad} / \mathrm{kNs}$

Nota-se através dos gráficos exibidos da Figura 39 a Figura 42 que o controlador proposto de fato manteve o posicionamento da meia nau, conforme desejado, com passeios menores que $10 \mathrm{~m}$. Na Figura 39, a condição final é indicada em preto.

A comparação do resultado exibido na Figura 41 com o consumo de potência exibido na Figura 42 mostra a queda brusca dos esforços de controle laterais do navio em função do tempo, conforme proposto pelo controle weathervane. 
Finalmente, ao analisar a Figura 40 é possível verificar que com a incidência de proa das ondas, as oscilações de posicionamento em $Y$ diminuem conforme 0 navio modifica seu aproamento. 


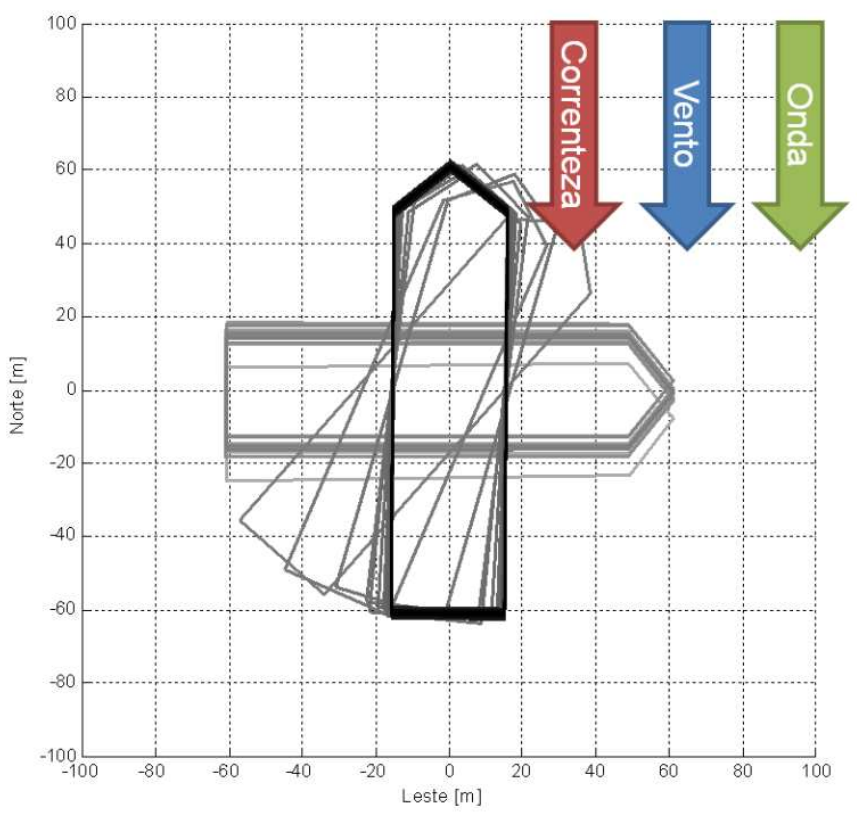

Figura 39 - Posição e aproamento do navio para o controle da meia-nau
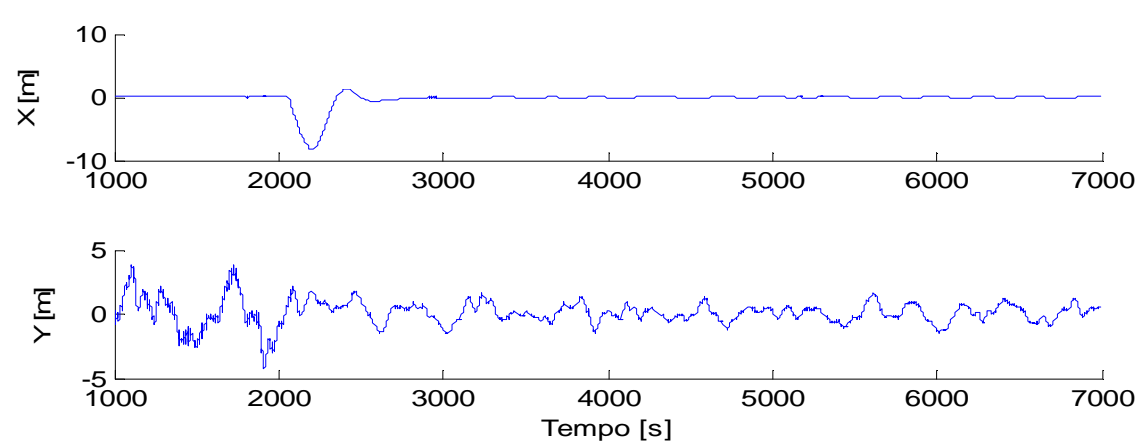

Figura 40 - Posição do ponto de controle

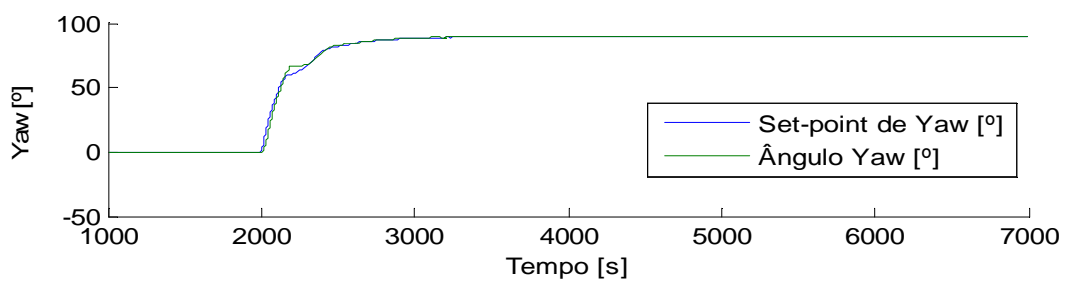

Figura 41 - Aproamento do navio

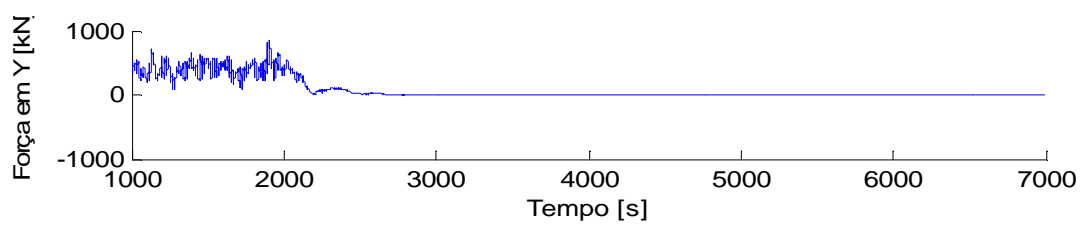

Figura 42 - Força lateral de controle 


\subsubsection{Controle da proa}

Operações de alívio utilizam controle da proa do navio ou de um ponto virtual a frente de sua proa (geralmente, controle do ponto ao qual o aliviador está conectado). As condições de simulação foram as seguintes:

- Correnteza S(indo para), com $\mathrm{V}_{\mathrm{C}}=0,7 \mathrm{~m} / \mathrm{s}$

- Vento $\mathrm{N}$ (vindo de), com $\mathrm{V}_{\mathrm{W}}=9 \mathrm{~m} / \mathrm{s}$

- Onda $\mathrm{N}$ (vindo de), com $\mathrm{T}_{\mathrm{P}}=8 \mathrm{~s}$ e $\mathrm{H}_{\mathrm{S}}=2 \mathrm{~m}$

- Ponto de controle $40 \mathrm{~m}$ a frente da proa do navio

- Set-point na coordenada [0, 0]

- $\Psi_{\text {inicial }}=0^{\circ}$

- $\Psi_{\text {desejado }}=90^{\circ}$

- $K_{\text {int }}=1,1 \times 10^{-6} \mathrm{rad} / \mathrm{kNs}$

Nota-se através dos gráficos exibidos da Figura 43 a Figura 46 que a o ponto de controle permaneceu com pequeno passeio, menores que $10 \mathrm{~m}$, conforme mostra a Figura 44. O aproamento varia mais lentamente que o caso anterior, graças ao ganho de adaptação $K_{\text {int }}$.

A comparação do resultado exibido na Figura 45 com o consumo de potência exibido na Figura 46 mostra um aumento inicial dos esforços de controle laterais do navio, seguido de sua suavização. Também nota-se que com a evolução do controlador no tempo, a força de controle lateral tende a zero.

Neste caso, a diminuição das forças de controle se deu de forma gradual, diferente do caso anterior que a utilização do sistema DP diminuiu de forma repentina.

Este caso utiliza ganho de adaptação que é uma ordem de grandeza menor que o caso anterior, pois com o controle da proa, a movimentação do navio se dá de forma lateral, e devido à sua geometria, há uma grande massa de líquido movida, gerando resistência hidrodinâmica para movimentação transversal. Portanto, a alteração no ângulo de aproamento deve ser feita mais lentamente. 


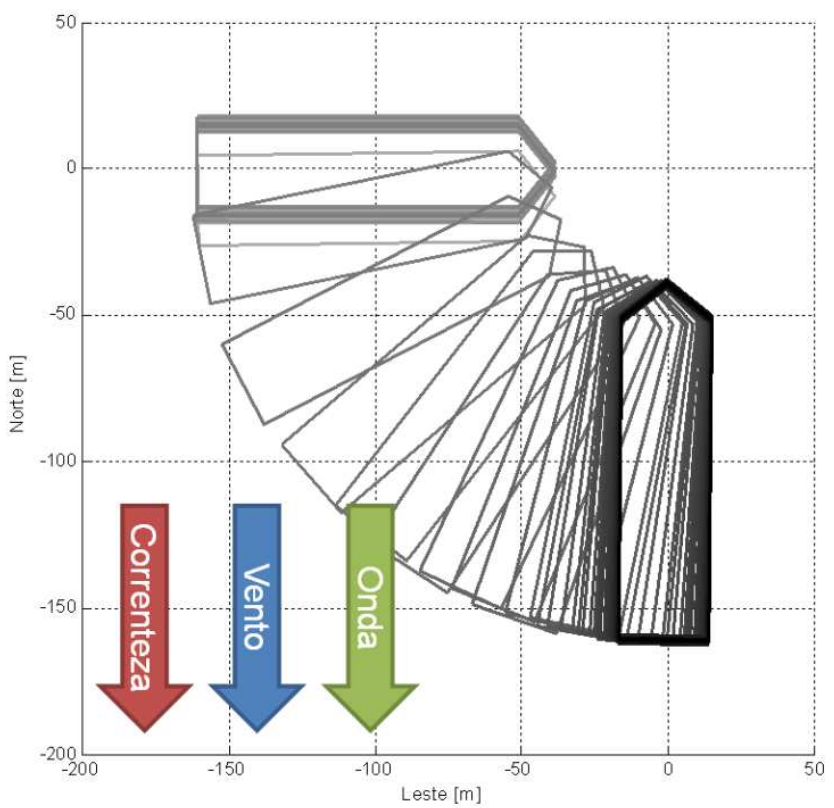

Figura 43 - Posição e aproamento do navio para o controle da proa
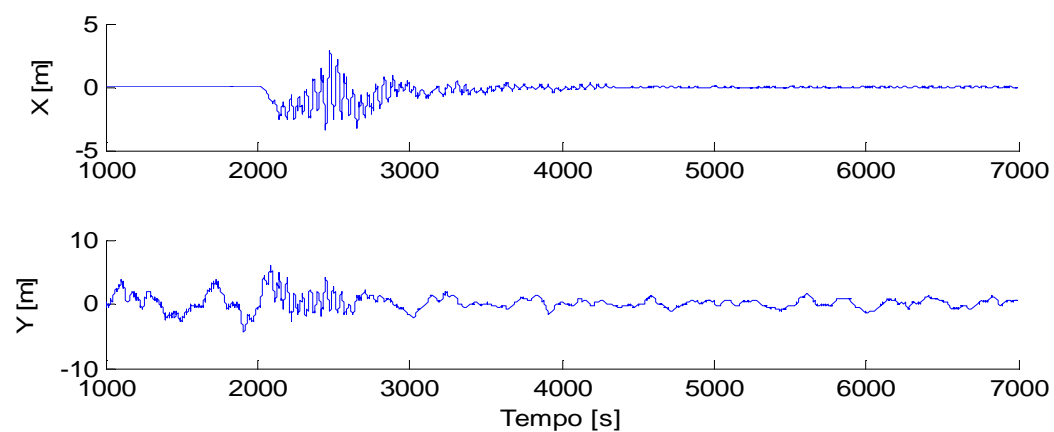

Figura 44 - Posição do ponto de controle

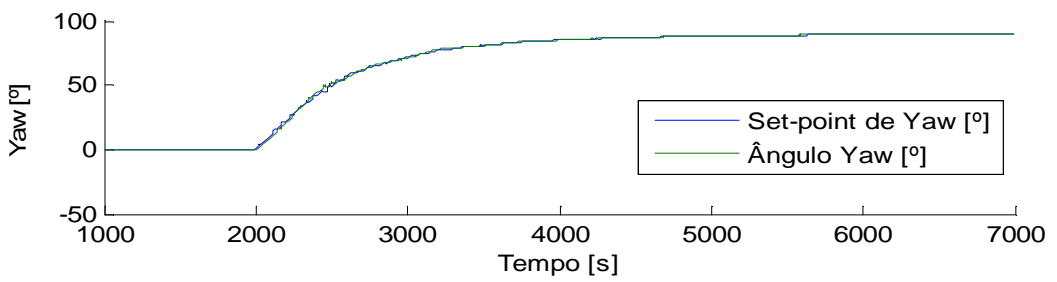

Figura 45 - Aproamento do navio

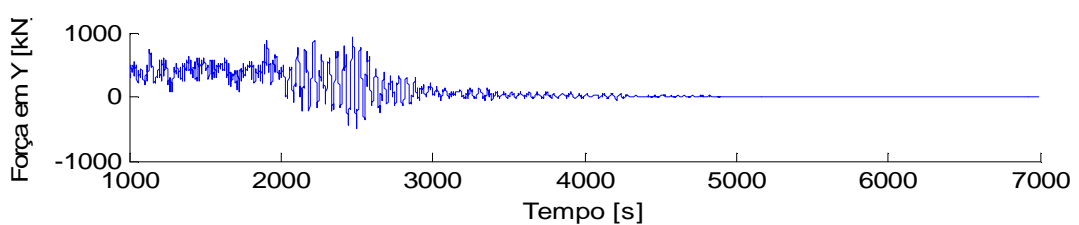

Figura 46 - Força lateral de controle 


\subsubsection{Controle de ponto no costado da embarcação}

Este caso estuda o controle de um ponto de controle posicionado a 35 metros da meia nau do navio, porém deslocado em sua direção transversal.

As condições de simulação foram as seguintes:

- Correnteza S(indo para), com $\mathrm{V}_{\mathrm{C}}=0,7 \mathrm{~m} / \mathrm{s}$

- Vento $\mathrm{N}$ (vindo de), com $\mathrm{V}_{\mathrm{W}}=9 \mathrm{~m} / \mathrm{s}$

- Onda $\mathrm{N}$ (vindo de), $\operatorname{com} \mathrm{T}_{\mathrm{P}}=8 \mathrm{~s}$ e $\mathrm{H}_{\mathrm{S}}=2 \mathrm{~m}$

- Ponto de controle $20 \mathrm{~m}$ além da lateral do navio

- Set-point na coordenada $[0,0]$

- $\Psi_{\text {inicial }}=0^{\circ}$

- $\Psi_{\text {desejado }}=90^{\circ}$

$$
\text { - } \quad K_{\text {int }}=2,2 \times 10^{-6} \mathrm{rad} / \mathrm{kNs}
$$

Nota - se através dos gráficos exibidos da Figura 47 a Figura 46 que a movimentação do navio se deu de forma rápida. Este caso apresentou passeios menores que 10m, conforme mostra a Figura 48.

A comparação do resultado exibido na Figura 49 com o consumo de potência exibido na Figura 46 mostra a queda rápida dos esforços de controle laterais do navio em função do tempo, conforme proposto pelo controle weathervane.

Neste caso, a diminuição das forças de controle se deu de forma repentina, mesmo com o ganho do controlador sendo cinco vezes menor que no caso de controle da meia nau.

Como o movimento do navio se dá basicamente de forma longitudinal, há pouca resistência hidrodinâmica comparado com o caso anterior, então o ganho do controlador pôde ser aumentado.

Finalmente, ao analisar a Figura 48 é possível verificar que com a incidência frontal de ondas, as oscilações de posicionamento em $Y$ diminuem conforme o navio modifica seu aproamento. 


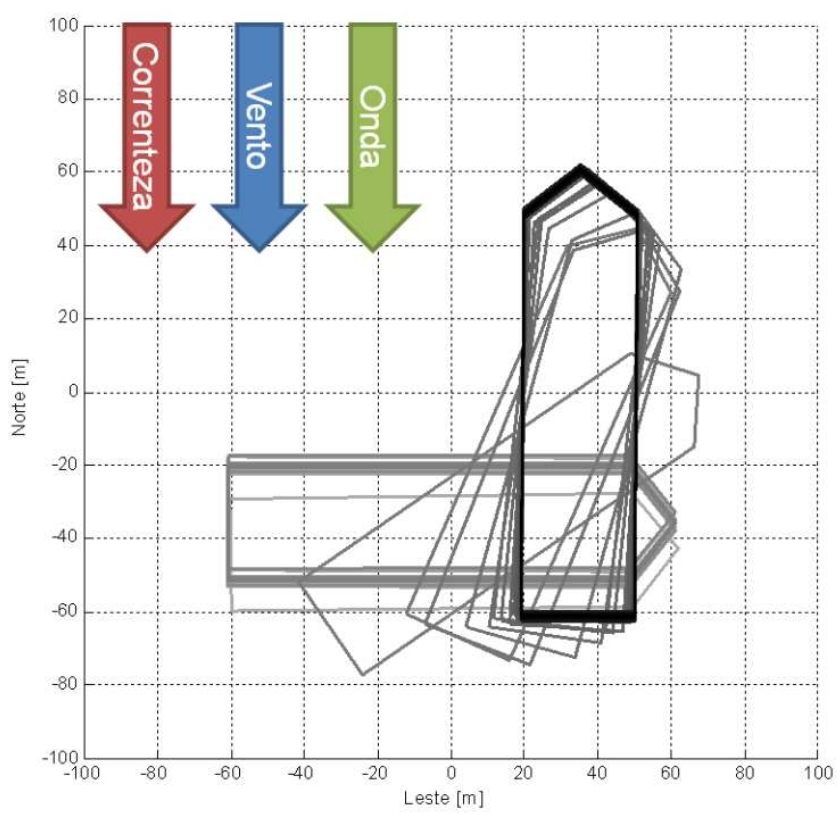

Figura 47 - Posição e aproamento do navio para o controle de sua lateral
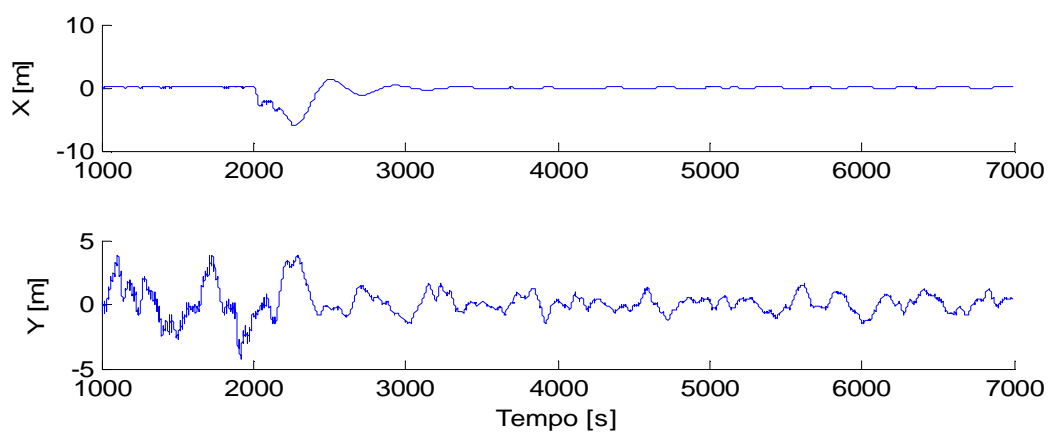

Figura 48 - Posição do ponto de controle

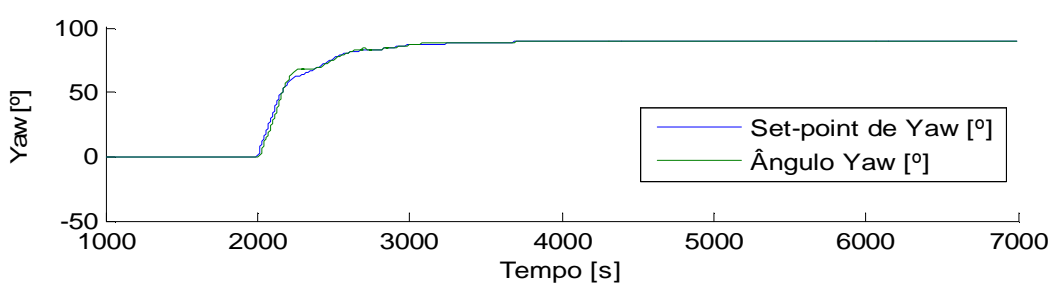

Figura 49 - Aproamento do navio

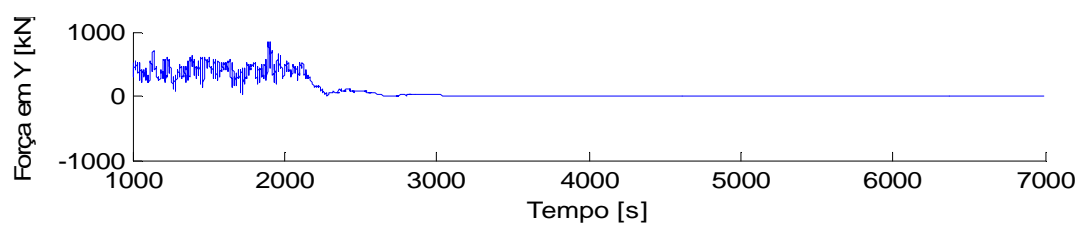

Figura 50 - Força lateral de controle 


\subsubsection{Controle da popa}

Este caso estuda o controle de um ponto na popa do navio, caso intrinsecamente instável e de difícil execução, mesmo para controladores padrão como o PID.

As condições de simulação foram as seguintes:

- Correnteza S(indo para), com $\mathrm{V}_{\mathrm{C}}=0,7 \mathrm{~m} / \mathrm{s}$

- Vento $\mathrm{N}$ (vindo de), com $\mathrm{V}_{\mathrm{W}}=9 \mathrm{~m} / \mathrm{s}$

- Onda N (vindo de), com $\mathrm{T}_{\mathrm{P}}=8 \mathrm{~s}$ e $\mathrm{H}_{\mathrm{S}}=2 \mathrm{~m}$

- Ponto de controle $40 \mathrm{~m}$ além da popa do navio

- Set-point na coordenada $[0,0]$

- $\Psi_{\text {inicial }}=0^{\circ}$

- $\Psi_{\text {desejado }}=90^{\circ}$

- $K_{\text {int }}=1,1 \times 10^{-6} \mathrm{rad} / \mathrm{kNs}$

Nota-se através dos gráficos exibidos da Figura 51 a Figura 54 que a adaptação do aproamento do navio se deu forma lenta. Este caso apresentou passeios de até $25 \mathrm{~m}$, além de regime oscilatório conforme mostra a Figura 52.

A comparação do resultado exibido na Figura 53 com o consumo de potência exibido na Figura 54 mostra o regime oscilatório da solução, com forças de controle de mesma magnitude que o valor inicial.

Mesmo com a instabilidade intrínseca do controle de popa, o controlador desenvolvido não levou o navio a derivar, apenas a um ciclo limite. 


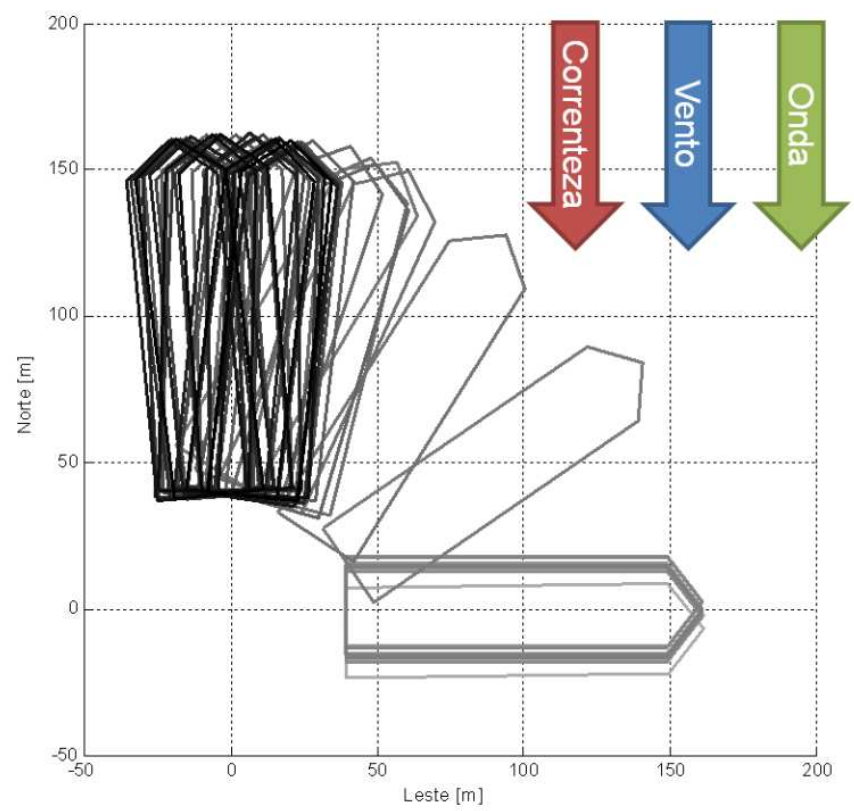

Figura 51 - Posição e aproamento do navio para o controle de sua popa
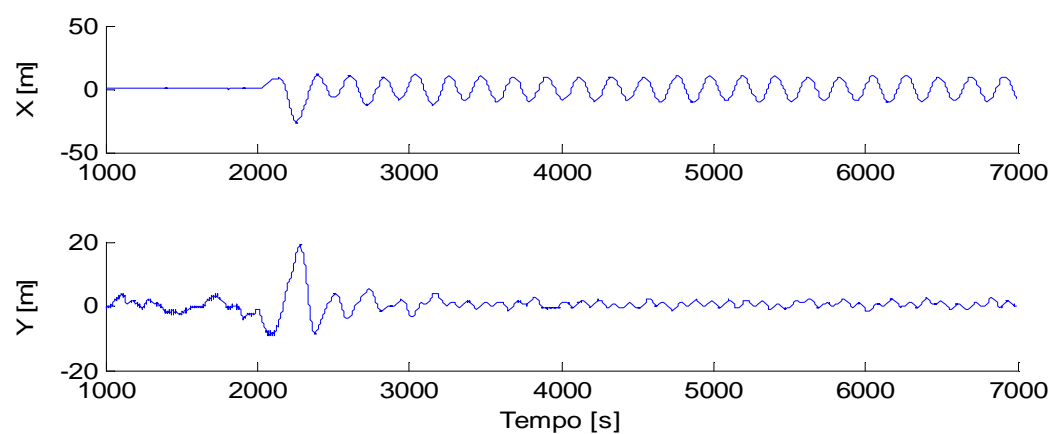

Figura 52 - Posição do ponto de controle

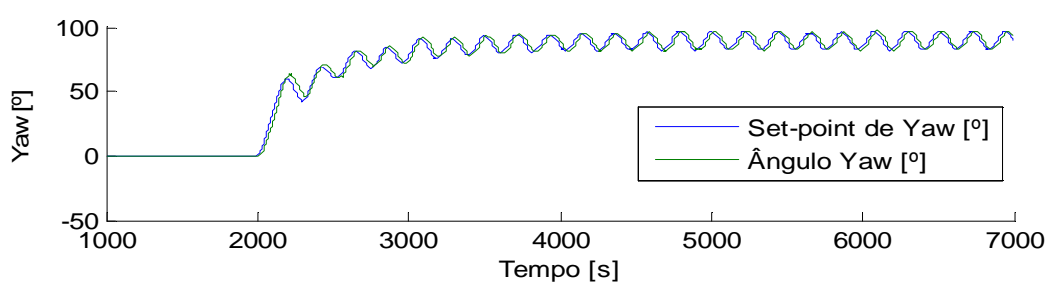

Figura 53 - Aproamento do navio

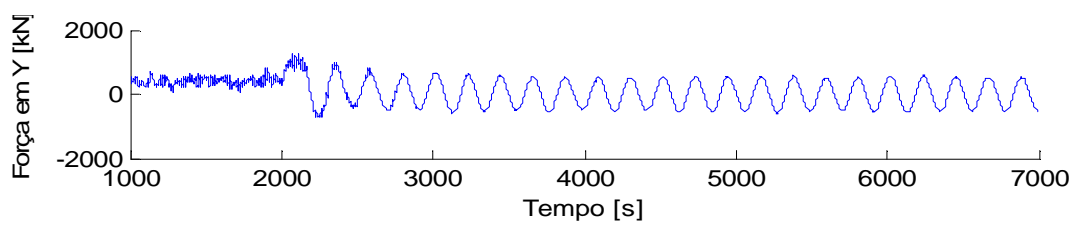

Figura 54 - Força lateral de controle 


\subsubsection{Caso com ondas bi-modais}

Este caso estuda o comportamento do controlador sob a influência de um caso com duas incidências distintas de ondas. A segunda componente de onda, denominada swell, possui características diferentes da onda primária.

As condições de simulação foram as seguintes:

- Correnteza S(indo para), com $\mathrm{V}_{\mathrm{C}}=0,7 \mathrm{~m} / \mathrm{s}$

- Vento $\mathrm{N}$ (vindo de), com $\mathrm{V}_{\mathrm{W}}=9 \mathrm{~m} / \mathrm{s}$

- Onda N (vindo de), com $\mathrm{T}_{\mathrm{P}}=8 \mathrm{~s}$ e $\mathrm{H}_{\mathrm{S}}=2 \mathrm{~m}$

- Swell E (vindo de), com $T_{P}=13 \mathrm{~s}$ e $H_{S}=1 \mathrm{~m}$

- Ponto de controle na meia-nau

- Set-point na coordenada $[0,0]$

- $\Psi_{\text {inicial }}=0^{\circ}$

- $\Psi_{\text {desejado }} \cong 95^{\circ}$

- $K_{\text {int }}=1 \times 10^{-5} \mathrm{rad} / k N s$

Nota-se através dos gráficos exibidos da Figura 55 a Figura 58 que a convergência ao aproamento weathervane se deu de forma rápida. Este caso apresentou passeios menores que 10m, conforme mostra a Figura 56.

Os resultados aqui apresentados, apesar de similares aos resultados da simulação de controle sem swell, apresentam oscilações de pequena amplitude no posicionamento da meia nau, no aproamento e principalmente na utilização do sistema DP.

Mesmo com estas oscilações citadas, é possível notar a diminuição considerável na utilização do sistema DP.

Finalmente, ao analisar a Figura 56 é possível verificar que com a incidência frontal de ondas, as oscilações de posicionamento em $Y$ diminuem conforme o navio modifica seu aproamento. 


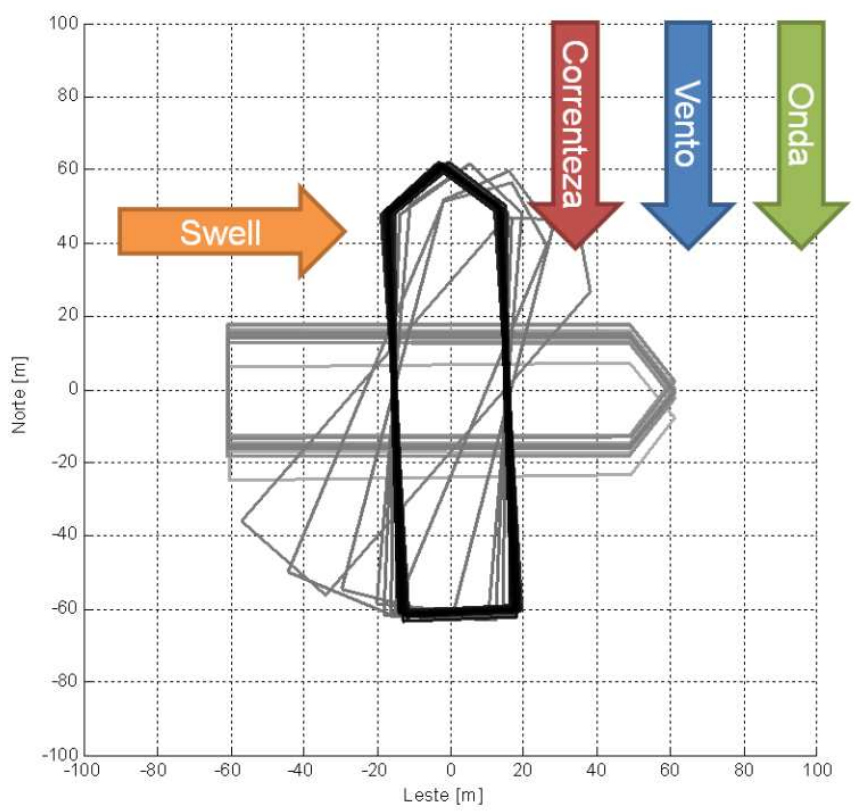

Figura 55 - Posição e aproamento do navio para o controle em caso multi ondas
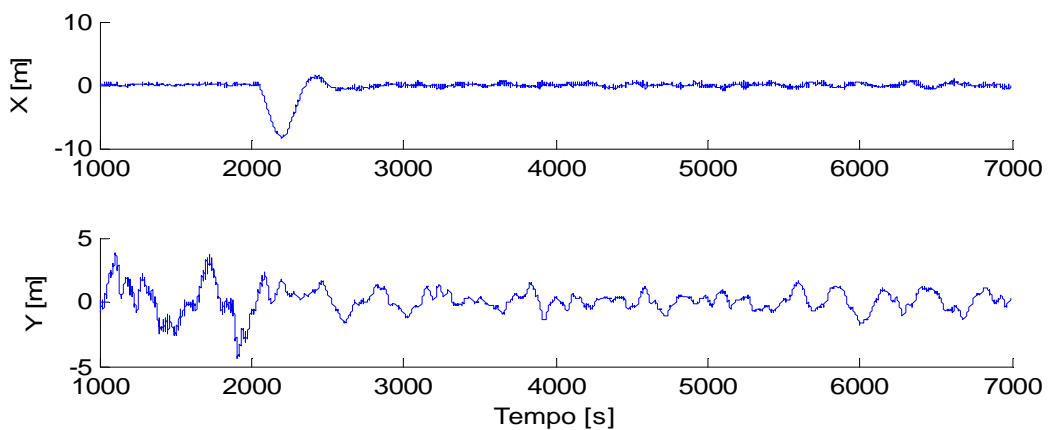

Figura 56 - Posição do ponto de controle

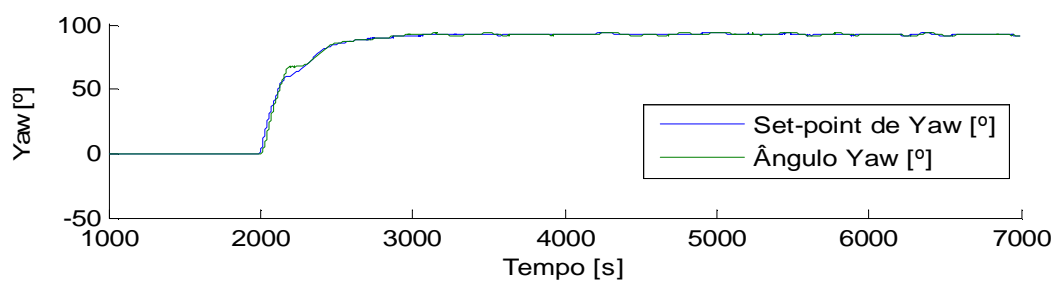

Figura 57 - Aproamento do navio

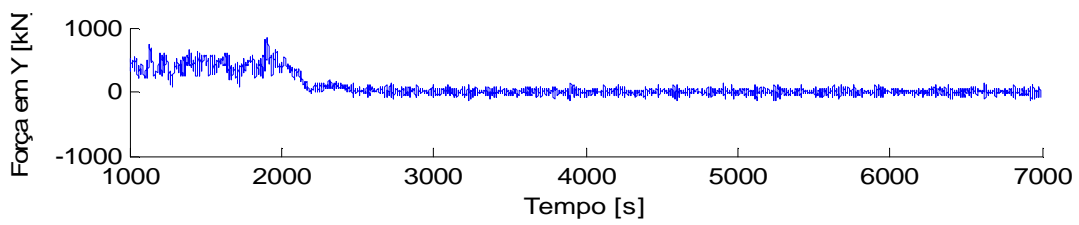

Figura 58 - Força lateral de controle 
6.3.7 Alteração do set-point

Este caso estuda o comportamento do controlador sob a influência de um caso com duas incidências distintas de ondas. A segunda onda, que será denominada swell, possui características diferentes da onda primária.

As condições de simulação foram as seguintes:

- Correnteza $S$ (indo para), com $V_{C}=0,7 \mathrm{~m} / \mathrm{s}$

- Vento $N$ (vindo de), com $V_{W}=9 \mathrm{~m} / \mathrm{s}$

- Onda $\mathrm{N}$ (vindo de), com $\mathrm{T}_{\mathrm{P}}=8 \mathrm{~s}$ e $\mathrm{H}_{\mathrm{S}}=2 \mathrm{~m}$

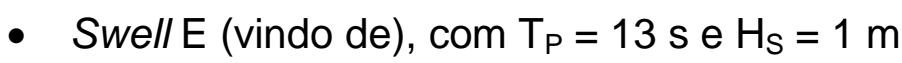

- Ponto de controle na meia-nau

- Set-point variável

- $\Psi_{\text {inicial }}=0^{\circ}$

- $\Psi_{\text {desejado }} \cong 95^{\circ}$

- $K_{\text {int }}=1 \times 10^{-5} \mathrm{rad} / \mathrm{kNs}$

Durante esta simulação, o set-point foi interpolado linearmente 4 vezes diferentes, sempre alterando 20 metros em 500 segundos. A posição do set-point está visível na Figura 60.

Nota-se através dos gráficos exibidos da Figura 59 a Figura 62 a estabilidade desta solução. Este caso apresentou passeios menores que $10 \mathrm{~m}$, conforme mostra a Figura 56.

É possível afirmar que neste caso, aplicar mudanças no set-point através de interpolações teve pouca influência. Um dos cuidados necessários é a aplicação de mudanças suaves, para não saturar o sistema de controle.

Ao se deslocar lateralmente, o aproamento do navio foi alterado devido às forças hidrodinâmicas, porem esta mudança no aproamento permaneceu inferior a quatro graus. 


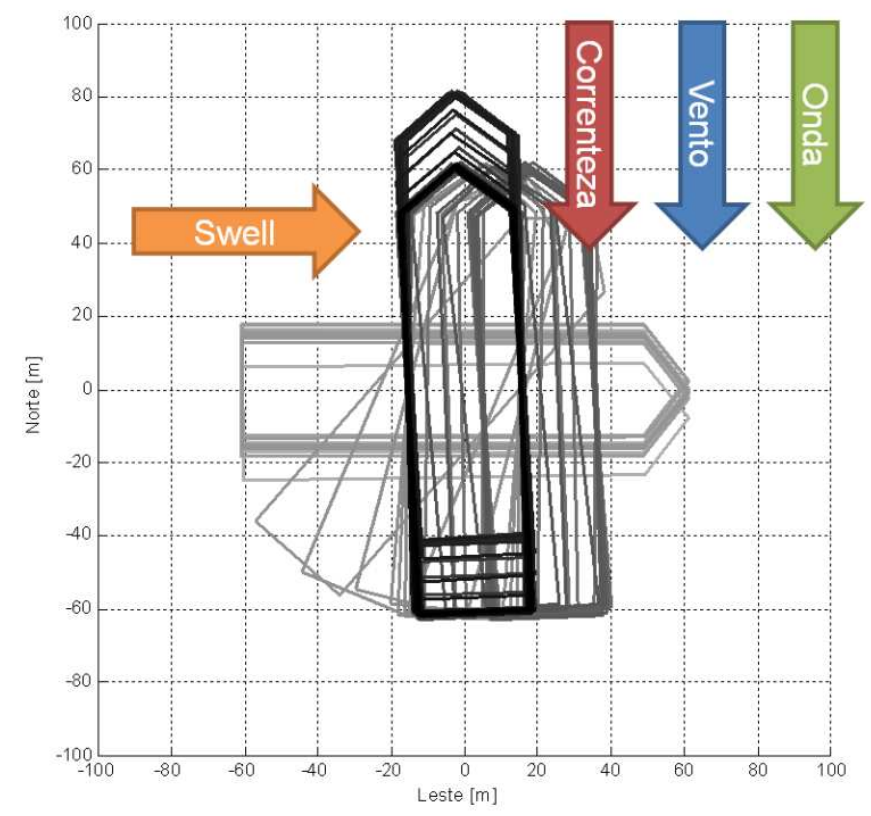

Figura 59 - Posição e aproamento do navio para o controle em caso de alteração de set-point
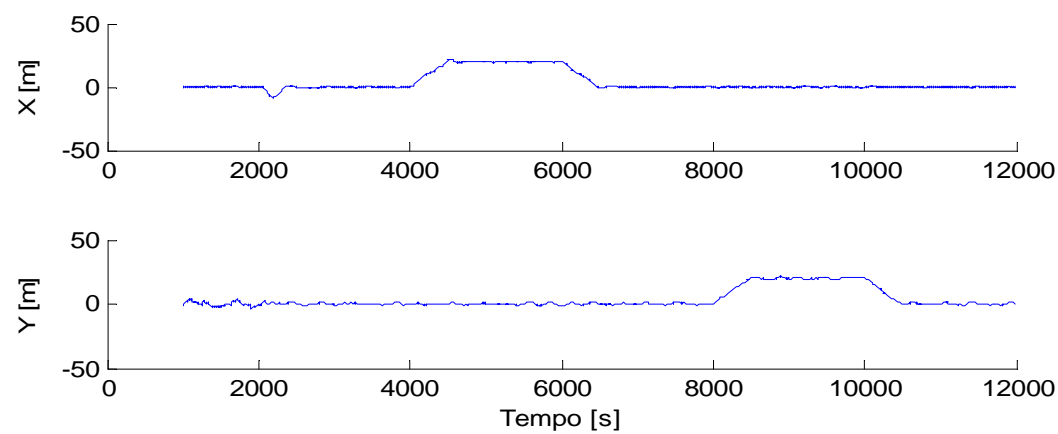

Figura 60 - Posição do ponto de controle

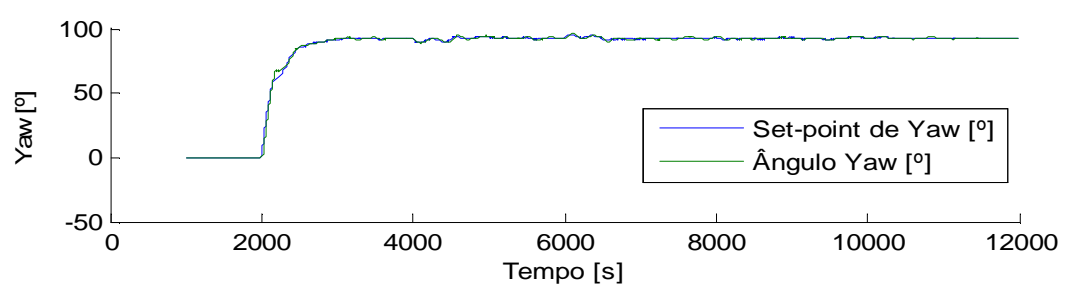

Figura 61 - Aproamento do navio

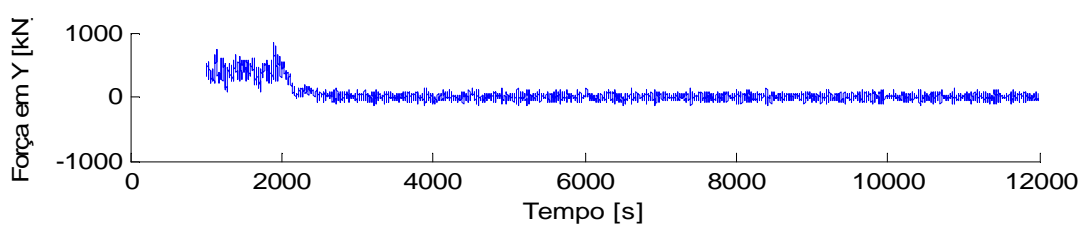

Figura 62 - Força lateral de controle 


\subsubsection{Condição típica brasileira \#1}

Este caso estuda o comportamento do controlador em uma condição real, comum na costa brasileira. As condições de simulação foram as descritas na análise 2, presente na seção 4.5.2:

- Correnteza S(indo para), com $\mathrm{V}_{\mathrm{C}}=1 \mathrm{~m} / \mathrm{s}$

- Vento NE (vindo de), com $V_{W}=20 \mathrm{~m} / \mathrm{s}$

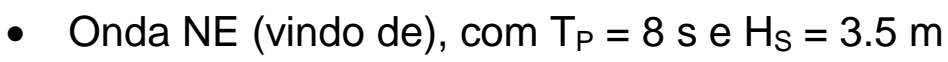

- Ponto de controle na meia-nau

- Set-point na coordenada [0, 0]

- $\Psi_{\text {inicial }}=0^{\circ}$

- $\Psi_{\text {desejado }} \cong 52^{\circ}$

- $K_{\text {int }}=1 \times 10^{-5} \mathrm{rad} / \mathrm{kNs}$

Nota-se através dos gráficos exibidos na Figura 63 a Figura 66 que a convergência ao aproamento weathervane se deu de forma rápida. Este caso apresentou passeios inferiores a 10m, conforme mostra a Figura 64 .

$\mathrm{O}$ aproamento desejado foi atingido com o controlador weathervane e a força lateral de controle do Sistema DP tende a zero, sendo que o controle nesta condição foi satisfatório.

Com condições ambientais incidentes desalinhadas, a solução final apresenta pequenas oscilações, pois as ondas induzem esforços oscilatórios na embarcação.

O resultado está coerente com a análise presente no capítulo 4, com o ângulo do controlador weathervane tendendo ao mesmo valor ali verificado. 


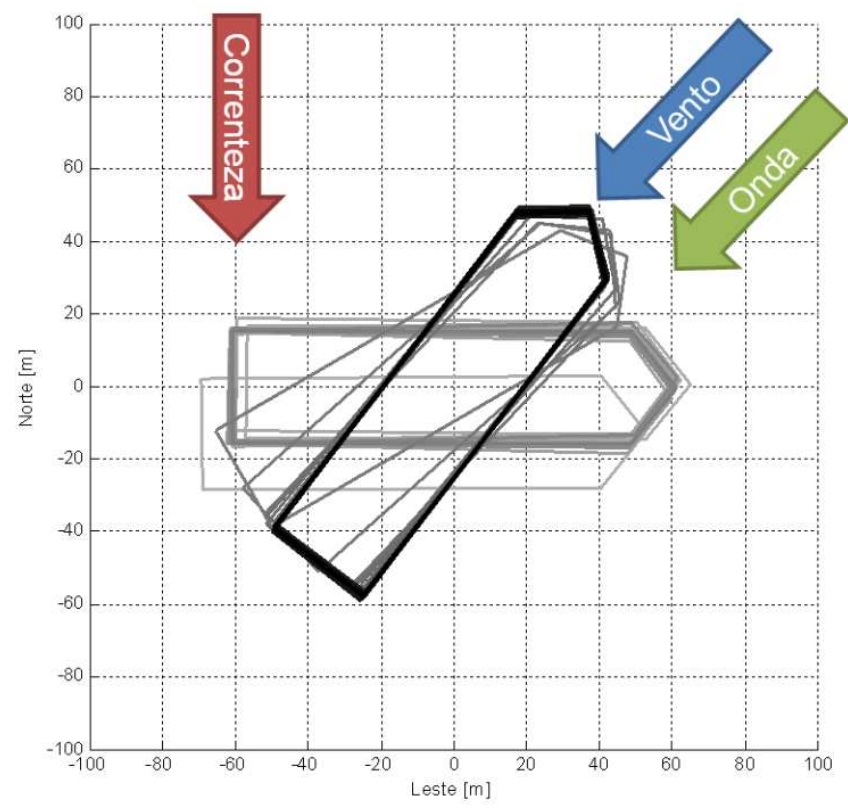

Figura 63 - Posição e aproamento do navio sob a condição brasileira típica \#1
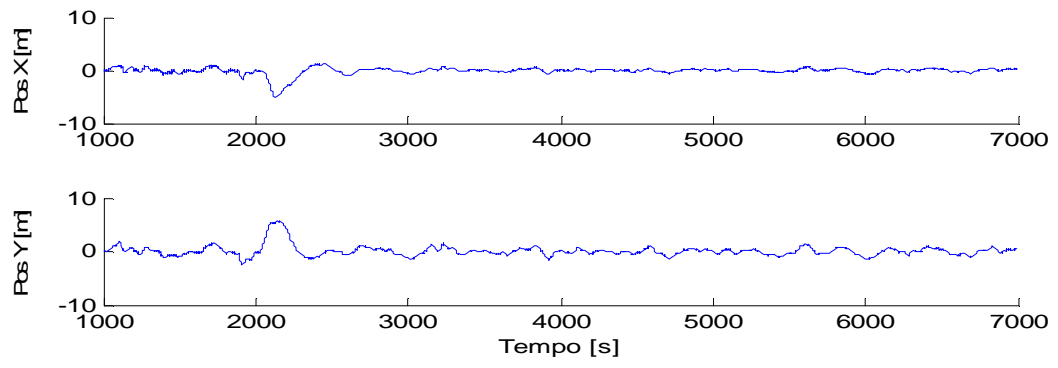

Figura 64 - Posição do ponto de controle

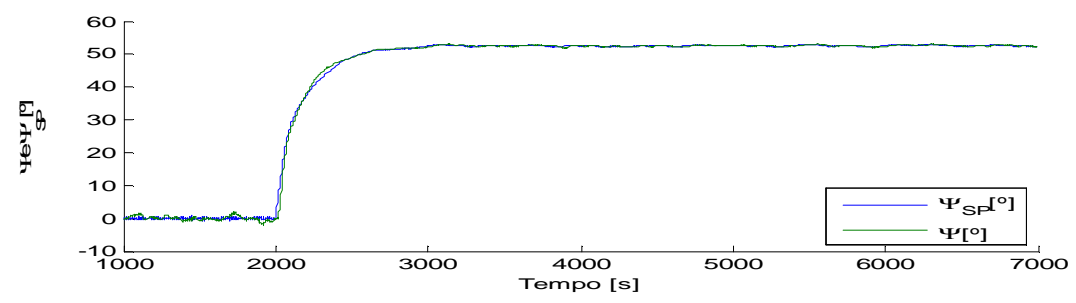

Figura 65 - Aproamento do navio

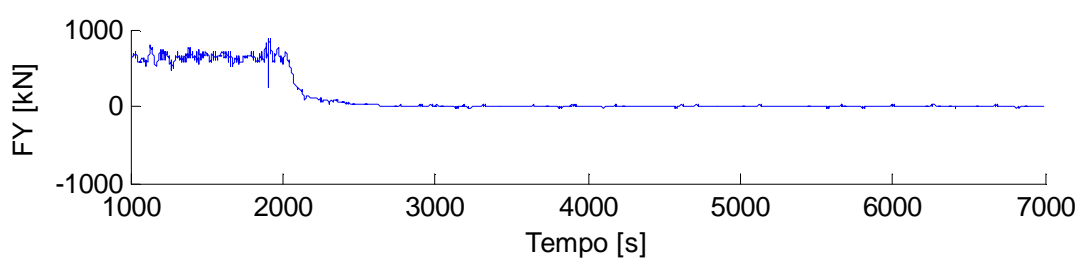

Figura 66 - Força lateral de controle 


\subsubsection{Condição típica brasileira \#2}

Este caso estuda o comportamento do controlador em uma condição real, comum na costa brasileira. As condições de simulação foram as descritas na análise 3, presente na seção 4.5.3:

- Correnteza S(indo para), com $\mathrm{V}_{\mathrm{C}}=1,0 \mathrm{~m} / \mathrm{s}$

- Vento SE (vindo de), com $\mathrm{V}_{\mathrm{W}}=20 \mathrm{~m} / \mathrm{s}$

- Onda SE (vindo de), $\operatorname{com} \mathrm{T}_{\mathrm{P}}=8 \mathrm{~s}$ e $\mathrm{H}_{\mathrm{S}}=3.5 \mathrm{~m}$

- Ponto de controle na meia-nau

- Set-point na coordenada [0, 0]

- $\Psi_{\text {inicial }}=0^{\circ}$

- $\Psi_{\text {desejado }} \cong-25^{\circ}$

- $K_{\text {int }}=1 \times 10^{-5} \mathrm{rad} / k N s$

Nota-se através dos gráficos exibidos da Figura 67 a Figura 70 que houve convergência para o aproamento weathervane.

É perceptível também a diminuição no erro de posição do navio após a mudança de aproamento, pois na condição inicial, o ângulo de incidência de ondas era de $45^{\circ}$, enquanto no aproamento final, este está por volta de $20^{\circ}$. Com ângulos de incidência de onda menores, há menos oscilação na posição do navio.

A redução na força de controle lateral pode ser vista se tomada uma média de longo termo da série temporal apresentada na Figura 70. 


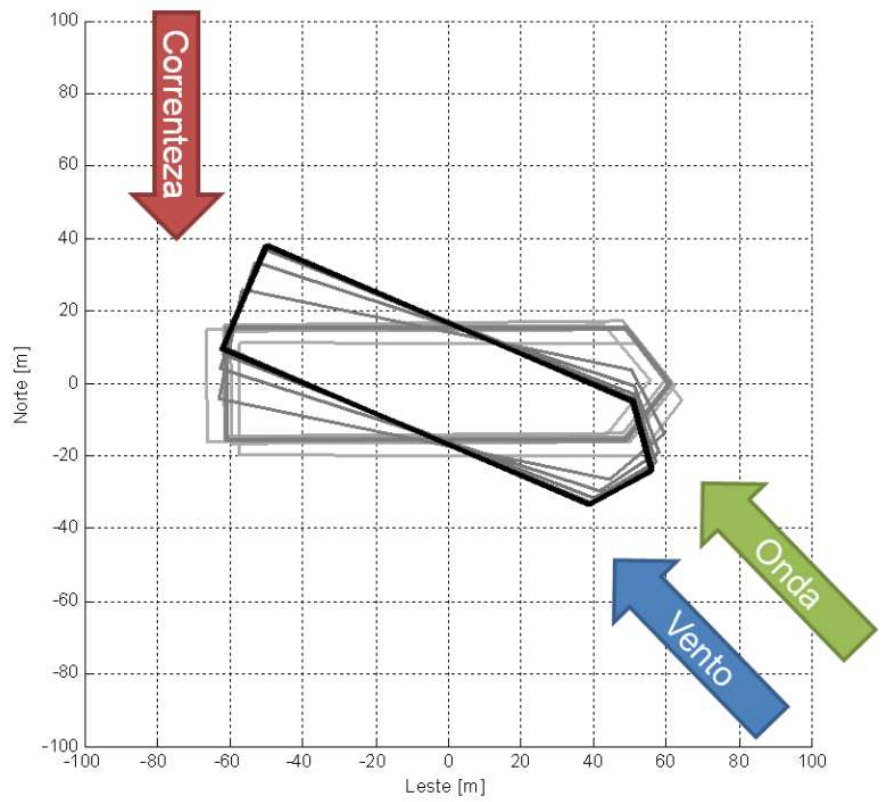

Figura 67 - Posição e aproamento do navio sob a condição brasileira típica \#2
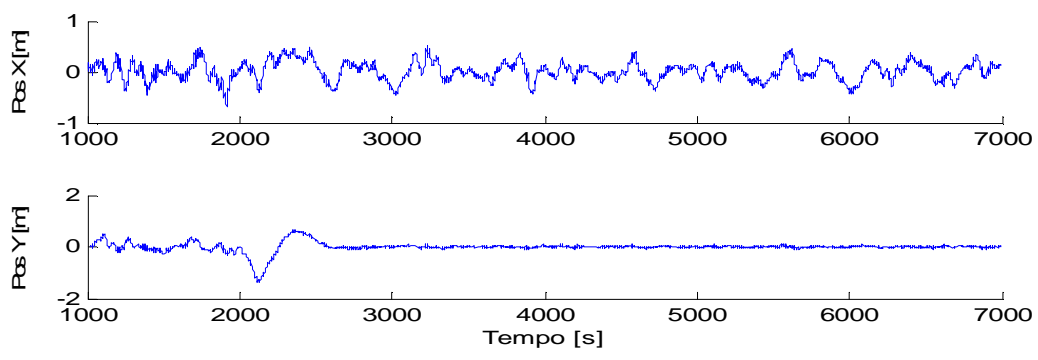

Figura 68 - Posição do ponto de controle

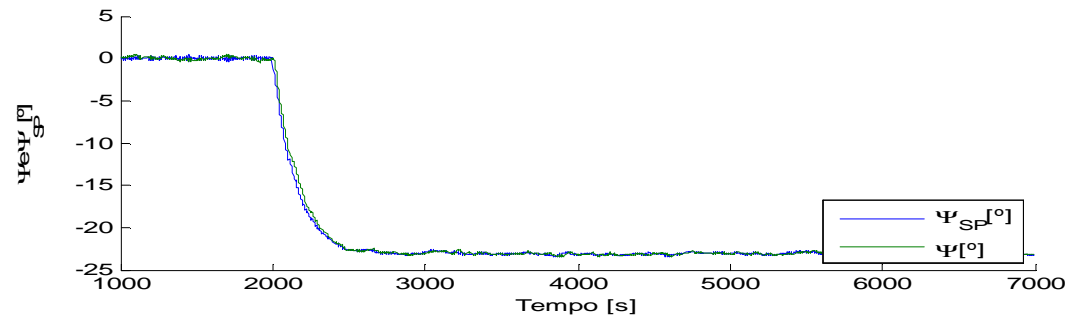

Figura 69 - Aproamento do navio

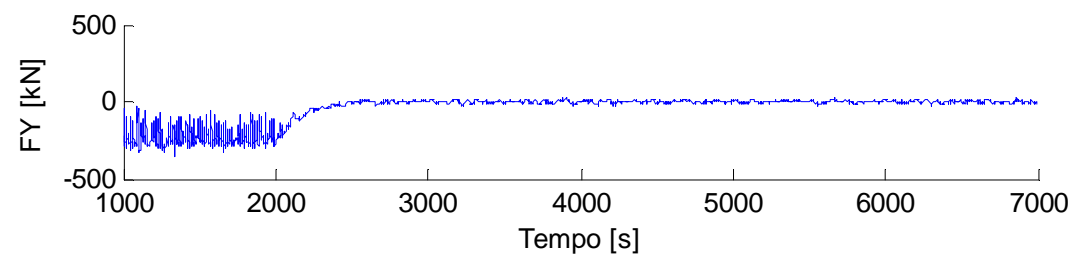

Figura 70 - Força lateral de controle 
6.3.10 Condição típica brasileira \#3

Este caso estuda o comportamento do controlador em uma condição real, comum na costa brasileira. As condições de simulação foram as descritas na análise 4, presente na seção 4.5.4:

- Correnteza $\mathrm{S}$ (indo para), com $\mathrm{V}_{\mathrm{C}}=1 \mathrm{~m} / \mathrm{s}$

- Vento NE (vindo de), com $\mathrm{V}_{\mathrm{W}}=20 \mathrm{~m} / \mathrm{s}$

- Onda NE (vindo de), $\operatorname{com} \mathrm{T}_{\mathrm{P}}=8 \mathrm{~s}$ e $\mathrm{H}_{\mathrm{S}}=3.5 \mathrm{~m}$

- Swell S (vindo de), $\operatorname{com} \mathrm{T}_{\mathrm{P}}=12 \mathrm{~s}$ e $\mathrm{H}_{\mathrm{S}}=2 \mathrm{~m}$

- Ponto de controle na meia-nau

- Set-point na coordenada $[0,0]$

- $\Psi_{\text {inicial }}=0^{\circ}$

- $\Psi_{\text {desejado }} \cong 50^{\circ}$

- $K_{\text {int }}=1 \times 10^{-5} \mathrm{rad} / k N s$

Este caso possui as mesmas características que a condição típica brasileira \#1, porém com a inclusão de onda de swell incidindo perpendicularmente à onda original.

Graças à pequena amplitude do swell e do longo período, os esforços devido à segunda onda fazem pouca diferença no resultado final. 


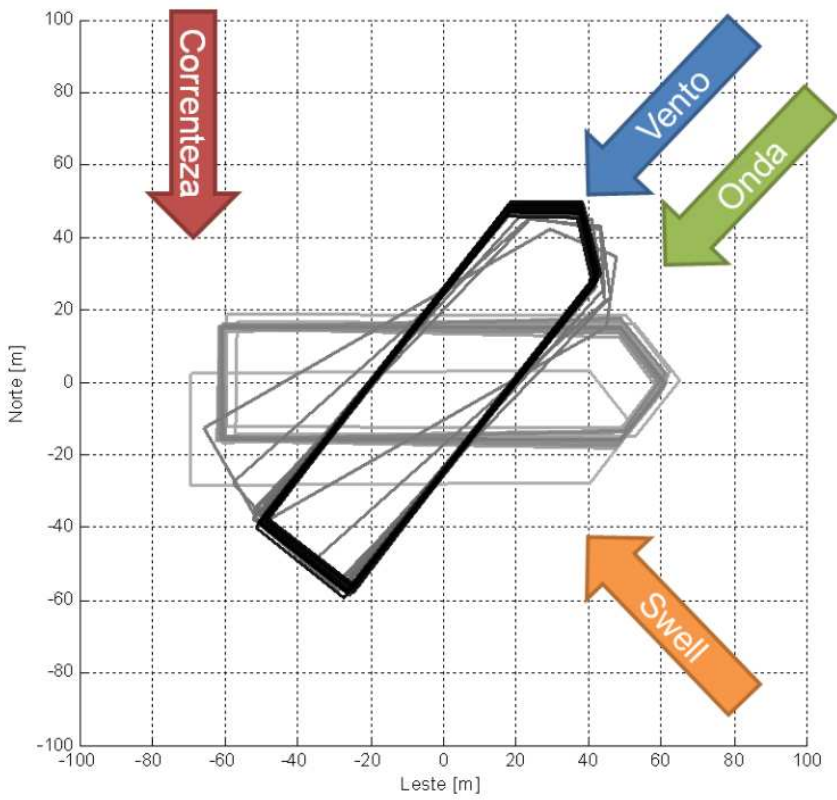

Figura 71 - Posição e aproamento do navio sob a condição brasileira típica \#3
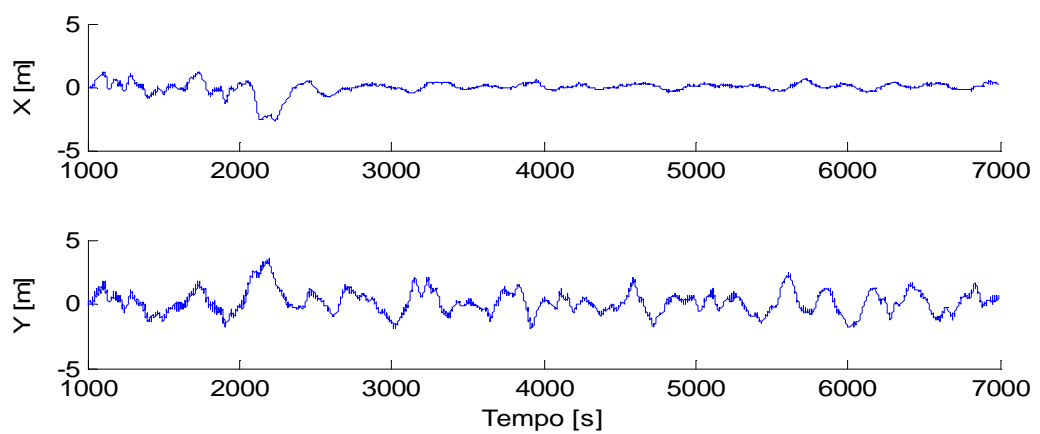

Figura 72 - Posição do ponto de controle

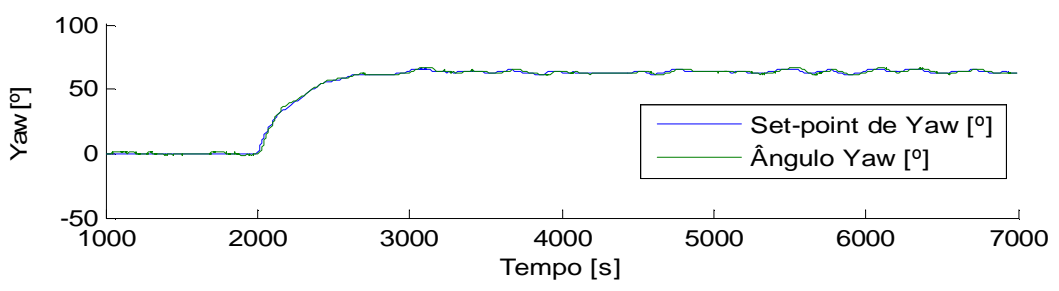

Figura 73 - Aproamento do navio

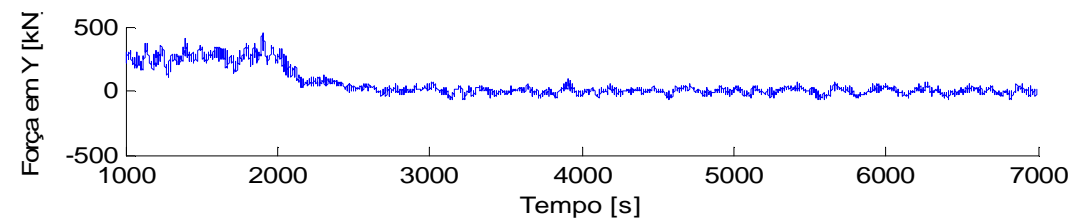

Figura 74 - Força lateral de controle 


\section{RESULTADOS EXPERIMENTAIS}

Este capítulo descreve o aparato laboratorial utilizado nos ensaios experimentais, seguido pela descrição dos parâmetros utilizados em cada ensaio e, em seguida, apresentam-se os resultados e discussões.

Os dados e resultados presentes neste capítulo foram utilizados para a produção dos trabalhos apresentados em Miyazaki e Tannuri (2012b), Miyazaki e Tannuri (2012c) e Miyazaki e Tannuri (2013a)

\subsection{Modelo utilizado}

O modelo utilizado para testes, exibido na ,é um navio na escala 1:125 de um típico aliviador DP da classe Suezmax em calado vazio, com parâmetros apresentados na :

Tabela 9 - Principais dados físicos e geométricos do navio em escala real

\begin{tabular}{lcc}
\hline Propriedade & $\begin{array}{c}\text { Valor em escala } \\
\text { real }\end{array}$ & $\begin{array}{c}\text { Valor em escala } \\
\text { de modelo (1:125) }\end{array}$ \\
\hline Comprimento total & $277,0 \mathrm{~m}$ & $2,22 \mathrm{~m}$ \\
Distância entre perpendiculares [ $\left.\mathrm{L}_{\mathrm{PP}}\right]$ & $262,0 \mathrm{~m}$ & $2,10 \mathrm{~m}$ \\
Boca [B] & $46,0 \mathrm{~m}$ & $0,37 \mathrm{~m}$ \\
Calado [T] & $8,0 \mathrm{~m}$ & $0,064 \mathrm{~m}$ \\
Massa [M] & $80.617 \mathrm{ton}$ & $41,3 \mathrm{~kg}$ \\
Momento de inércia [l $\mathrm{l}]$ & $4,85 \cdot 10^{7} \mathrm{ton} \cdot \mathrm{m}^{2}$ & $1,59 \mathrm{~kg} \cdot \mathrm{m}^{2}$ \\
\hline
\end{tabular}




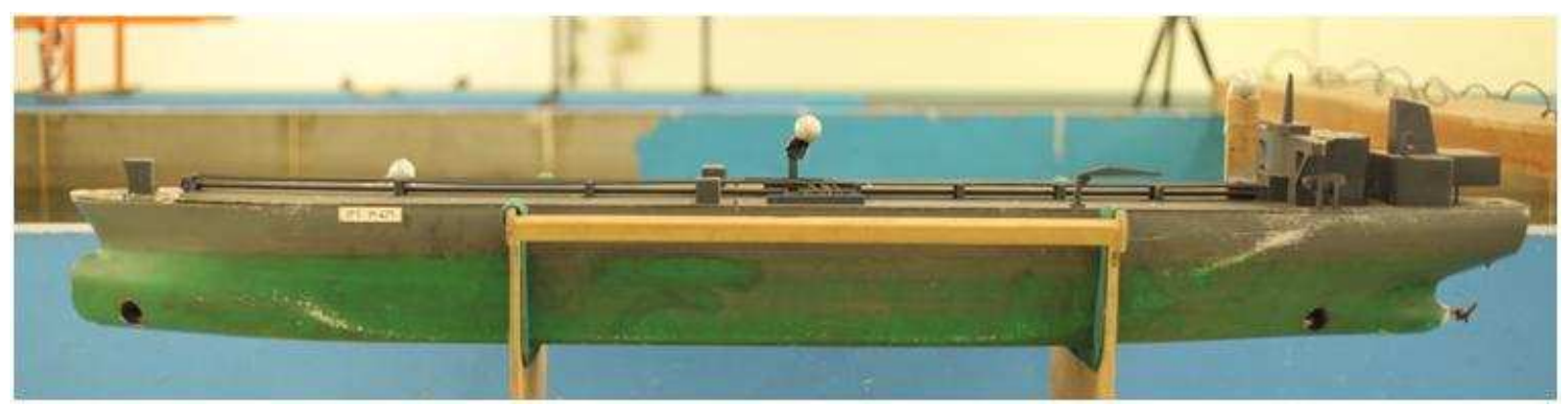

Figura 75 - Modelo utilizado durante ensaios no tanque de provas numérico

O modelo real possui sistema de propulsão conforme apresentado na, e pode ser visualizado da a .

Tabela 10 - Dados do sistema de propulsão do navio DP em escala real (valores entre parênteses equivalem à escala de modelo)

\begin{tabular}{lccl}
\hline \multicolumn{1}{c}{ Propulsor } & Posição X & Empuxo máximo & Empuxo mínimo \\
\hline Propulsor principal & $-129 \mathrm{~m}(-1,03 \mathrm{~m})$ & $1200 \mathrm{kN}(0,61 \mathrm{~N})$ & $-539,1 \mathrm{kN}(-0,27 \mathrm{~N})$ \\
Propulsor túnel de popa & $-94,6 \mathrm{~m}(-0,76 \mathrm{~m})$ & $181,2 \mathrm{kN}(0,09 \mathrm{~N})$ & $-181,2 \mathrm{kN}(-0,09 \mathrm{~N})$ \\
Propulsor túnel de proa & $120,8 \mathrm{~m}(0,97 \mathrm{~m})$ & $244,1 \mathrm{kN}(0,12 \mathrm{~N})$ & $-244,1 \mathrm{kN}(-0,12 \mathrm{~N})$ \\
\hline
\end{tabular}

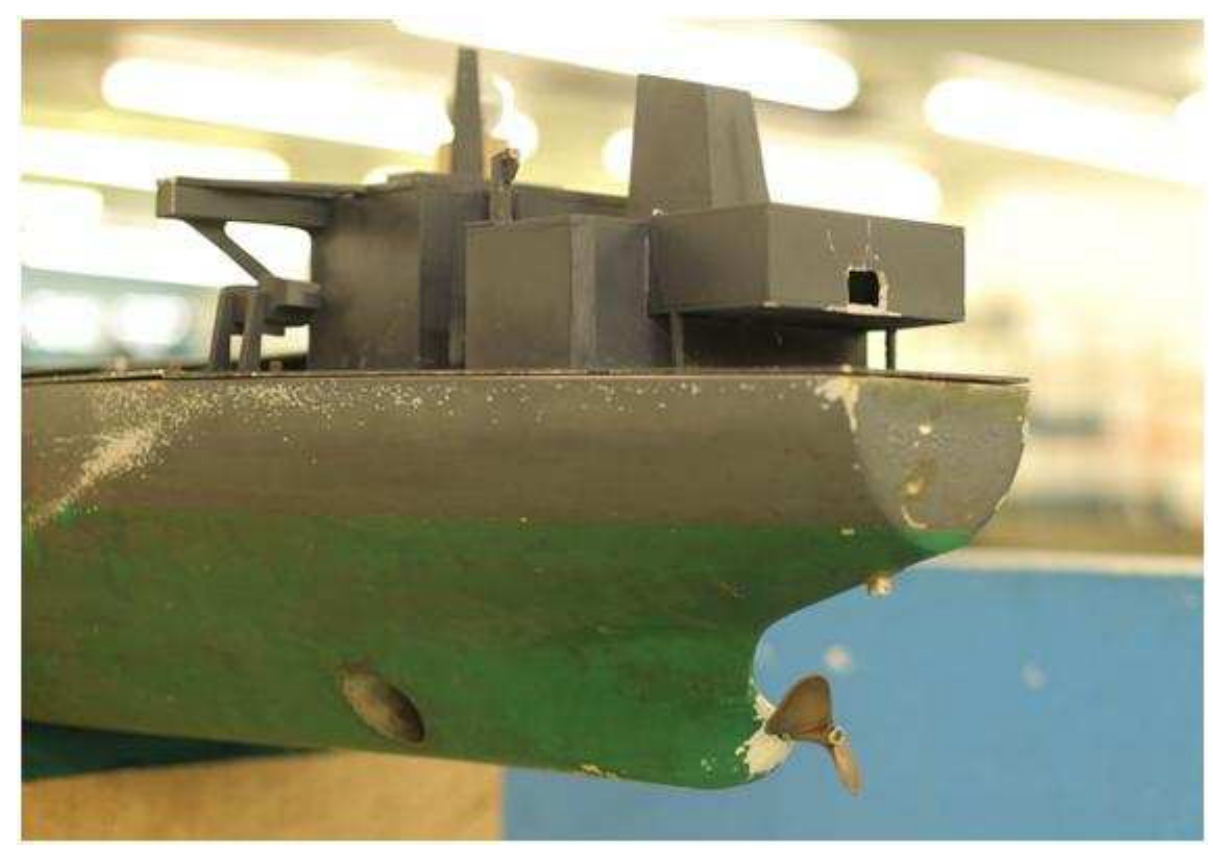

Figura 76 - Propulsor principal e propulsor túnel de popa do modelo 


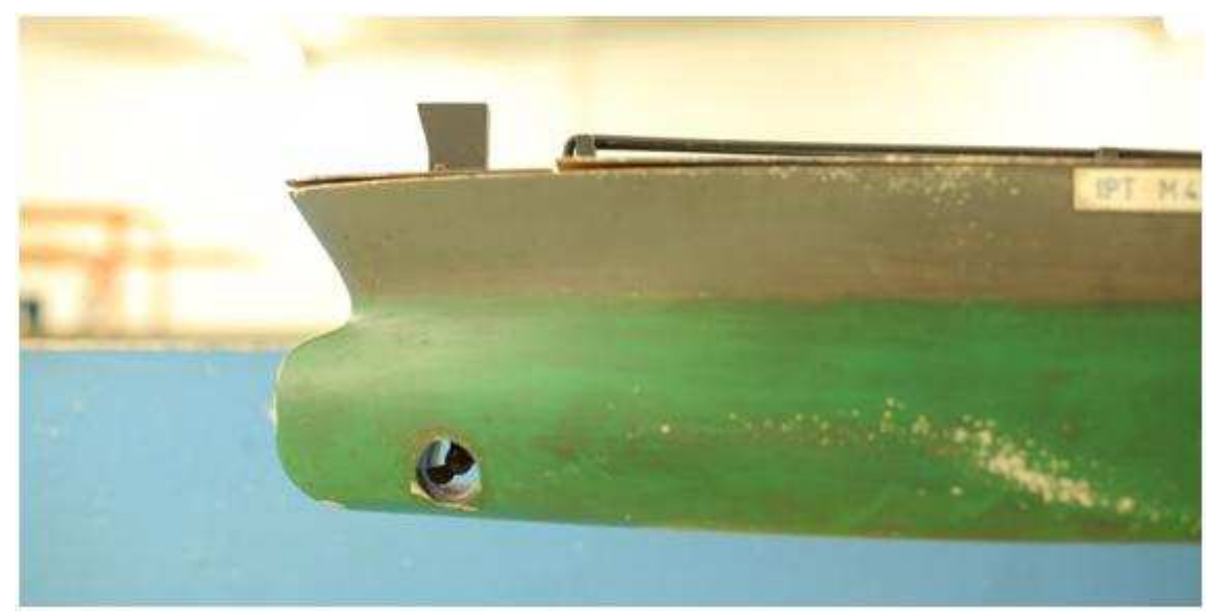

Figura 77 - Propulsor túnel de proa do modelo utilizado durante ensaio

\subsection{Aparato experimental}

Os ensaios experimentais foram realizados no Tanque de Provas Didático do Departamento de Engenharia Naval e Oceânica da Escola Politécnica da USP (Universidade de São Paulo). Na Figura 78 pode-se ver o arranjo experimental completo durante a execução de um dos ensaios. Nesta seção serão detalhados cada um dos equipamentos utilizados bem como a integração dos mesmos. Para um detalhamento completo do laboratório, ver Morishita et al (2009).

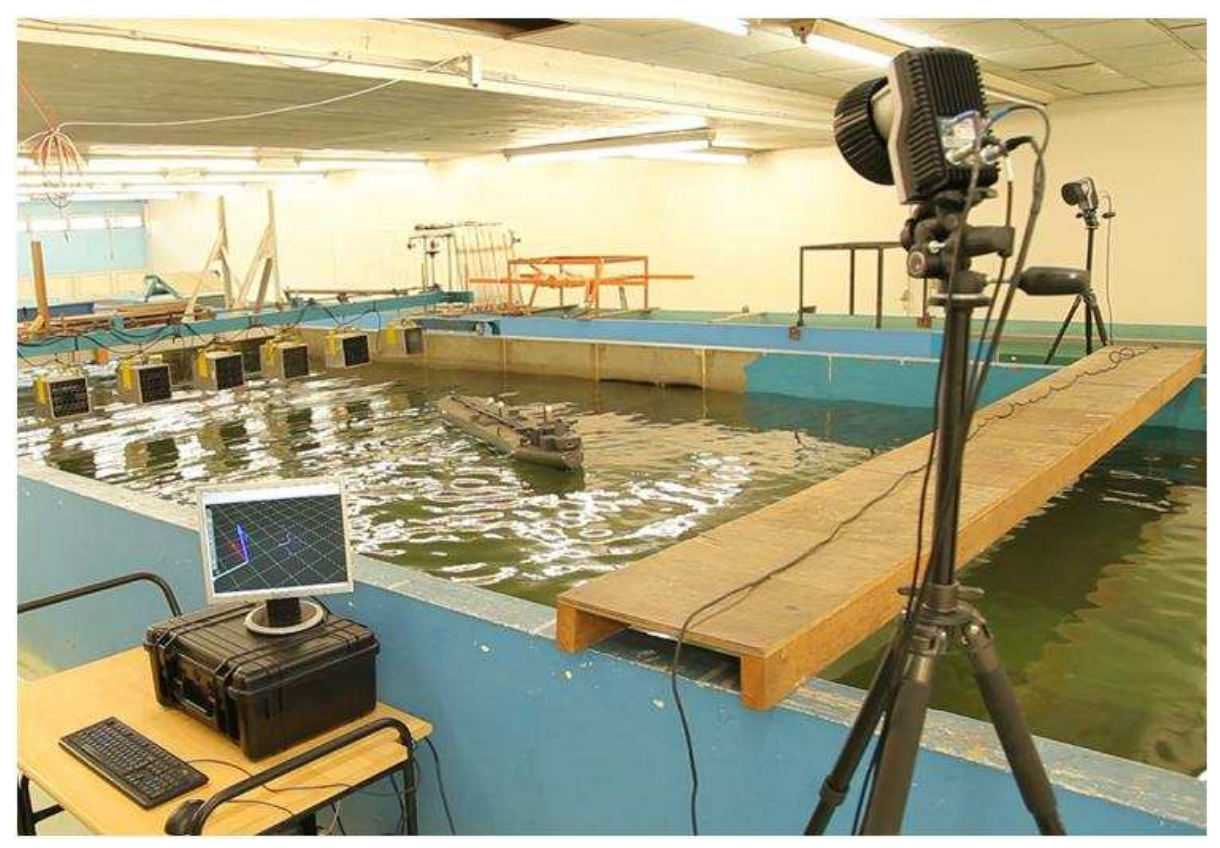

Figura 78 - Montagem completa do aparato experimental utilizado 


\subsubsection{Geração de vento}

O sistema possui sete ventiladores, conforme mostra a Figura 79. Estes ventiladores possuem um duto e sistemas de colmeia fixados a jusante dos mesmos para aumentar a homogeneidade direcional do vento gerado. O sistema está posicionado sobre o tanque e possui regulagem de altura, direção (sempre paralela à superfície do tanque) e magnitude do vento. Desta forma é possível gerar ventos em qualquer direção horizontal e com a velocidade desejada, simulando diversas condições reais, inclusive condições desalinhadas de vento e onda.

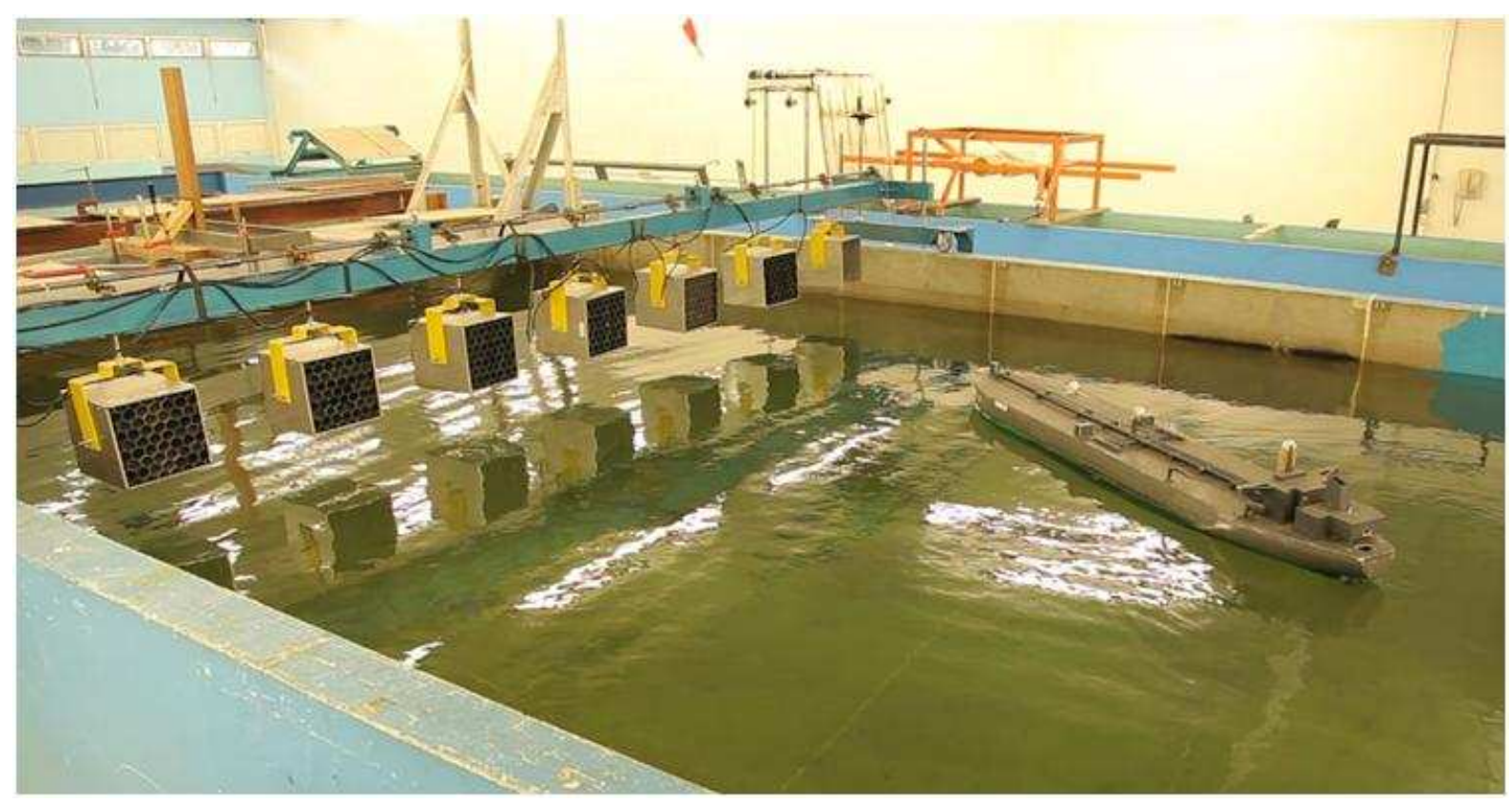

Figura 79 - Geradores de vento instalados no tanque de provas

O detalhe do sistema de ajuste angular do sistema gerador de vento pode ser visto tanto na Figura 80 quanto na Figura 81. Nestas imagens é possível observar que os ventiladores são mantidos paralelos graças a um eixo único que transmite através de engrenagens $90^{\circ}$ o deslocamento angular do eixo motor para o suporte de cada ventilador. 


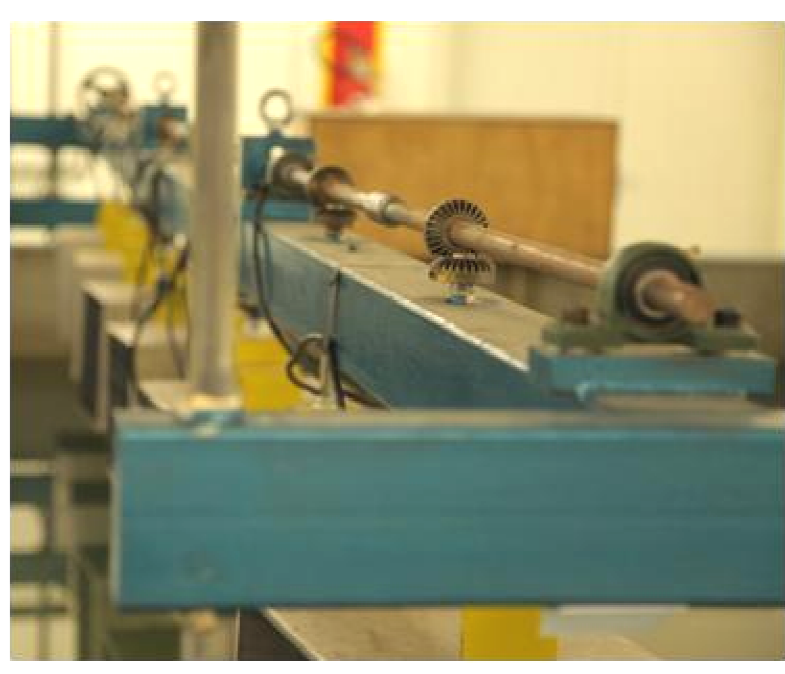

Figura 80 - Detalhe da transmissão de ângulo do sistema de geração de vento

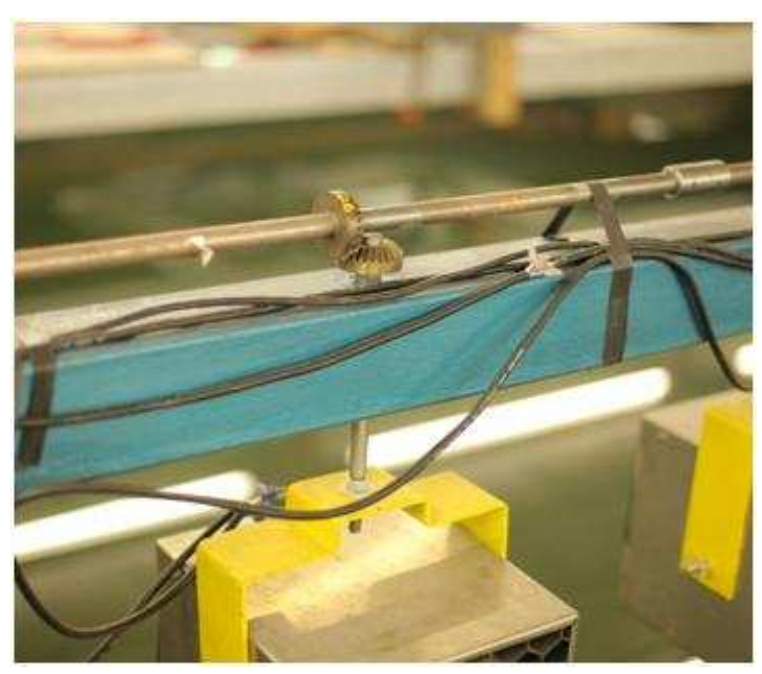

Figura 81 - Transmissão que ajusta o ângulo de cada ventilador

A velocidade do vento gerado pelo sistema decorre do acionamento dos ventiladores ser feito através de um grupo de inversores de frequência. Neste conjunto de acionamento é possível definir diversos parâmetros, como a tensão e a frequência de alimentação do conjunto de ventiladores. Detalhes sobre o sistema de controle do gerador de ventos pode ser encontrado em Parra e Tannuri (2011).

A velocidade média de incidência de vento agindo sobre o navio é calculada empiricamente, encontrando-se qual a velocidade que melhor estima os esforços agentes para determinado casco e aproamento.

\subsubsection{Geração de ondas}

Em uma das extremidades do tanque está localizado o sistema gerador de ondas, que consiste em uma parede móvel (denominada flap), articulada em sua parte inferior, conforme mostra o diagrama apresentado na Figura 82: 


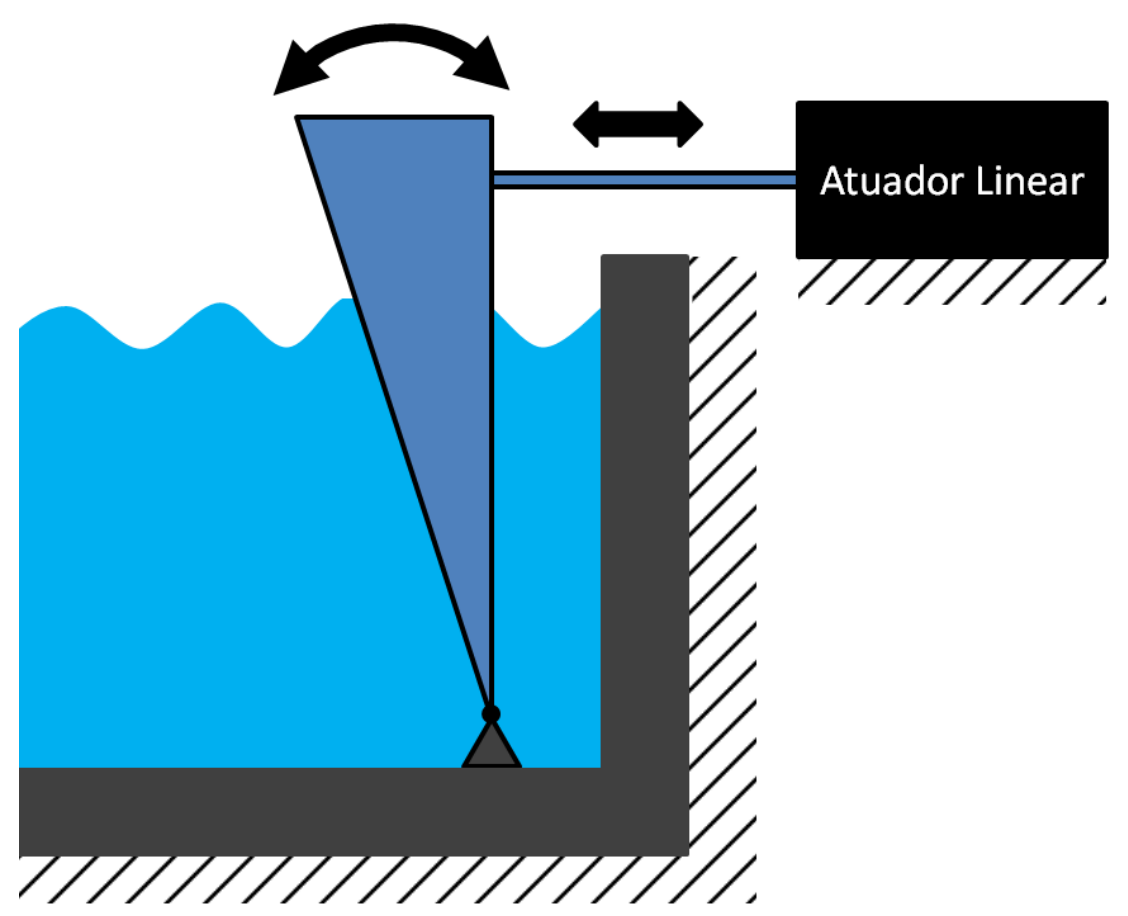

Figura 82 - Diagrama de funcionamento do gerador de ondas

Este flap é acionado por um atuador linear exibido na Figura 83, que possui como referência o sinal gerado por seu controlador analógico. A saída do controlador analógico é composta por um sinal senoidal com período e amplitude controláveis. O controlador responsável pela geração de ondas também está exibido na Figura 83, na parte direita da imagem. 


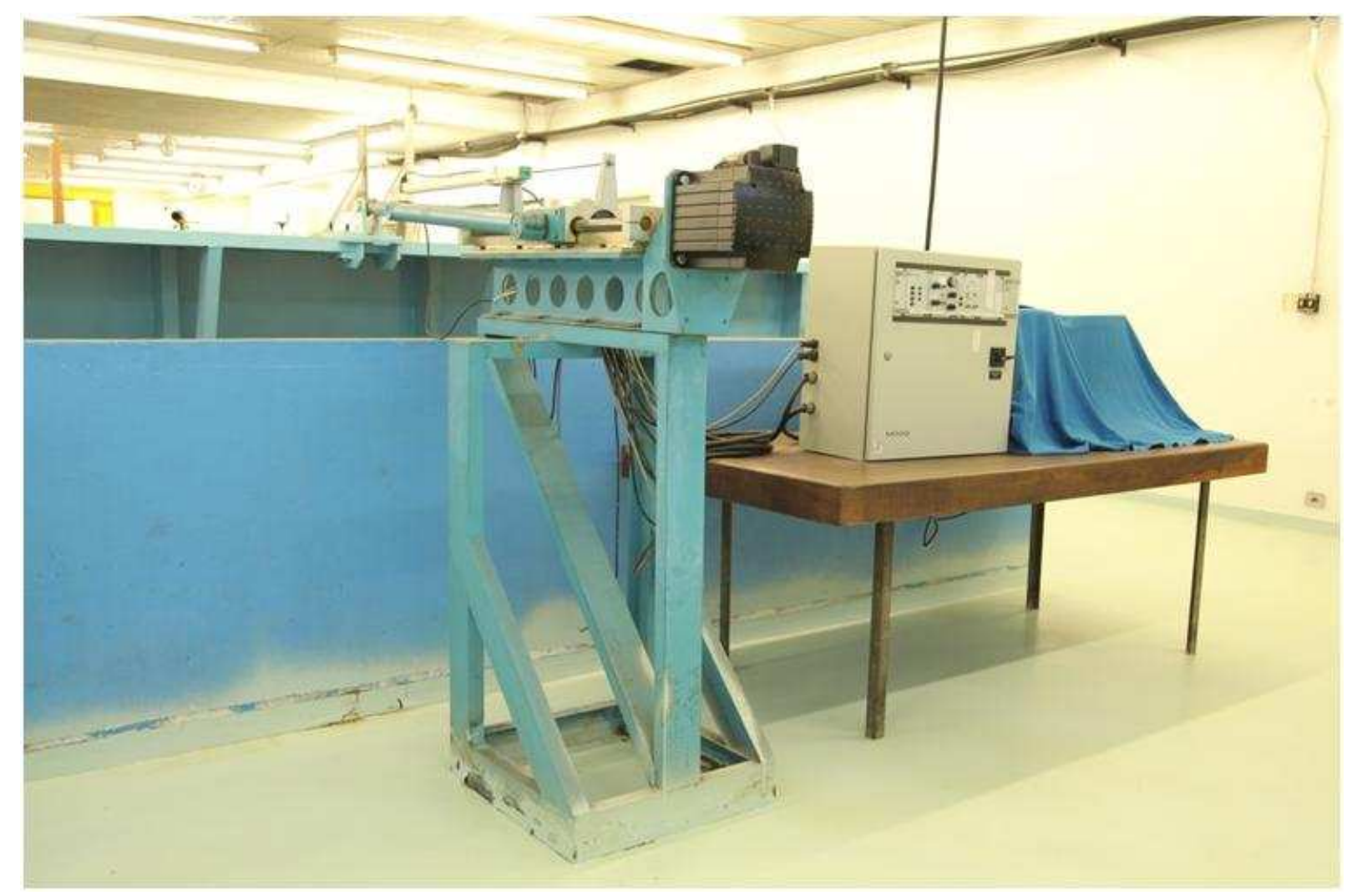

Figura 83 - Atuador e controlador do flap gerador de ondas

O sistema de absorção de ondas é do tipo passivo, sendo constituído por uma praia artificial de madeira.

\subsubsection{Sistema de medição de posição e aproamento}

Para obter a medida de posição e aproamento do navio utilizada pelo Sistema DP foi utilizado o método óptico de rastreamento desenvolvido pela empresa Qualisys.

O sistema óptico é composto por emissores de luz infravermelha (IR - Infra Red) e câmeras com filtros IR, para detecção de pontos reflexivos. O sistema utilizado oferece a solução completa em um único aparelho, com um emissor IR em forma de anel envolvendo a lente da câmera, conforme exibido na Figura 84: 


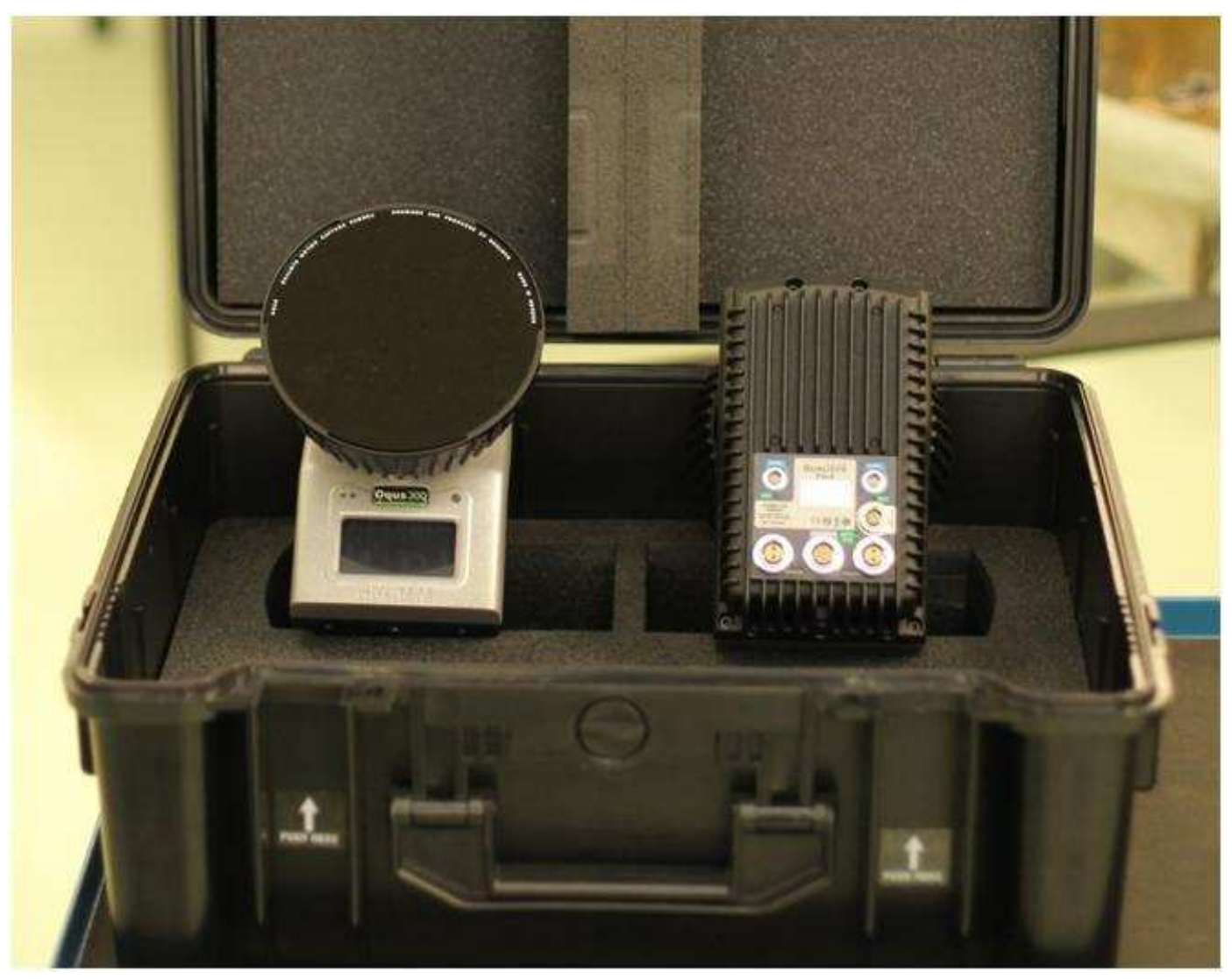

Figura 84 - Câmeras Qualisys utilizadas para detecção da posição do modelo utilizado para ensaios

Em conjunto com as câmeras exibidas na Figura 84, pequenas esferas reflexivas são fixas ao objeto rastreado. Estas esferas (chamadas de alvos) refletem a luz IR emitida pelo gerador de luz IR, sendo exibido como um ponto luminoso software de processamento de imagens. Estas esferas podem ser vistas na Figura 85:

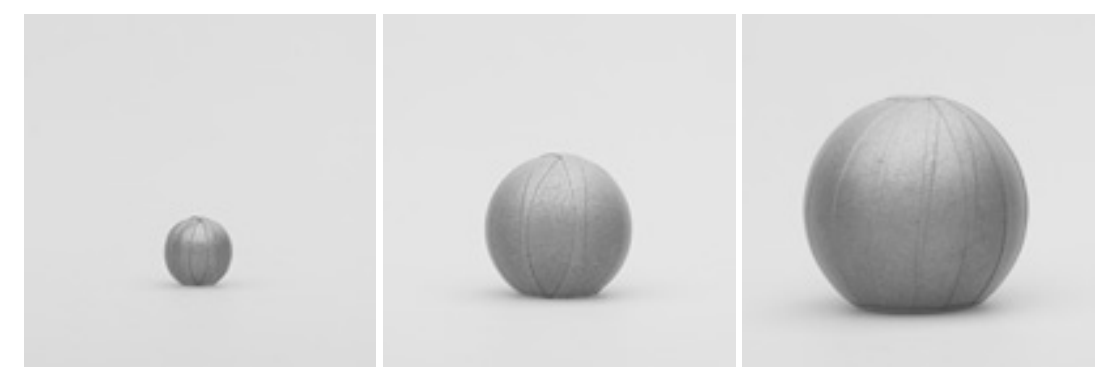

Figura 85 - Alvos reflexivos acoplados ao modelo (disponível em diversos tamanhos)

Ao se colocarem ao menos três alvos em um corpo rígido, é possível rastrear os seis graus de liberdade deste corpo, contanto que ao menos duas câmeras capturem a posição destes três pontos do corpo, conforme mostra a Figura 86. 
Ainda na Figura 86, pode-se visualizar o sistema de rastreamento, que apresenta uma medição em tempo real do navio dentro do tanque de provas físico, onde é possível perceber na tela do computador o rastreamento das três esferas posicionadas no navio. Ao fundo, notam-se os alvos fixos ao corpo.

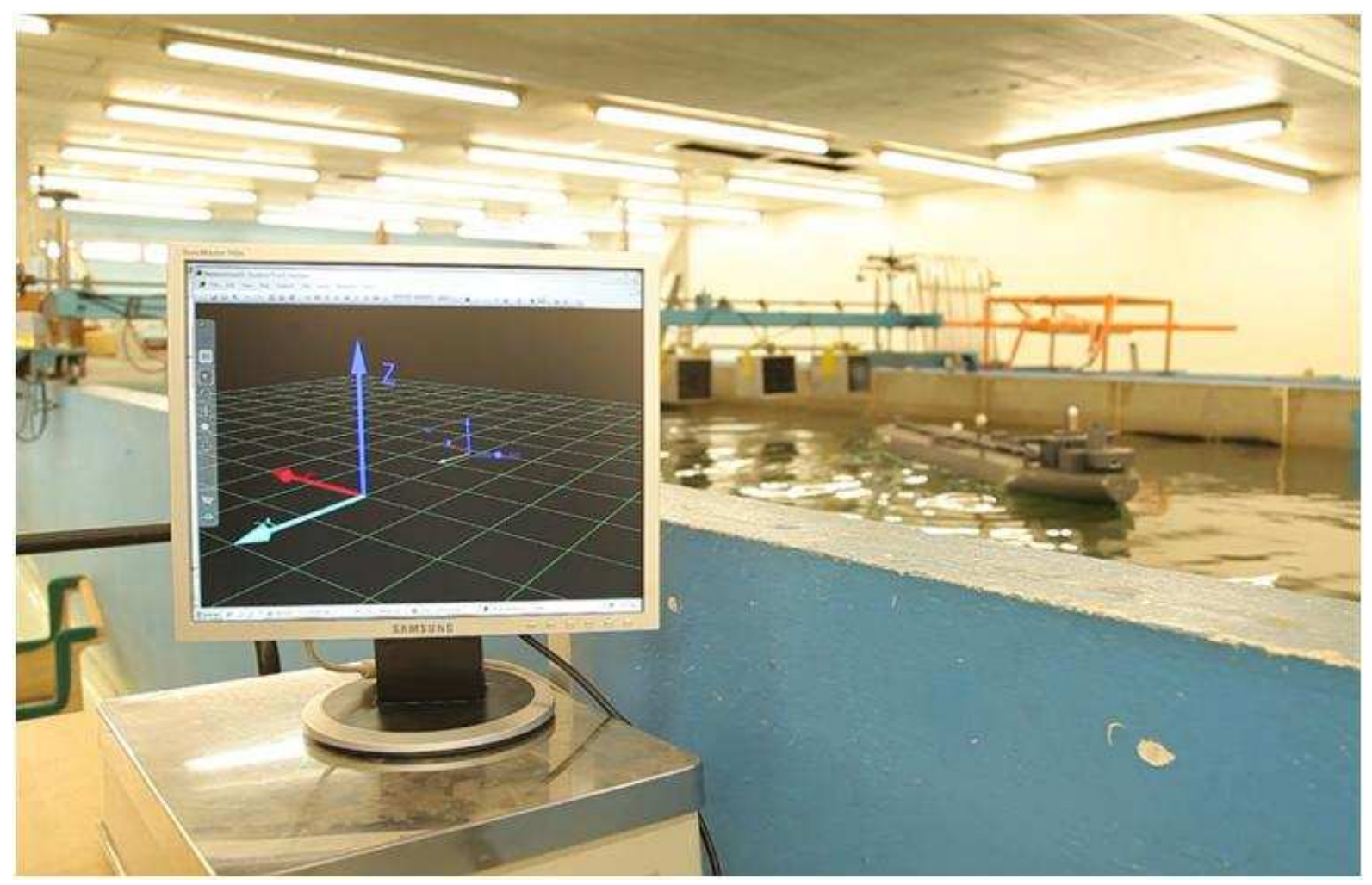

Figura 86 - Sistema rastreando o posicionamento do modelo em tempo real

Os dados de posição e aproamento do navio são enviados para o controlador desenvolvido no Simulink, que atua como o sistema de controle e alocação de empuxo do navio. A arquitetura computacional do sistema de comunicação e controle é apresentada em Tannuri et. al. (2008).

\subsubsection{Sistema de controle}

O controlador implementado durante as simulações é composto por três controladores PID desacoplados, um para grau de liberdade horizontal: movimento longitudinal, lateral e aproamento. Os três controladores são desacoplados, e seu diagrama pode ser visto na Figura 34. Além do controlador PID desacoplado utilizado como base, também foi inserida a lei de adaptação para aproamento automático, de acordo com as condições ambientais incidentes, seguindo a formulação apresentada na equação (36). 
Além do cálculo dos esforços que devem ser aplicados em cada grau de liberdade do navio, o sistema desenvolvido (em linguagem Matab/Simulink) também é responsável por alocar a propulsão no conjunto de propulsores presentes no modelo. A lógica de alocação de propulsão neste caso específico é bem simples, pois o navio possui apenas dois propulsores tipo túnel (um fixo na popa e outro fixo na proa) e um propulsor principal, conforme exibido na . Como não há leme neste modelo, o sistema possui apenas três variáveis de controle (forças nos três graus de liberdade controlados) e 3 atuadores, a solução da alocação de propulsão é única, e desta forma não é necessário realizar minimização de consumo do Sistema DP em função da alocação de propulsão, e sim uma simples solução de sistema algébrico.

\subsubsection{Comunicação}

Para o controle do navio, uma conexão via radio frequência (RF) é estabelecida, com os módulos de comunicação exibidos nas figuras Figura 87 e Figura 88:

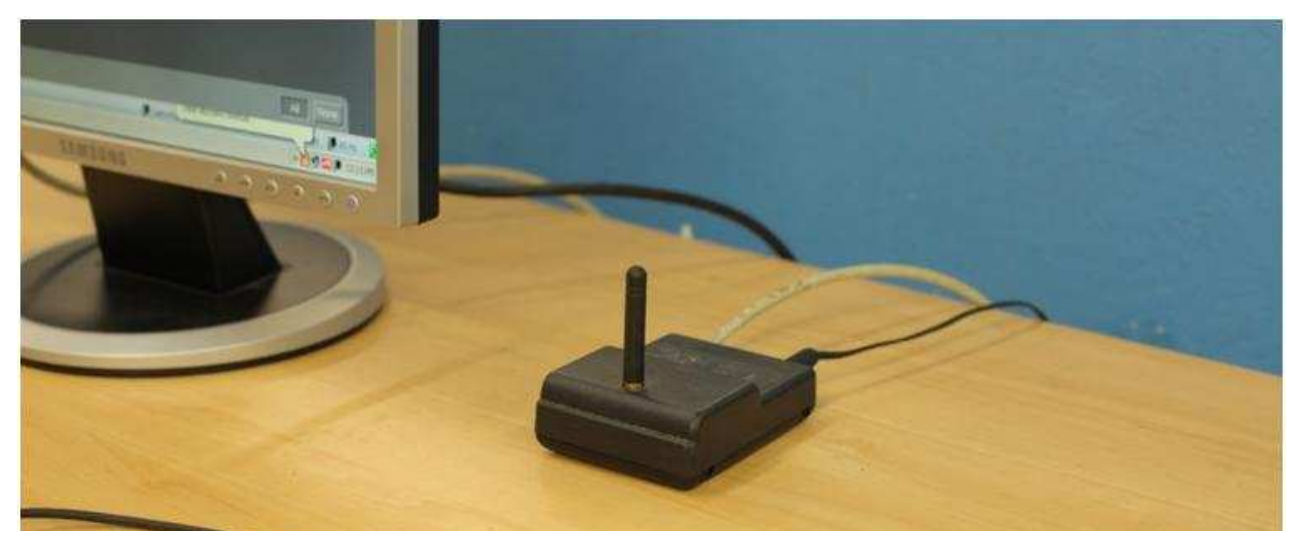

Figura 87 - Módulo RF conectado ao computador 


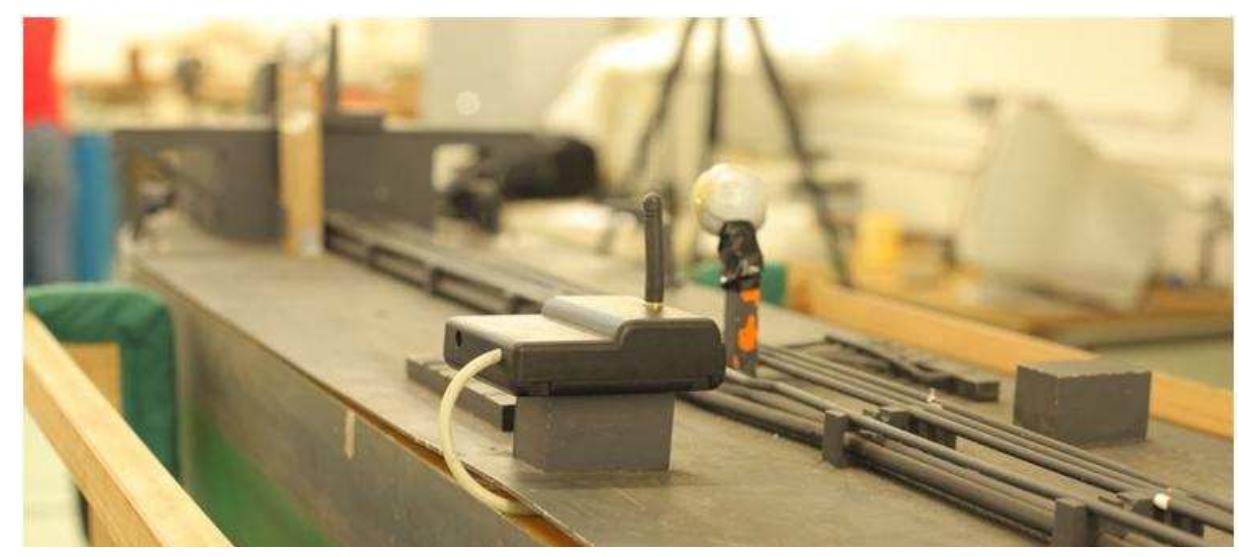

Figura 88 - Módulo RF conectado ao modelo

O módulo exibido na Figura 87 está conectado à porta serial do computador, e se comunica diretamente com a malha de controle em execução no computador principal, que envia a rotação desejada de cada propulsor a $10 \mathrm{~Hz}$.

\subsection{Descrição dos testes}

Serão descrito cinco testes nesta seção, nos quais diversos parâmetros puderam ser analisados, como variação da resposta para diferentes pontos de controle, ou mesmo resposta à condição ambiental variável.

A Tabela 11 resume as condições em que cada ensaio foi conduzido:

Tabela 11 - Condições de ensaio dos cinco casos

\begin{tabular}{|c|c|c|c|c|c|c|}
\hline Caso & $\begin{array}{l}\text { Ponto de } \\
\text { controle }\end{array}$ & $\begin{array}{l}\text { Direção de } \\
\text { vento }\end{array}$ & $\begin{array}{c}\text { Intensidade do } \\
\text { vento }\end{array}$ & $\begin{array}{l}\text { Direção de } \\
\text { onda }\end{array}$ & $\begin{array}{c}\text { Amplitude da } \\
\text { onda }\end{array}$ & $\begin{array}{l}\text { Período da } \\
\text { onda }\end{array}$ \\
\hline Condição 1 & Meia nau & Sul (indo para) & $30 \mathrm{~m} / \mathrm{s}$ & $\begin{array}{c}\text { Norte } \\
\text { (vindo de) } \\
\text { Norte }\end{array}$ & Não medido & $7.5 \mathrm{~s}$ \\
\hline Condição 2 & Proa & Sul (indo para) & $30 \mathrm{~m} / \mathrm{s}$ & $\begin{array}{l}\text { (vindo de) } \\
\text { Norte }\end{array}$ & Não medido & $7.5 \mathrm{~s}$ \\
\hline Condição 3 & Lateral & Sul (indo para) & $30 \mathrm{~m} / \mathrm{s}$ & $\begin{array}{l}\text { (vindo de) } \\
\text { Norte }\end{array}$ & Não medido & $7.5 \mathrm{~s}$ \\
\hline Condição 4 & Рopa & Sul (indo para) & $30 \mathrm{~m} / \mathrm{s}$ & $\begin{array}{l}\text { (vindo de) } \\
\text { Norte }\end{array}$ & Não medido & $7.5 \mathrm{~s}$ \\
\hline Condição 5 & Meia nau & Sul (indo para) & $30 \mathrm{~m} / \mathrm{s}$ & (vindo de) & 0 & $7.5 \mathrm{~s}$ \\
\hline
\end{tabular}

A velocidade de vento utilizada durante os ensaios é de $30 \mathrm{~m} / \mathrm{s}$, enquanto velocidades típicas médias de águas brasileiras variam entre $8 \mathrm{~m} / \mathrm{s}$ e $20 \mathrm{~m} / \mathrm{s}$ de acordo com a estação do ano segundo, conforme estudo de Sphaier. 
Os ensaios utilizaram velocidade superior de vento para ressaltar o efeito do weathervane e compensar a falta de correnteza.

Cada simulação está dividida em dois intervalos distintos:

- O intervalo inicial do ensaio serve para que erros de posicionamento sejam eliminados e que o controlador entre em estado de equilíbrio. Neste intervalo, o ganho adaptativo $K_{i n t}$ é nulo, e desta forma, o sistema atua como um navio com Sistema DP convencional.

- A partir de um determinado instante de tempo, após a estabilização do sistema, a lei de adaptação do Sistema DP é ativada, e o controlador busca o aproamento ótimo.

Todos os casos se iniciam com desalinhamento de $30^{\circ}$ entre o set-point do Sistema DP e o aproamento de weathervane.

Como fator de desempenho $(Q)$, será utilizada apenas a influência dos propulsores tipo túnel, pois devido a não-linearidades presentes no modelo ensaiado.

Devido à presença de ruídos na leitura do propulsor principal, a influência deste sobre $o$ fator de desempenho foi desconsiderada para facilitar a visualização dos resultados. A Figura 89 exemplifica os resultados levando em conta o propulsor principal, e desconsiderando-o.

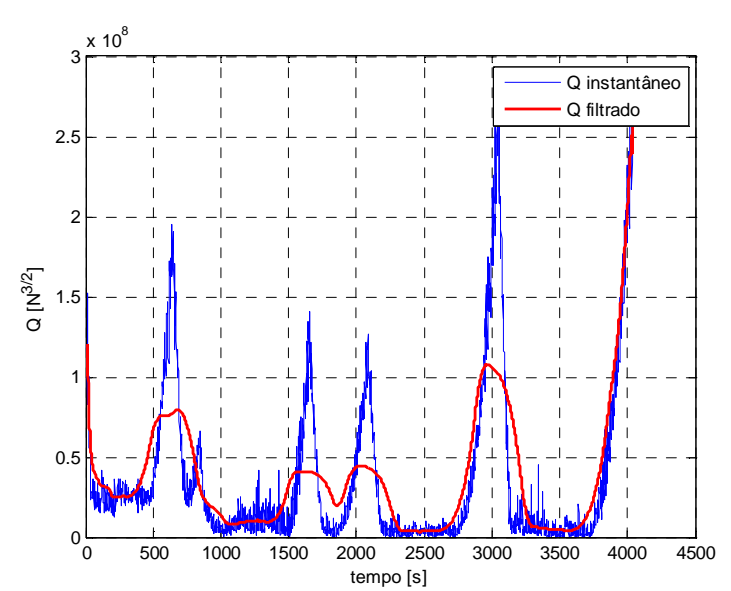

(a)

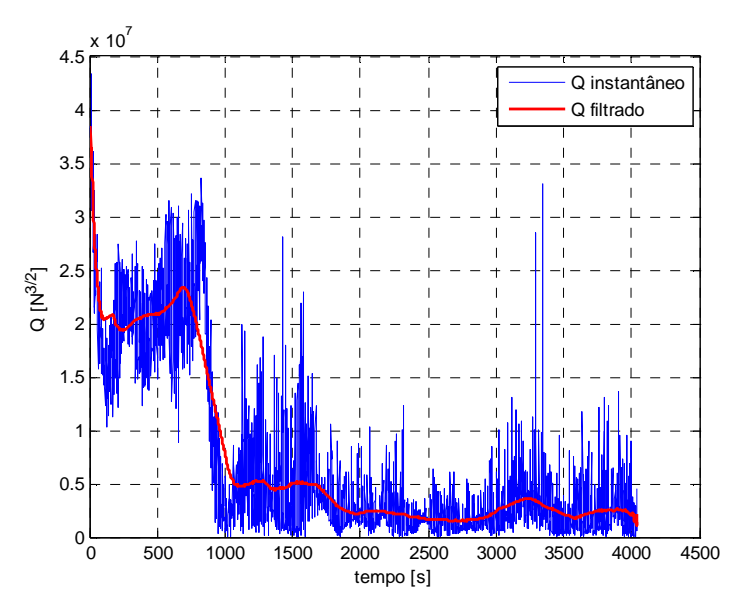

(b)

Figura 89 - Utilização do sistema propulsor (a) considerando propulsor principal

(b) desconsiderando propulsor principal 


\subsection{Resultados}

\subsubsection{Caso 1}

O primeiro caso apresenta condições incidentes alinhadas com o tanque de provas, constantes ao longo do tempo, e incidindo pela direção norte. O ponto de controle do navio está posicionado à meia nau.

A primeira etapa do experimento, até aproximadamente 750 s, consiste no período para o Sistema DP estabilizar o navio, no qual o ganho adaptativo foi mantido nulo. Após 750s, o ganho adaptativo é ativado, com $K_{i n t}=1.37 \times 10^{-6} \frac{\mathrm{rad}}{\mathrm{kNs}}$. 


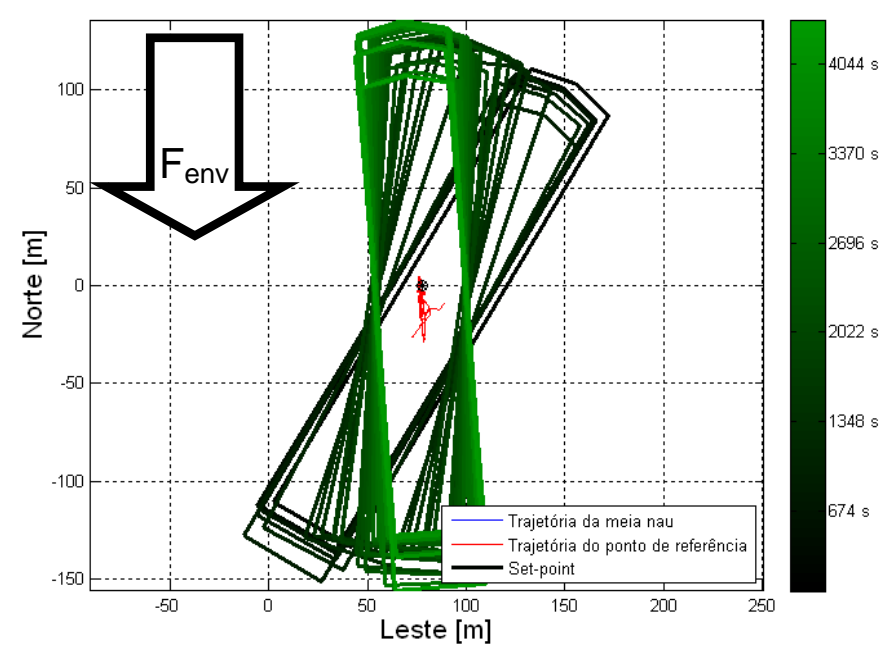

Figura 90 - Ensaio 1 - Posicionamento do navio ao longo do tempo
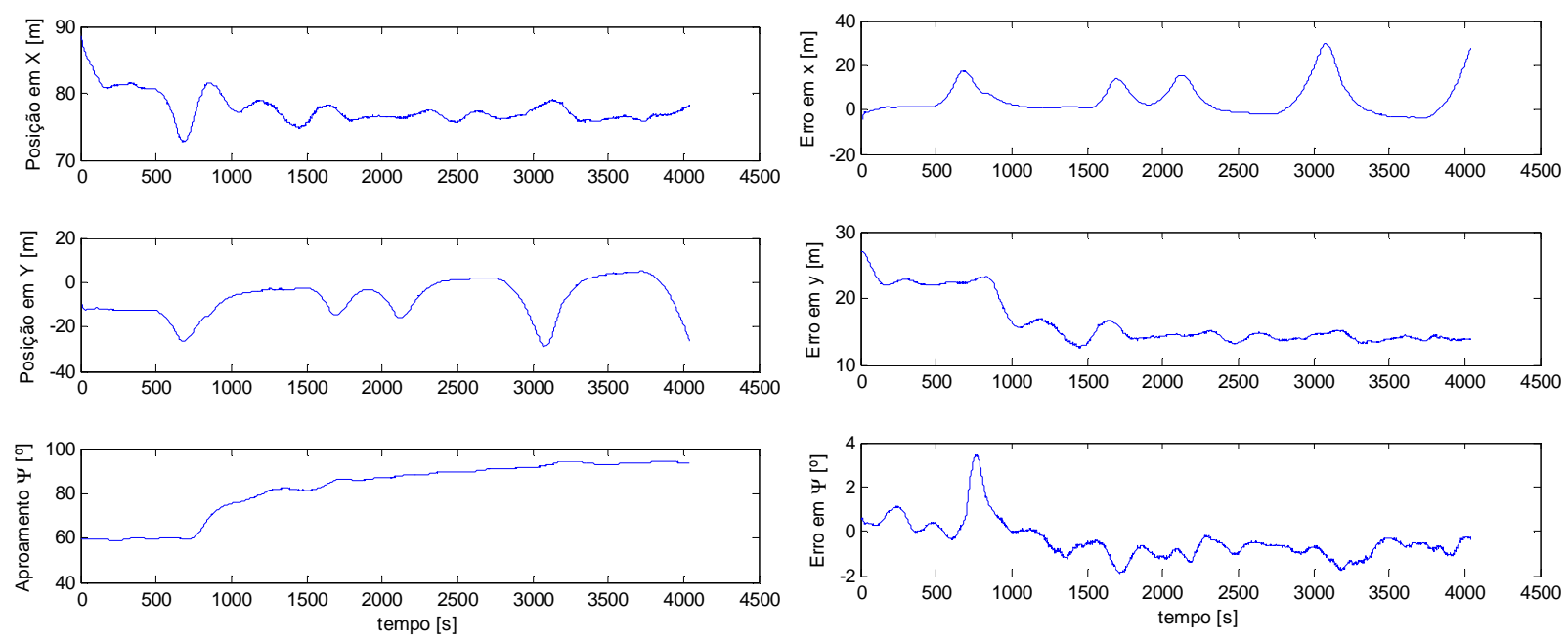

Figura 91 - Posição e aproamento

Figura 92 - Erro do Sistema DP
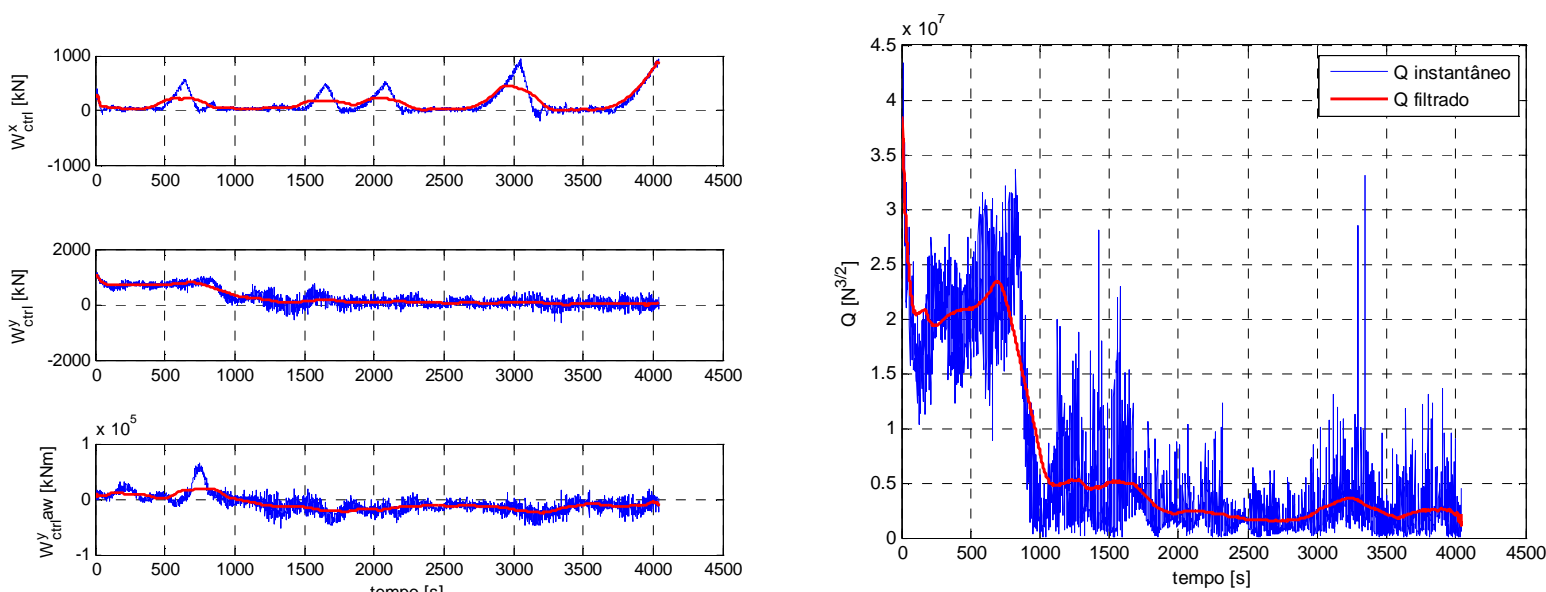

Figura 93 - Esforços de controle

Figura 94 - Consumo total de potência 
Verifica-se na Figura 91 a mudança do aproamento do navio ao longo do tempo, buscando automaticamente o aproamento ideal, que neste caso é facilmente definido como o alinhamento com as condições ambientais (90\%). Analisando os resultados exibidos na Figura 93 e na Figura 94, é possível notar como o consumo de potência do navio está diretamente ligado ao seu aproamento.

A Figura 93 apresenta a queda dos esforços laterais de controle em função do aproamento, alinhado com condições ambientais incidentes e consequentemente levado à menor requisição de potência. Os esforços de controle nos outros dois graus de liberdade controlados permanece, em média, praticamente constante ao longo do tempo.

A única causa de aumento nos esforços de controle de aproamento é decorrente da variação do set-point do aproamento, porém após entrar em regime, com pouca ou nula variação no aproamento, os esforços em yaw voltam ao patamar inicial, ao final do teste. Nota-se também um problema detectado posteriormente no propulsor principal que causa aumentos repentinos do erro e do esfoço de controle na direção longitudinal. Este problema, entretanto, não invalida os resultados que permitem inferir a efetividade do controle proposto em termos de redução dos níveis de consumo.

Pela Figura 94 é possível notar que logo ao iniciar o processo de weathervaning, há aumento temporário da utilização do Sistema DP, seguida por uma queda brusca em sua utilização média.

\subsubsection{Caso 2}

O segundo caso analisado consiste no controle da proa do navio, também com condições incidentes alinhadas e constantes ao longo do tempo, provindo da direção norte.

O ponto de controle se localiza a $187 \mathrm{~m}$ da meia nau, ou seja, $56 \mathrm{~m}$ a frente da proa do navio.

A primeira etapa do experimento, até aproximadamente 2000s, consiste no período para o Sistema DP estabilizar o navio, no qual o ganho adaptativo foi mantido nulo. Após 2000s, o ganho adaptativo é ativado, com $K_{\text {int }}=9.13 \times 10^{-7} \frac{\mathrm{rad}}{\mathrm{kNs}}$. 


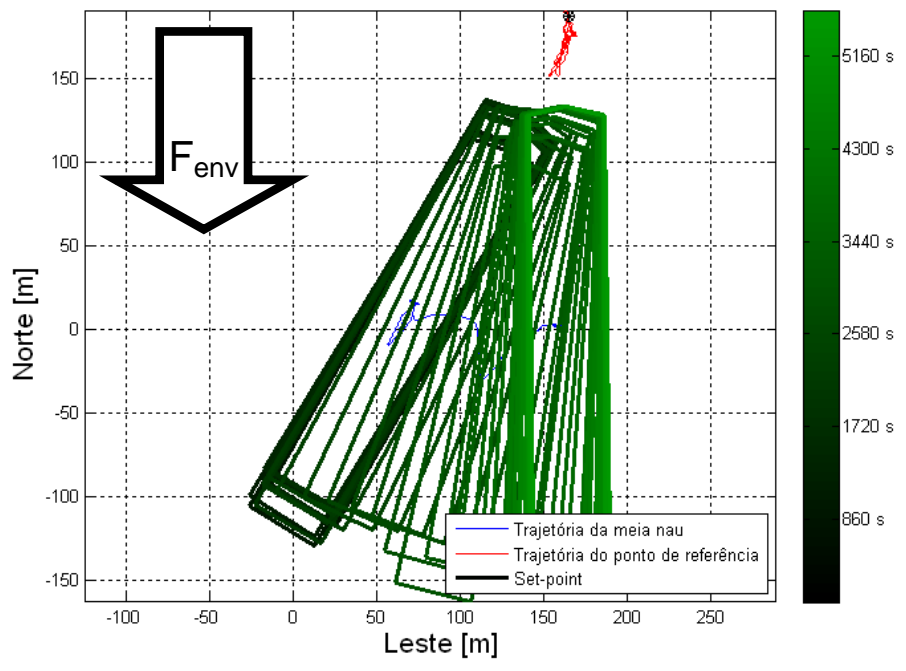

Figura 95 - Ensaio 2 - Posicionamento do navio ao longo do tempo
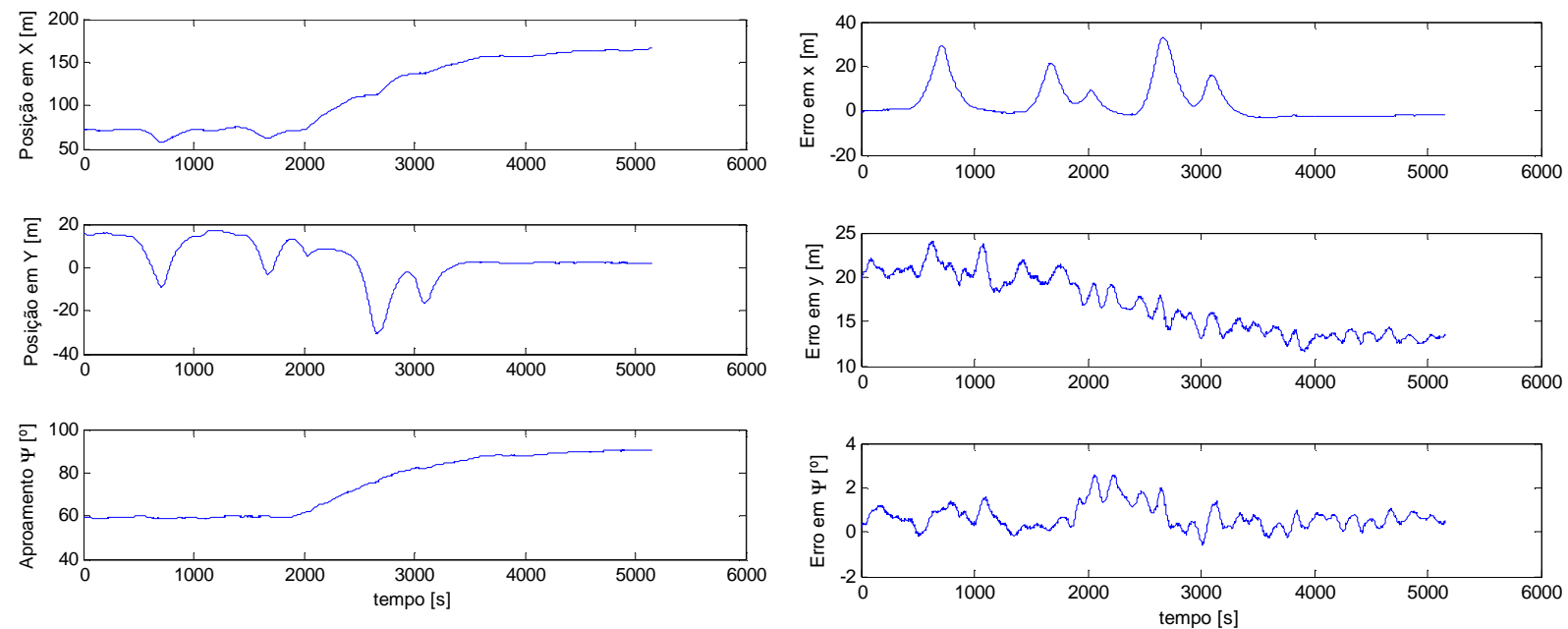

Figura 96 - Posição e aproamento
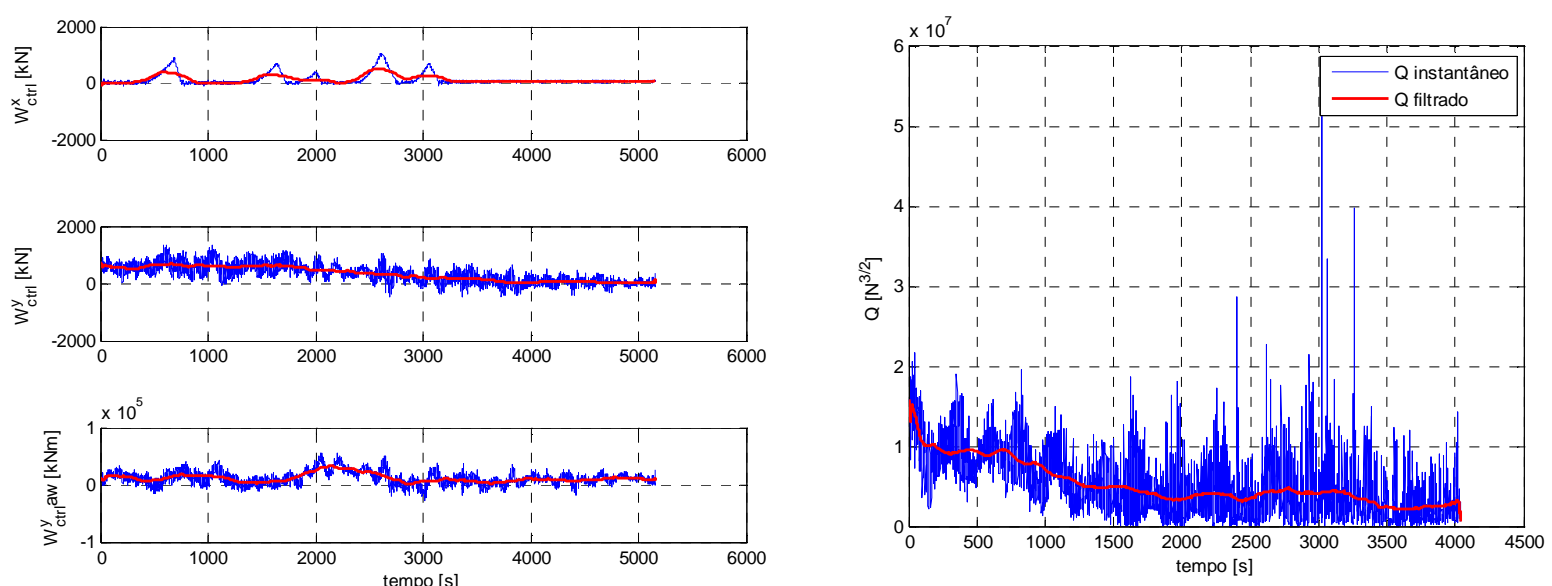

Figura 98 - Esforços de controle

Figura 99 - Consumo total de potência 
As mesmas conclusões do caso anterior podem ser obtidas pela análise dos resultados apresentados para o controle do ponto de proa.

Pela Figura 99, diferentemente do caso 1 simulado (controle de meia nau), nota-se uma queda suave da utilização do Sistema DP após a ativação do controle weathervane. Isto decorre pois o ganho de adaptação $K_{\text {int }}$ utilizado é menor do que no caso anterior.

Em teoria, é possível utilizar qualquer ganho $K_{\text {int }}$, desde que este seja inferior ao valor definido pela equação (46). Na realidade, por outro lado, devido às limitações de potência dos propulsores, que consequentemente saturam a saída do Sistema DP, não é possível manter o posicionamento para ganhos elevados.

\subsubsection{Caso 3}

Outro caso interessante é o controle de um ponto ao lado do navio, a $50 \mathrm{~m}$ da meia nau do navio, ou seja, a aproximadamente $27 \mathrm{~m}$ da lateral do navio. As condições ambientais incidentes estão alinhadas, vindo da direção norte e são constantes ao longo do tempo.

A primeira etapa do experimento, até aproximadamente $800 \mathrm{~s}$, consiste no período para o Sistema DP estabilizar o navio, no qual o ganho adaptativo foi mantido nulo. Após $800 \mathrm{~s}$, o ganho adaptativo é ativado, com $K_{\text {int }}=9.13 \times 10^{-7} \frac{\mathrm{rad}}{\mathrm{kNs}}$. 


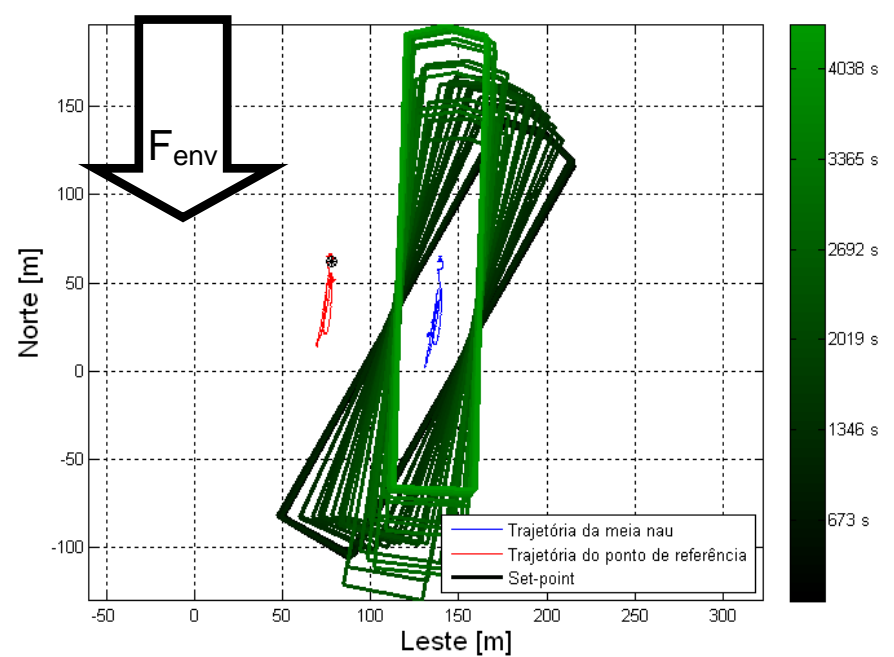

Figura 100 - Ensaio 3 - Posicionamento do navio ao longo do tempo
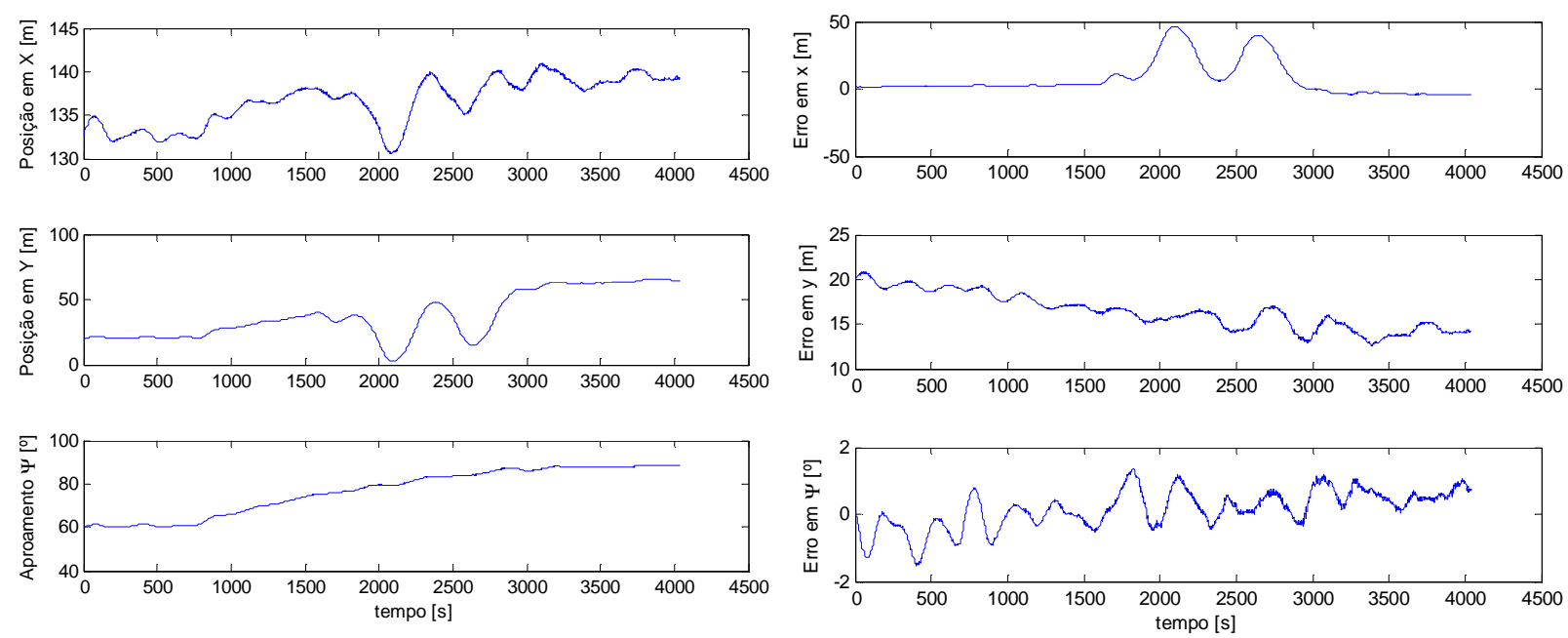

Figura 101 - Posição e aproamento

Figura 102 - Erro do Sistema DP
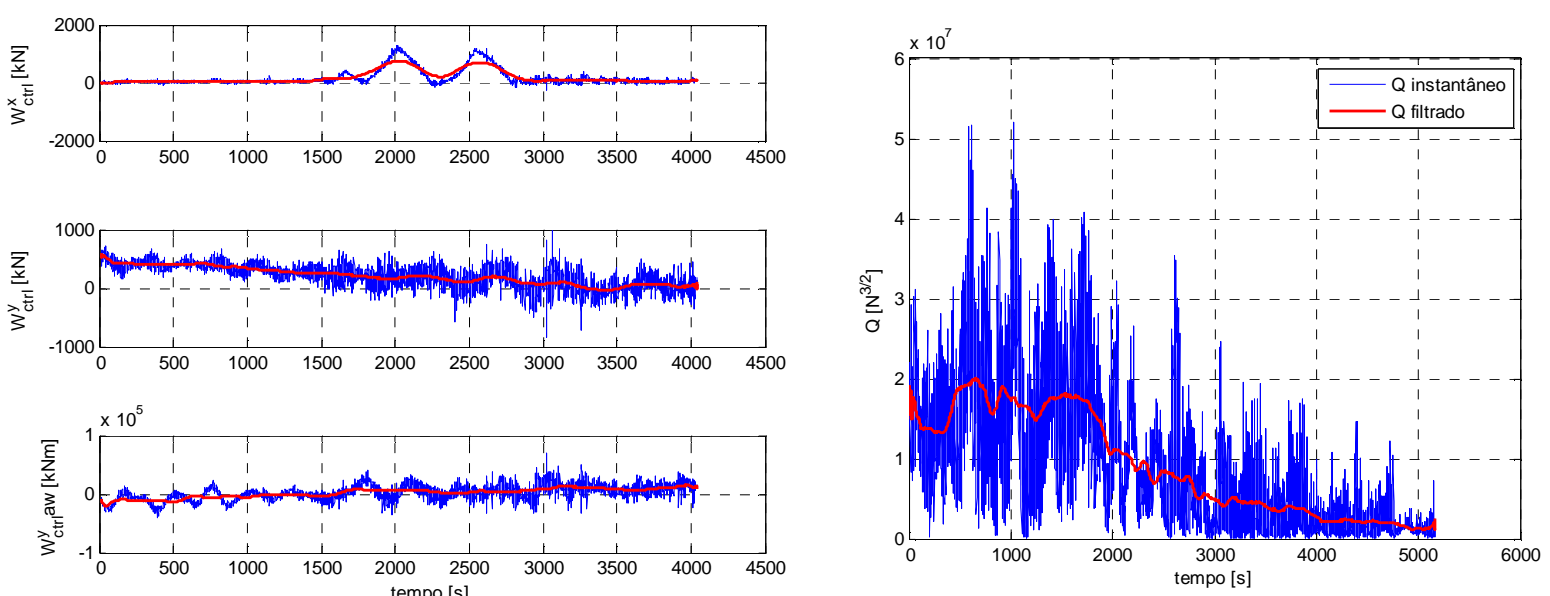

Figura 103 - Esforços de controle

Figura 104 - Consumo total de potência 
Novamente, o bom desempenho do controlador em termos de redução de potência pode ser atestado pelas figuras anteriores, destacando-se que o giro em torno do ponto de controle. O problema do propulso principal é o responsável pelos erros de posicionamento identificados entre 2000 s e 3000 s na direção longitudinal.

\subsubsection{Caso 4}

O quarto caso simulado consiste no controle da popa do navio

As condições ambientais são constantes ao longo do tempo, e incidindo da direção norte.

A primeira etapa do experimento, até aproximadamente $750 \mathrm{~s}$, consiste no período para o Sistema DP estabilizar o navio, no qual o ganho adaptativo foi mantido nulo. Após 750s, o ganho adaptativo é ativado, com $K_{i n t}=4.56 \times 10^{-7} \frac{\mathrm{rad}}{\mathrm{kNs}}$. 


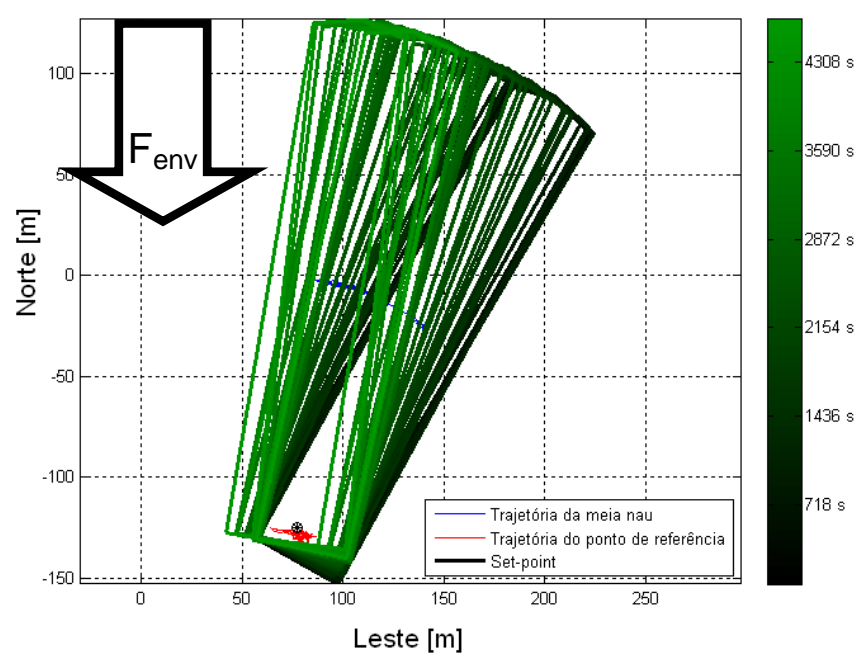

Figura 105 - Ensaio 4 - Posicionamento do navio ao longo do tempo
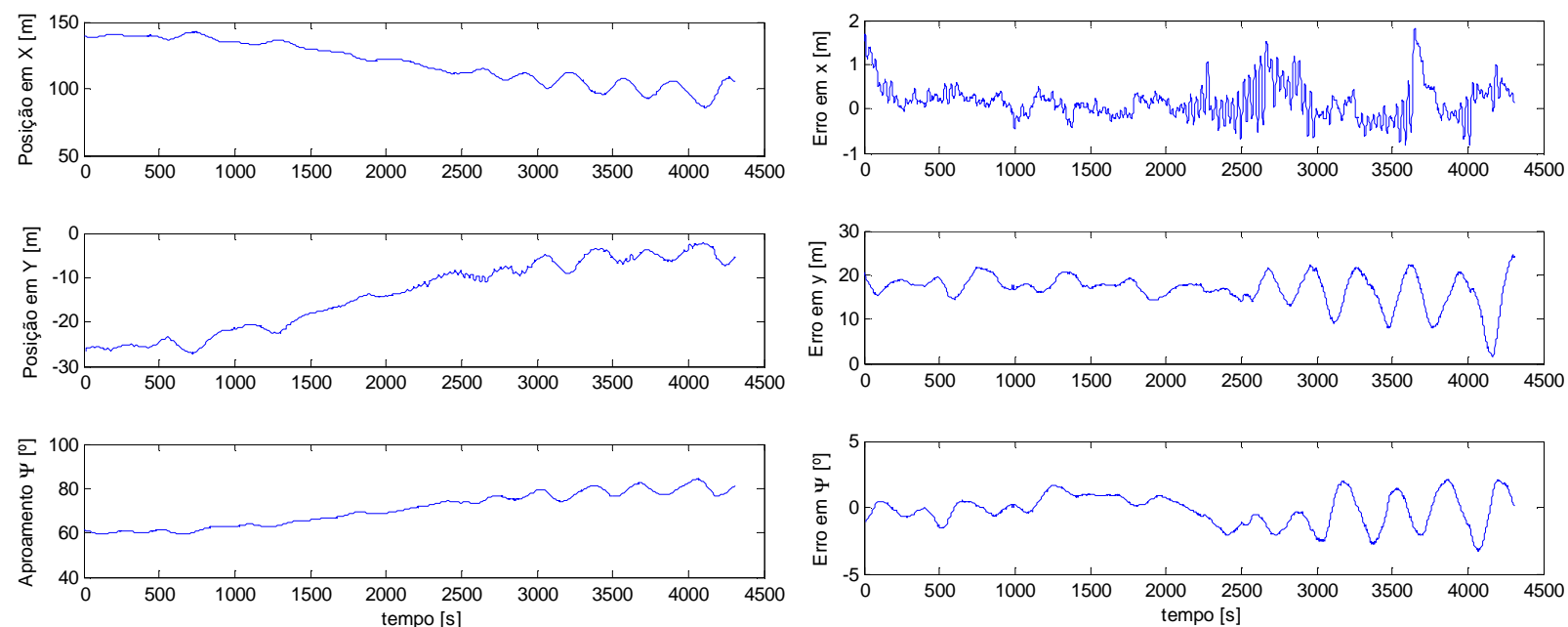

Figura 106 - Posição e aproamento

Figura 107 - Erro do Sistema DP
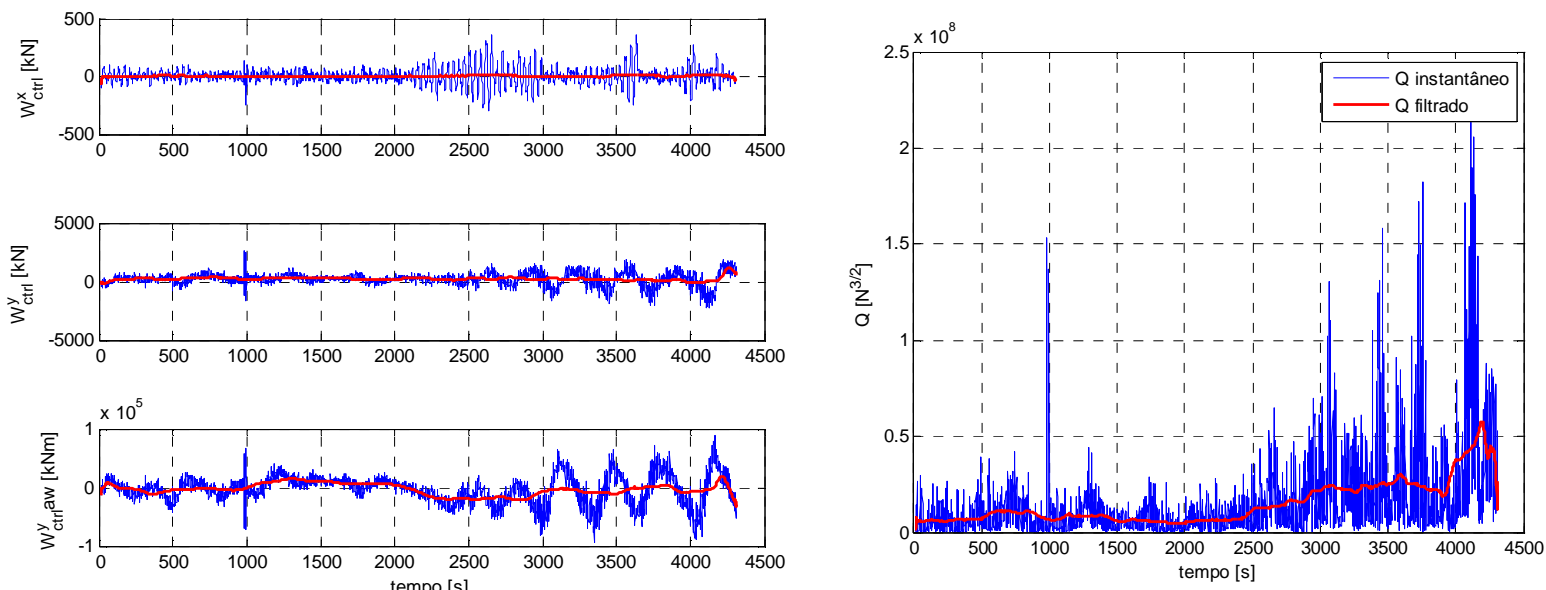

Figura 108 - Esforços de controle

Figura 109 - Consumo total de potência 
O controle da popa do navio, diferentemente dos outros casos estudados, é intrinsecamente instável, apresentando oscilações de grande amplitude e sendo necessário um ajuste muito mais preciso do controlador para resultados satisfatórios, mesmo com o controlador weathervane desligado.

Não foi possível verificar neste caso se o controlador instabiliza o sistema ou não, porém é possível notar que mesmo com oscilações, o aproamento está limitado dentro de uma faixa e o posicionamento do ponto de controle é satisfatório.

\subsubsection{Caso 5}

Este caso, similar ao primeiro caso simulado, porém sem incidência de ondas e com vento com direção variável. O vento, que inicialmente incide vindo da direção norte, e é rotacionado aproximadamente $30^{\circ}$ no sentido horário, depois para $30^{\circ}$ no sentido anti-horário (em relação ao norte). O ângulo de giro do vento não pôde ser medido com precisão devido ao aparato experimental utilizado, porém visualmente é possível estimar o ângulo entre o tanque de provas e o duto dos geradores de vento.

As mudanças de direção de vento ocorrem nos instantes $t=2500 \mathrm{~s}$ e $t=3800 s$

A primeira etapa do experimento, até aproximadamente $1000 \mathrm{~s}$, consiste no período para o Sistema DP estabilizar o navio, no qual o ganho adaptativo foi mantido constante e igual a zero. Após 1000s, o ganho adaptativo é ativado, com $K_{\text {int }}=1.37 \times 10^{-6} \frac{\mathrm{rad}}{\mathrm{kNs}}$. 


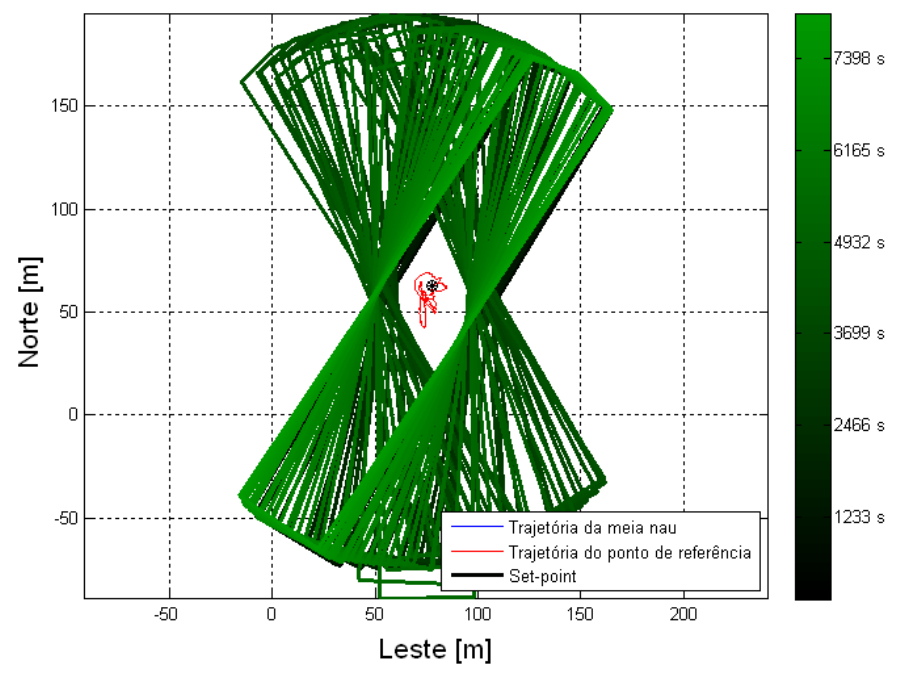

Figura 110 - Ensaio 5 - Posicionamento do navio ao longo
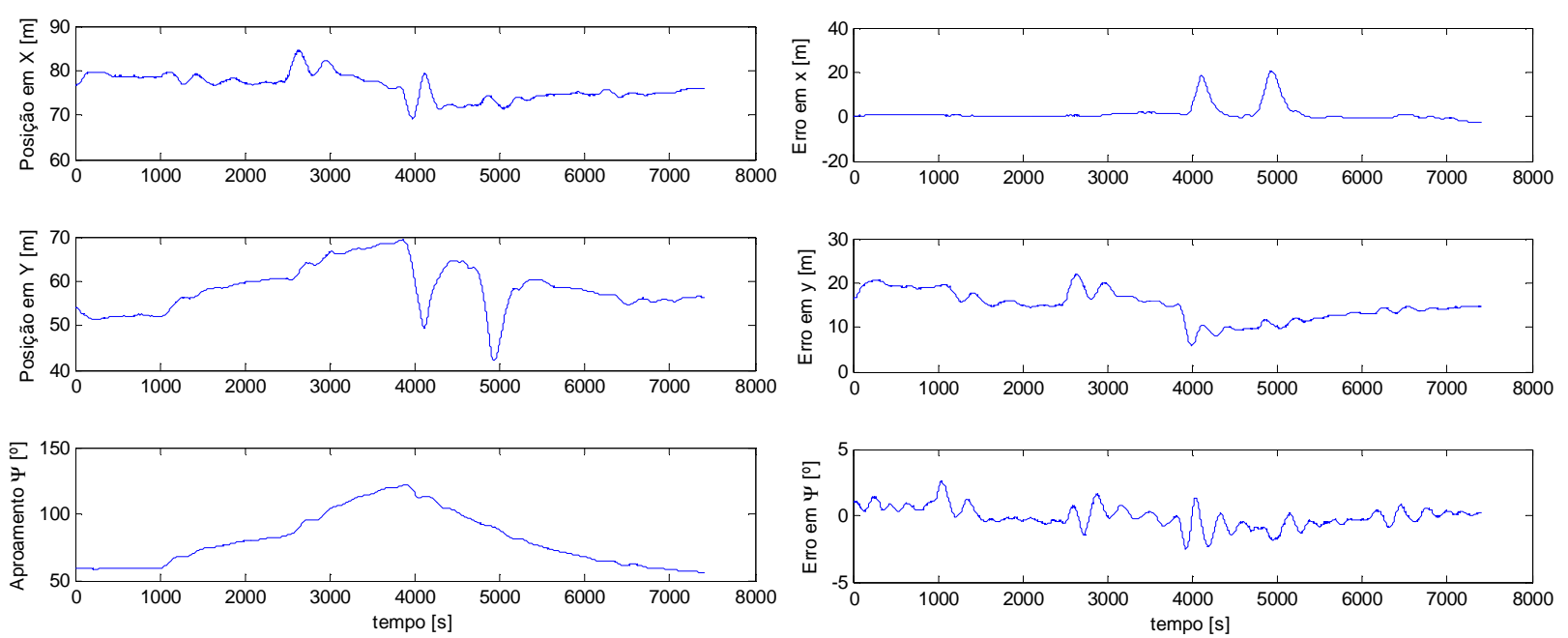

Figura 111 - Posição e aproamento
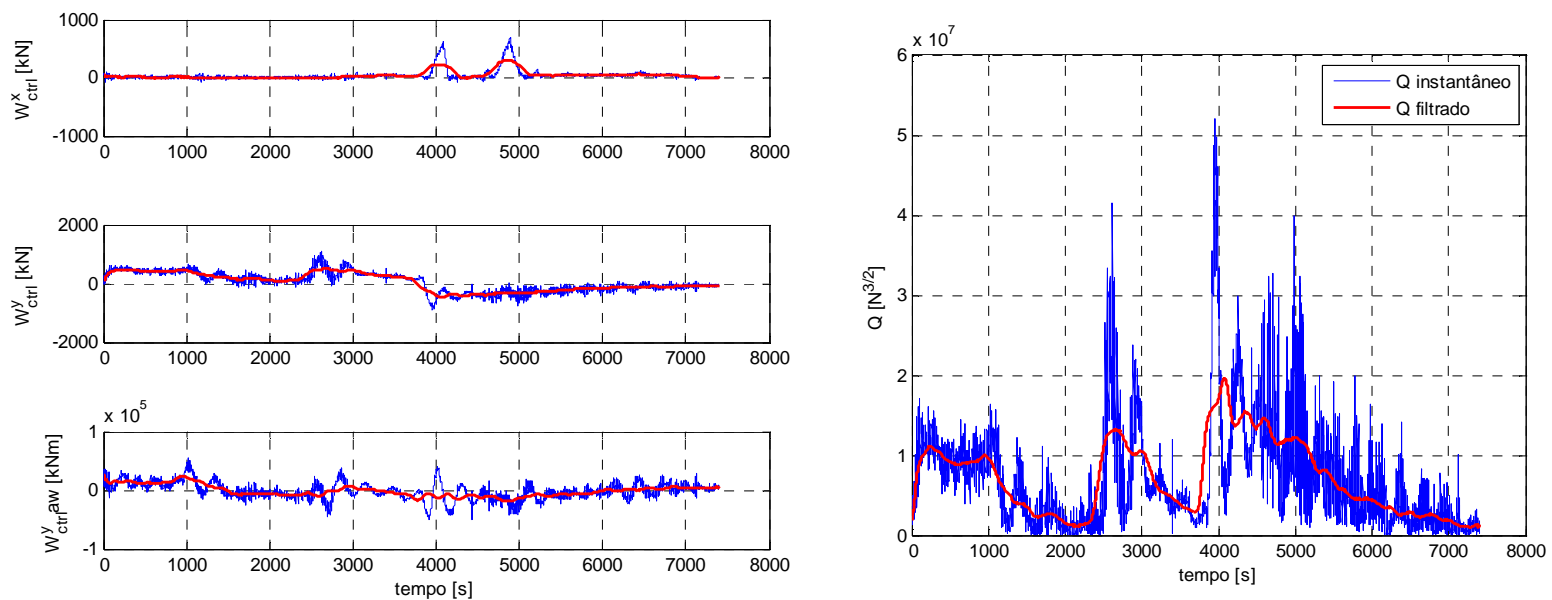

Figura 113 - Esforços de controle

Figura 114 - Consumo total de potência 
O último caso simulado apresenta o caso em que após o sistema entrar em regime, a condição ambiental incidente varia.

Analisando a Figura 114 fica claro que o consumo de potência do sistema em função do aproamento. Também fica claro que o controle weathervane proposto realmente leva o sistema a um aproamento de menor consumo de potência do que $o$ controle DP convencional.

Mesmo com a inclusão de condições ambientais variantes ao longo do tempo, o sistema apresentou boa estabilidade, sem oscilações indesejadas e sem perda do posicionamento do ponto de controle. 


\section{CONCLUSÕES}

Neste capítulo serão apresentadas as conclusões do trabalho desenvolvido.

\subsection{Eficiência do controlador}

Conforme visto nos capítulos 6 e 7, é possível notar que o sistema busca automaticamente um aproamento que em geral diminui consumo de potência do navio. O capítulo 6 também demonstra que o aproamento para o qual o sistema se estabiliza é muito próximo do aproamento apresentado no capítulo 4

O caso que apresentou pior desempenho após a aplicação do controle weathervane foi o controle de popa do navio. O desempenho insatisfatório do controlador weathervane foi atribuído ao ajuste não ideal dos ganhos do controlador PD.

Com isso, é possível ressaltar que a premissa adotada de ajuste correto do controlador é de fato fundamental para a eficiência do controlador, pois, de outra forma, este tende a uma solução oscilatória levando a um maior consumo de potência.

Outro caso que deve ser estudado mais a fundo é quando a condição de weathervane faz com que ondas incidam sobre o casco do navio de través, possivelmente gerando grandes oscilações e movimento de jogo de grande amplitude.

Os demais casos estudados, como as condições típicas nas águas brasileiras, apresentaram resultados satisfatórios, e possível aplicação em casos reais.

Também é notável que tanto condições com mares multi modais como casos em que há deslocamento do navio não fazem com que o controle se torne instável, conforme visto no capítulo 6 em diversas simulações.

Estes resultados, juntamente com a motivação apresentada no capítulo 1 são suficientes para provar que o controle weathervane proposto tem grande potencial econômico, principalmente se aplicado a operações em alto mar de longa duração. 


\subsection{Estabilidade do controlador}

O estudo de estabilidade do controlador apresentado no capítulo 4 mostra que este controlador é estável para ganhos de adaptação até um valor máximo. Como na maior parte dos sistemas de controle, o tempo de assentamento é proporcional ao ganho, porém até um valor máximo admissível, a partir do qual o sistema torna-se instável.

Outros fatores que podem levar o sistema à instabilidade, apresentados nos capítulos 5 e 7 são saturação dos propulsores, e ajuste inadequado dos ganhos do controlador base.

A estabilidade do controlador, por depender dos esforços ambientais agindo sobre o navio, depende tanto da geometria do navio no qual este controlador é aplicado, quanto da condição ambiental na qual o navio se encontra.

Mais estudos sobre a estabilidade do controlador devem ser realizados para diversas embarcações e sob influência de diferentes condições ambientais. Os resultados dos casos estudados apontam para um controlador estável, com potencial para aplicações reais.

\subsection{Trabalhos futuros}

Com a comprovação da funcionalidade do controlador proposto, os trabalhos futuros poderão incluir a aplicação da lei de adaptação obtida em outros tipos de controladores, por exemplo, controladores tipo backstepping ou por modos deslizantes (sliding mode).

Nestes casos seria necessário realizar novamente a análise de estabilidade para cada nova lei de controle proposta.

Dentre os novos controladores aos quais pode-se aplicar a lei de adaptação proposta, são extremamente interessantes os controladores cuja ação de controle depende de mais de um grau de liberdade (controladores acoplados).

Outro fator que não foi abordado neste trabalho, porém de grande interesse, é a influência do sistema propulsor sobre a resposta do controlador. Desta forma, a 
influência da dinâmica dos propulsores, bem como erros ou não linearidades em suas modelagens foram desconsideradas. Utilizar o feedback dos propulsores ao invés da força demandada pelo Sistema DP pode vir a aumentar seu desempenho. 


\section{REFERÊNCIAS}

ANP, Anuário Estatístico Brasileiro do Petróleo, Gás Natural e Biocombustíveis: Agência Nacional do Petróleo - ANP, 2011.

ARANHA, J.A.P., A formula for 'wave damping' in the drift of a floating body, Journal of Fluid Mechanics, Vol.275, pp.147-155, 1994.

ARANHA, J.A.P.; FERNANDES, A.C., On the second-order slow drift force spectrum, Applied Ocean Research, Vol.17, pp.311-313, 1995.

ARANHA, J.A.P.; Second order horizontal steady forces and moment of a floating body with small forward speed, Journal of Fluid Mechanics, Vol.313 1996

BEN, Balanço Energético Nacional: Ministério de Minas e Energia, 2011.

BERNTSEN, P. I. B.; AAMO, O. M.; LEIRA, B. J. Dynamic Positioning of Moored Vessels Based on Structural Reliability. Proceedings of the 45th IEEE Conference on Decision and Control, 2006.

BRAY, D. Dynamic Positioning. The oilfield Seamanship Series, Volume 9, Oilfield Publications LTD (OPL), 1998.

DAVISON, N.; THOMAS, N.; NIENHUIS, U. Application of an Alternative Concept in Dynamic Positioning to a Tanker Floating Production System. Offshore Technology, 1987.

Fossen, T. I. Guidance and control of ocean vehicles. UK: John Wiley and Sons, 1994

FOSSEN, T. A survey on nonlinear ship control: From theory to practice. Conference on Manoeuvring and control of marine craft, 2000

FOSSEN, T. I.; STRAND, J. P. Nonlinear passive weather optimal positioning control (WOPC) system for ships and rigs: experimental results. Automatica, v. 37, p. $701-715,2001$

HESPANHA, J. Tutorial on supervisory control. Anotações para o workshop Control Using Locig and Switching para a $40^{\mathrm{a}}$ Conference on Decision and Control, Orlando, Florida 2001

ITTC Report of the Seakeeping Committee, in: Proceedings of the $15^{\text {th }}$ International Towing Tank Conference, pp.531-534, 1984

KAASEN, K. E.; ANDERSSON, F.; LEHN, E.;OLSEN, C. W.; Offshore Loading Using Tankers of Opportunity: Model Testing of Weather-Vaning Dynamic Positioning. International Offshore and Polar Engineering Conference, 2005. 
KJERSTAD, Ø. K., BREIVIK, M., Weather optimal positioning control for marine surface vessels, 8th IFAC Conference on Control Applications in Marine Systems, 2010.

KONGSBERG K-Pos Dynamic Positioning: Kongsberg Maritime AS, 2006.

MEI, C. C., Applied Dynamics of Ocean Surface Waves, World Scientific Pub. Co., 2 Edição, 1989.

MELLO, O. H. Estudo do Controle Uni-Axial do Mancal de Levitação Magnética do Tipo Atração para Potência Nula (ZPC- Zero Power Control). 2011. Dissertação (Mestrado) - Escola Politécnica, Universidade de São Paulo, São Paulo, 2011

MIYAZAKI, M.R.; TANNURI, E.A., A General Approach for DP Weathervane Control: Numerical Results. ASME 31th International Conference on Ocean, Offshore and Arctic Engineering OMAE 2012, Rio de Janeiro, Brazil, 2012a.

MIYAZAKI, M.R.; TANNURI, E.A., A General Approach for DP Weathervane Control: Experimental Results. 9th IFAC Conference on Manoeuvring and Control of Marine Craft, MCMC 2012, Arenzano (GE), Itália, 2012b.

MIYAZAKI, M.R.; TANNURI, E.A., A General Approach for DP Weathervane Control. Internacional Dynamic Positioning Conference 2012, Marine Technology Society, Houston (TX), Estados Unidos, 2012c.

MIYAZAKI, M.R.; TANNURI, E.A A General Approach for DP Weathervane Control. Marine Technology Society Journal, 2013.

MIYAZAKI, M.R.; TANNURI, E.A.; OLIVEIRA, A.C. A minimum energy DP heading control: critical analysis and comparison of different strategies. ASME 32th International Conference on Ocean, Offshore and Arctic Engineering OMAE 2013, Nantes, França, 2013 (aceito para publicação).

MIZUNO, T. Vibration isolation system using zero-power magnetic suspensions. Preprints of $15^{\text {th }}$ World Congress IFAC, 2002.

MORISHITA, H. M. ; TANNURI, E. A.; SAAD, A. C.; SPHAIER, S. H.; LAGO, G. A.; MORATELLI, L.; Laboratory Facilities for Dynamic Positioning System. Manoeuvring and control of marine craft, 2009.

MORISHITA, H. M.; KUBOTA, L.; VESTRI, M. S.; GREUELL, S.; MORATELLI, L.; The empirical mode decomposition applied to dynamic positioning systems. 30th International Conference on Ocean, Offshore and Arctic Engineering, 2011, Rotterdam.

MORISHITA, M.; AZUKIZAWA, T.; KANDA, S.; TAMURA, N.; YOKOYAMA, T.; A new MAGLEV system for magnetically levitated carrier system. IEEE Transactions on Vehicular Technology, v. 38, n. 4, p. 230-236, 1989. 
OCIMF. Predictions of wind and current loads on VLCCs. Oil Companies International Marine Forum, 1994.

PARRA, L. A.; Tannuri, E. A. Control of a wind generation system applied to ocean basins. 21st Brazilian Congress of Mechanical Engineering (COBEM 2011), Natal, 2011.

PESCE, C. P.; TANNURI, E. A. Stability and dynamics of offshore single point mooring systems. Revista Brasileira de Ciências Mecânicas, 1998.

PINKSTER, J.; NIENHUIS, U. Dynamic Positioning Of Large Tankers At Sea. The Offshore Technology Conference, 1986.

QUESTOFFSHORE. The State of the Offshore U.S. Oil and Gas Industry. Quest Offshore Resources, inc, 2011.

SANDREA, I.; SANDREA, R. Global offshore oil: geological setting of producing provinces, E\&P trends, URR, and medium term supply outlook. Oil and Gas Journal, 2007.

SPHAIER, S. H. et. al. Evolution of crude oil offshore loading in Brazilian waters. Dynamic positioning conference,2009.

SUN, F.; OKA, K. Zero power non-contact suspension system with permanent magnet motion feedback. Journal of system design and dynamics, v. 3, p. 627638, 2009.

SØRDALEN, O. J. Optimal Thrust Allocation for Marine Vessels, Control Engineering Practice, Vol.5, No.9, pp1223-1231, 1997.

SØRENSEN, A. J. A survey of dynamic positioning control systems. Annual reviews in control, v. 35, n. 1, p. 123-136, 2011.

SØRENSEN, A. J.; LEIRA, B.; STRAND, J. P.; LARSEN, C. M.; Optimal setpoint chasing in dynamic positioning of deep-water drilling and intervention vessels. International Journal of Robust and Nonlinear Control, v.11, n. 13, p. 1187-1205, 2001.

TANNURI, E. A. Desenvolvimento de metodologia de projeto de sistema de posicionamento dinâmico aplicado a operações em alto-mar, 2002. $273 \mathrm{p}$. Tese (Doutorado) - Escola Politécnica, Universidade de São Paulo, São Paulo, 2002.

TANNURI, E. A.; AGOSTINHO, A. C.; MORISHITA, H. M.; MORATELLI L.; Dynamic positioning systems: An experimental analysis of sliding mode control. Control Engineering Practice, v. 18, n. 10, p. 1121-1132, $2010 .$.

TANNURI, E. A.; CAMPOS, T. S.; VILACA, R. M.; SAAD, A. C.; MORISHITA, H.M.; Arquitetura computacional para ensaios em tanque de provas de sistemas DP. 220 Congresso Nacional de Transporte Aquaviário, Construção Naval e Offshore, 2008. 
TANNURI, E. A.; MORISHITA, H. M.; SIMOS, A. N.; SAAD, A. C.; SILVA, S. H. S. C.; MATOS, V. F. F.; DP Assisted Offloading Operations in Brazilian Water. Dynamic Positioning Conference, 2009. 